\title{
Development of Pole Impact Testing at Multiple Vehicle Side Locations As Applied To The Ford Taurus Structural Platform
}

\author{
Mark Halford Warner \\ Brigham Young University - Provo
}

Follow this and additional works at: https://scholarsarchive.byu.edu/etd

Part of the Mechanical Engineering Commons

\section{BYU ScholarsArchive Citation}

Warner, Mark Halford, "Development of Pole Impact Testing at Multiple Vehicle Side Locations As Applied To The Ford Taurus Structural Platform" (2004). Theses and Dissertations. 226.

https://scholarsarchive.byu.edu/etd/226

This Thesis is brought to you for free and open access by BYU ScholarsArchive. It has been accepted for inclusion in Theses and Dissertations by an authorized administrator of BYU ScholarsArchive. For more information, please contact scholarsarchive@byu.edu, ellen_amatangelo@byu.edu. 


\section{DEVELOPMENT OF POLE IMPACT TESTING AT MULTIPLE VEHICLE SIDE LOCATIONS AS APPLIED TO THE FORD TAURUS STRUCTURAL PLATFORM}

By

Mark H. Warner

A thesis submitted to the faculty of

Brigham Young University

in partial fulfillment of the requirements for the degree of

Master of Science

Department of Mechanical Engineering

Brigham Young University

December 2004 
Copyright (C) 2004 Mark H. Warner

All Rights Reserved 


\title{
BRIGHAM YOUNG UNIVERSITY \\ GRADUATE COMMITTEE APPROVAL
}

\author{
of a thesis submitted by
}

Mark H. Warner

This thesis has been read by each member of the following graduate committee, and by majority vote, has been found to be satisfactory.

Date

Date

Date
Carl D. Sorensen, Chair

Spencer P. Magleby

Robert H. Todd 


\section{BRIGHAM YOUNG UNIVERSITY}

As chair of the candidates graduate committee, I have read the thesis of Mark H. Warner in it's final form, and have found that (1) its format, citations, and bibliographical style are consistent and acceptable and fulfill university and department style requirements; (2) its illustrative materials including figures, tables, and charts are in place; and (3) the final manuscript is satisfactory to the graduate committee and is ready for submission to the university library.

Date

Carl D. Sorensen, Chair

Accepted for the Department

Matthew R. Jones, Graduate Coordinator

Accepted for the College

Douglas M. Chabries, Dean

Ira A. Fulton College of Engineering and

Technology 


\begin{abstract}
DEVELOPMENT OF POLE IMPACT TESTING AT MULTIPLE

VEHICLE SIDE LOCATIONS AS APPLIED TO THE

FORD TAURUS STRUCTURAL PLATFORM
\end{abstract}

\author{
By Mark H. Warner \\ Department of Mechanical Engineering \\ Master of Science
}

\begin{abstract}
A test method was developed whereby repeated pole impacts could be performed at multiple locations per test vehicle, allowing a comparison of energy and crush relationships. Testing was performed on vehicles moving laterally into a 12.75 inch diameter rigid pole barrier. Crush energy absorption characteristics at the different locations were analyzed, and the results compared to test data from broad moving barrier crashes and available crash tests with similar pole impacts.
\end{abstract}

The research documents the crush stiffness characteristics for narrow impacts at various points on the side of the Taurus vehicle platform. Factors encountered during the research include the importance of rotational energy accounting and 
uncertainties related to crush energy related to induced deformation. The findings show that the front axle and A-pillar regions are much stiffer than the CG and Bpillar areas to narrow rigid pole impact. The central CG region produced stiffness relations that correspond well with published broad-impact data when the effective crush width was assumed to be roughly three times the pole diameter. Results of this research sustain the theory that stiffness properties vary significantly along the side of a vehicle. Though not practical as a tool in every circumstance, the multiple impact location technique should be considered when side impact crush energy absorption characteristics are key to the outcome of an accident reconstruction. 


\section{ACKNOWLEDGMENTS}

Sincere thanks to the many professors here at Brigham Young University who have helped me for the past several years. Special thanks to those who believed in me, even when I didn't believe in myself, and gently compelled me to change. Words cannot express my gratitude to the Lord for the opportunities I have had. It was by His will and hand that I was accepted to the University, and I have been blessed here.

I am most grateful for the support of my family. For the support of my children, who have struggled with their homework beside me, as I was struggling with mine. For my fabulous, invincible, dedicated sweetheart Serena. Her infinite capacity for cleaning, cooking, baking, laundry, tutoring, lawn mowing, gardening, weeding, piano, parent-teachering, carpooling, and the thousands of seemingly small things that make our house a wonderful home. For her nurturing spirit and motherly love. Her examples of determination, service, and love stand above all others. As I watch her, I know I can never give up.

This work is dedicated to my father, Dr. Charles Y. Warner. His relentless patience in helping me all of these years has been the foundation for my growth. 
As I have climbed my Mount Everest, he has always been above me with a hand or rope. 


\section{TABLE OF CONTENTS}

1.0 INTRODUCTION 1

2.0 BACKGROUND 5

2.1 Side Impact in Crash Safety 5

2.2 Federal Safety Standards Relating to Side Impact 5

2.3 Energy in Reconstruction of Side Crashes 9

2.4 The Velocity-Time Diagram 14

$\begin{array}{lll}2.5 & \text { Restitution } & 15\end{array}$

$\begin{array}{lll}2.6 & \text { Rotation } & 16\end{array}$

2.7 Crush Energy as a Reconstruction Tool 21

2.8 Review of Related Literature 21

3.0 TEST METHOD DEVELOPMENT 25

3.1 The Rigid Barrier / Crash Test Facility 25

$\begin{array}{lll}3.2 & \text { Tow System } & 26\end{array}$

$\begin{array}{lll}3.3 & \text { Speed Measurement } & 28\end{array}$

3.4 Photography / Videography 28

ix 
3.5 Side Impact Technique Development

$\begin{array}{lll}4.0 & \text { RESULTS } & 35\end{array}$

4.1 Test Locations and Velocities $\quad 35$

4.2 Restitution Documentation 35

$\begin{array}{lll}4.3 & \text { Rotation Effects } & 37\end{array}$

$\begin{array}{lll}4.4 & \text { Crush Measurement } & 40\end{array}$

4.5 Crush Energy Calculation 42

4.6 Crush Energy as a Function of Width 46

4.7 Bowing and Effective Width 48

$\begin{array}{lll}5.0 & \text { DISCUSSION } & 49\end{array}$

5.1 Barrier Width 49

5.2 Barrier Width as a function of Pole Width 50

5.3 Yaw Energy 55

5.4 Energy Comparisons Based upon Impact Location 57

$\begin{array}{lll}\text { 6.0 CONCLUSIONS } & 59\end{array}$

6.1 Multiple Impact Location Test Technique 59

6.2 Variations in Stiffness Between Impact Locations 59

6.3 Importance ofYaw Energy in Calculating Crush Energy 60 
$\begin{array}{lll}6.4 & \text { Transition Zones } & 60\end{array}$

6.5 Pole Impact Data Compared to NHTSA 214 Test Data 61

$\begin{array}{lll}6.6 & \text { Applications } & 61\end{array}$

7.0 RECOMMENDATIONS FOR FUTURE RESEARCH 63

8.0 REFERENCE MATERIALS 65

$\begin{array}{lll}9.0 & \text { APPENDICES } & 73\end{array}$ 


\section{LIST OF FIGURES}

2.1 Euro NCAAP Side Impact Test Procedure 6

2.2 Euro Side Impact Test Configuration 7

2.3 V-T Diagram for Central Impact 15

2.4 R distance from Pole Center of Rotation to $\mathrm{CG} \quad 18$

2.5 V-T Diagram for Non-Central Impact 20

3.1 Photographs of Test Facility 25

3.2 Pole Test Fixture 26

$\begin{array}{lll}\text { 3.3 Impact Configuration and Location } & 27\end{array}$

3.4 Photographs of Friction Shoes 29

3.5 Photographs of Digital Surveying Technique 32

3.6 Photographs of Accelerometers and Rotation Rate Sensor 34

4.1 Vehicle Motion Analysis / Test B5 38

4.2 Integrated Yaw Rate / Test B5 39

4.4.1 Composite Crush Map of Vehicle B 41

4.4.2 Composite Crush Map of Vehicle C 42

4.5 Energy / Crush Distance Correlations 45

4.6 CG Test and Neptune Data 47

5.1 CG: Varying Pole Widths Compared to Neptune Data 50 
5.3 A Pillar: Varying Pole Widths / Neptune Data 53

5.4 B Pillar: Varying Pole Widths / Neptune Data 54

6.1 Comparison of Crush Energy / Linear Crush Distance 56 


\section{LIST OF TABLES}

3.1 Test Vehicle Weight Measurements 33

4.1 Impact Speed and Linear Crush 35

4.2 Crush Energy Calculation Matrix 44

5.1 Pole Width Correlations 51

5.2 Highlighted Crush Energy Calculations 55 


\section{LIST OF APPENDICES}

A. FMVSS 214 "Dynamic" Side Impact Protection 74

B. European Side Impact Test 78

C. Excerpts from Neptune Engineering, Inc. Website 80

D. Neptune Crash Data for 1999 Taurus Side 87

E. Yaw Moment of Inertia for 1999 Taurus 88

F. Charles Y. Warner Brief Regarding Energy Models 89

$\begin{array}{ll}\text { G. Selected Test Vehicle Photographs } & 97\end{array}$

H. NHTSA Bowing Protocol 103 


\section{NOMENCLATURE / DEFINITION OF TERMS}

$\mathrm{m}$ : vehicle mass, $\mathrm{lbm}$

w: vehicle weight, $1 \mathrm{bf}$

$\mathrm{v}_{0}$ : the velocity of the test vehicle immediately prior to impact

$\mathrm{v}_{\mathrm{r}}:$ CG rebound velocity

$\Omega$ : (Omega) rotational velocity in degrees or radians

I : rotational moment of inertial

C: Crush (inches or feet)

$\mathrm{R}$ : distance (feet) from vehicle CG to center of rotation about pole

d: Impactor width

$\varepsilon:$ Restitution at the vehicle $\mathrm{CG}$

CE: Crush Energy (per impact)

$\mathrm{CE}_{\mathrm{TO}}$ : Total Crush Energy

EBS: Equivalent Barrier Speed

$\mathrm{F}_{\mathrm{AVE}}$ : Average Force

$\mathrm{F}_{\text {TOT: Total Force }}$ 


\subsection{INTRODUCTION}

Each year, over 6 million automobile accidents occur in the United States. Roughly 37,000 of these accidents result in fatalities, and over $10 \%$ of the fatal accidents and about one-fourth of the occupant fatalities involve vehicles struck in the side [FARS data]. Though not as common as frontal collisions, side impacts often impart more severe forces and accelerations to occupants because protection space is limited. Such impacts can result in more severe injuries, as the protection provided by vehicle side structures cannot manage forces as readily as the large "crumple zones" employed by vehicles in frontal impacts.

Accident reconstruction encompasses a wide variety of engineering techniques. For decades, engineers and inspectors estimated the severity and pre-collision parameters of accidents based upon such factors as skid mark length, tire to roadway friction coefficients, and the principles of skidding energy and momentum conservation. These techniques are still a valuable and important part of accident reconstruction, but sometimes skid marks have faded, or the vehicles have traveled across surfaces where no skid marks can be recorded and measured (i.e. wet or snow covered roads or high traffic areas). As new vehicles incorporate advanced braking systems with anti-skid controls, these situations 
require the use of additional tools. Reconstruction methods rely upon structural crush energy estimates to determine vehicle kinematics prior to accident impacts.

Several methods have been developed and tested which allow the engineer to relate post-collision crush geometry to crush energy. Some of these models simply relate the maximum depth of crush to a kind of "rule of thumb" as a calculated or predicted pre-impact speed for the vehicle. Other models take a more technical empirical approach; assigning varying "plastic spring" force constants or "crush energy coefficients" to the surfaces of the vehicle as functions of crush depth and width. Virtually all models refer to vehicle crash testing, either as a basis for development or for verification purposes.

Numerous computer programs have been developed to aid the engineer in accurately estimating the pre-collision speeds and attitudes of vehicles. This work is supplemented using a program called PC Crash, a robust and widely accepted tool for automobile accident reconstruction [PC Crash].

This work is not in itself an attempt to design or recommend better protection systems for occupants. It is intended as a step toward better understanding of side impact forces, and how they are transformed into crush energy by body structures in various locations along the side of the vehicle. It is hoped that this work will provide valuable reference material to researchers in reconstruction of accidents. 
A method for impacting a test vehicle at multiple locations along the side has been developed. Comparing calculated crush energy from test data at multiple impact locations provides the researcher with a better understanding of the variation in stiffness along the vehicle side. Though not practical as a tool in every circumstance, this technique should be considered when side impact crush energy absorption characteristics are key to the outcome of an accident reconstruction.

Repeated crash testing was performed on 1999 model Ford Taurus sedans. The techniques employed, data gathered, and test results are included in the body of this writing, in addition to conclusions and recommendations for future work. Common accident reconstruction methods include the measurement and comparison of post-accident crush patterns to those of a controlled crash test. This work helps to quantify and compare the stiffness of vehicle side structures at various locations on the Ford Taurus platform. The basis for comparison between tests is the calculated crush energy absorbed by the vehicle structures. 


\subsection{BACKGROUND}

\subsection{Side Impact in Crash Safety}

The side impact accident places the driver and/or occupants of a vehicle at higher risk than other types of accidents, given an equal level of crush energy absorbed. The doors of a typical sedan are always constructed to be less than one foot thick, and size, strength, and weight considerations dictate limits to door strength as applied to intrusion resistance. Passengers are often seated low enough that adverse vehicle frontal structures align with the abdomen, pelvis, and thoracic zones of occupants. Structural architecture limits the compatibility and effectiveness of side structures and restraint systems, as do mass, stiffness, and geometric differences between vehicles of various types.

\subsection{Federal Safety Standards Relating to Side Impact}

Federal Motor Vehicle Safety Standard 214 (FMVSS 214) prescribes a side impact performance level required of all automobiles certified in the United States [FMVSS 214]. It involves impacts into stationary production vehicles by a crabbed (angled) deformable moving barrier weighing about $3000 \mathrm{lbs}$. The 
barrier is angled at 27 degrees and pulled along an approach track so as to strike the front door area at about $33 \mathrm{mph}$. A deformable barrier face over 5 feet wide first contacts the front door and its pillars simultaneously, hence the "crabbed, deformable, moving” barrier, CDMB (See Figure 2.1, below).

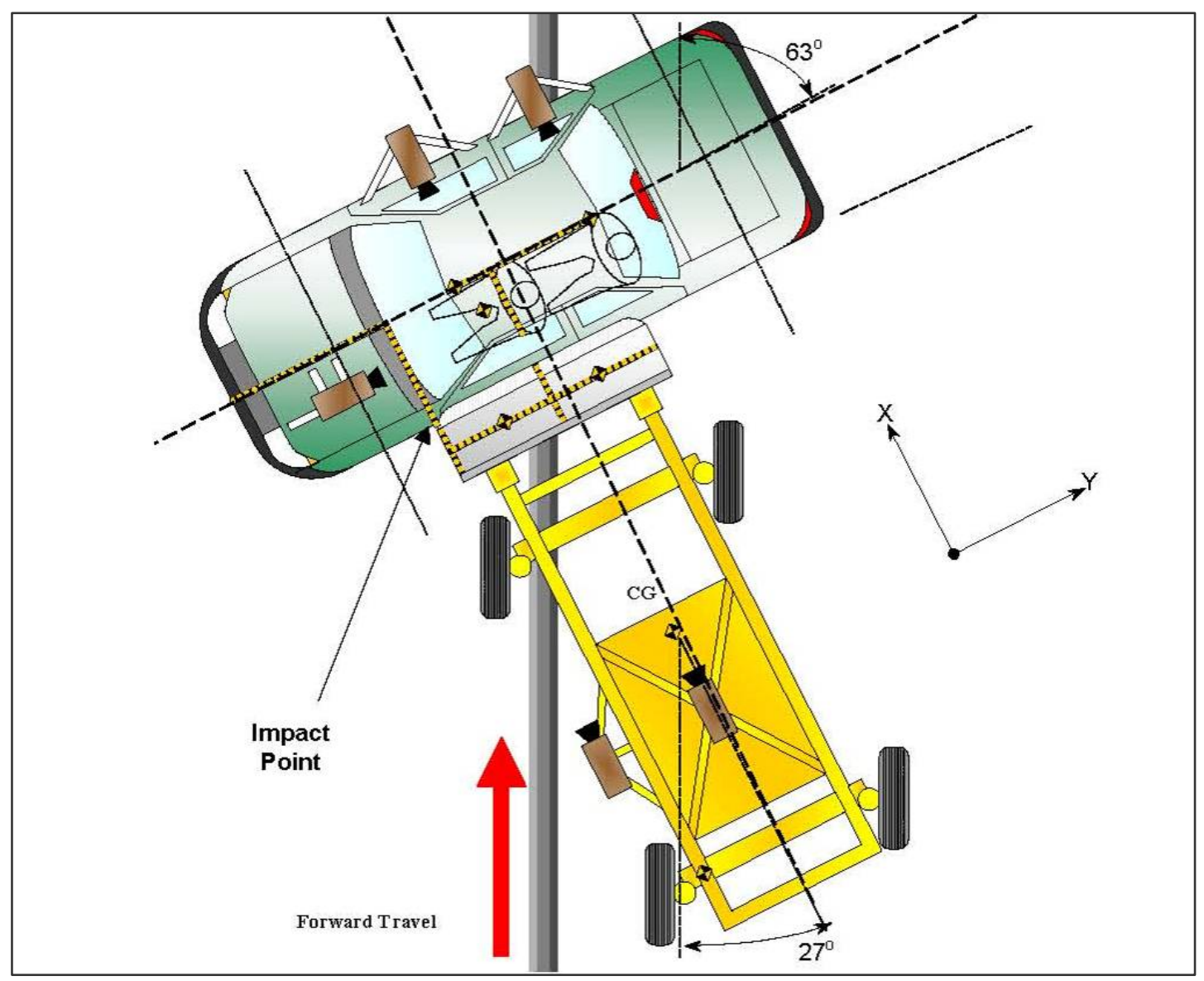

Figure 2.1 NHTSA 214 Side Impact Test Procedure

Canadian test requirements are similar to those of the U.S. [Canada]. The European Economic Union also uses a moving deformable barrier or pole barrier, but addresses the stationary vehicle at a right angle (90 or 270 degrees) [Euro]. 


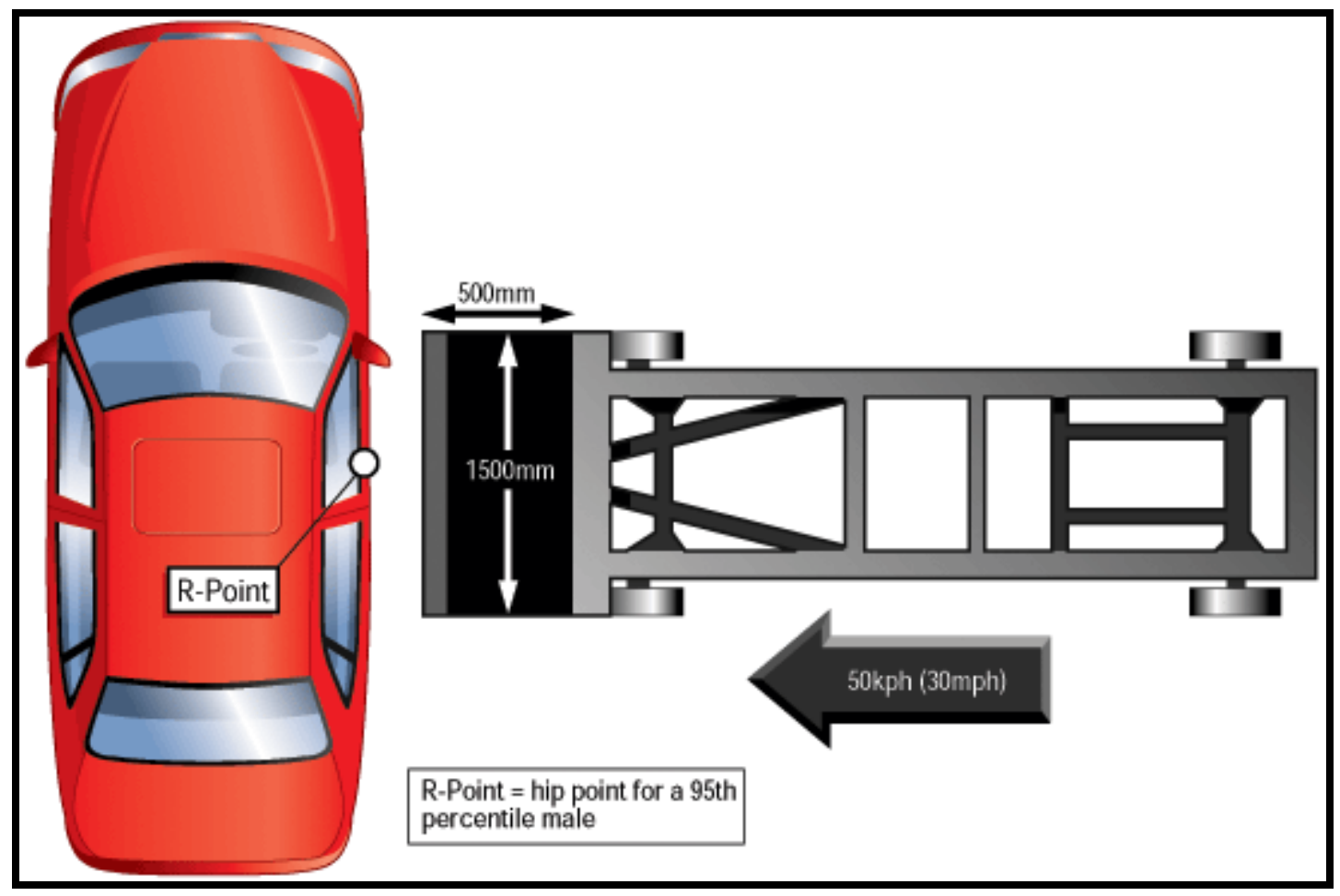

Figure 2.2 Euro NCAP Side Impact Test Procedure

Australian and Japanese requirements are similar. These test protocols

emphasize the measurements recorded on inertial and deflection instruments in a seated side impact dummy. Appendices A and B provide more details relating to FMVSS 214 and the Euro side impact tests. EuroNCAP (European New Car Assessment Program) are conducted at higher speeds with similar respective physical setups. NCAP energy levels are about 40 percent higher than the respective compliance tests. All of these tests are designed primarily to validate the vehicle's dummy protection capabilities. They are not intended to be used for energy based reconstruction analysis. 
These standards are attempts to represent "typical" side impact crashes, but by using a complex crash test orientation and design, the results are not optimal for crash reconstruction applications. Crabbed Deformable Moving Barrier faces are more than five feet wide. As a result, localized impacts are not well represented with respect to structural characteristics. Barrier face structural deformation and yield force characteristics are not always well documented. The impacts are not central, so rotations of both barrier and subject vehicle are involved in absorption of initial kinetic energies. Induced crush effects are not well understood.

In recent years, the popularity of higher, heavier, stiffer vehicles like pickups and SUVs has changed the typical structural relationships between striking and struck vehicles [Bradsher, 2002]. This change has been recognized in some crash testing, but applications to reconstruction remain complex [IIHS, 2000; IIHS, 2003].

Data from many crash tests are published in the open literature. Many of these have been collated by Neptune Engineering, Inc. and other similar agencies to assist reconstructionists in characterizing vehicle structures [Neptune, 2003]. These characterizations and models must be studied carefully to make useful application in the general reconstruction case. Very few reliable data for direct application to narrow fixed object impact are available. Most side crush energy research has not given full account of rotation effects in non-central side impacts 
[Neptune, 1994; Asay, 2002]. The great majority of side impact crash test data are derived in non-central crashes. Even in those cases where vehicle sides have struck poles, the center of impact is usually targeted on the occupant head region rather than the vehicle $\mathrm{CG}$, as injury criteria are of primary concern.

\subsection{Energy in Reconstruction of Side Crashes}

The theory of side impact reconstruction is that an energy estimate might be achieved by measurement of the vehicle deformation to serve as a means of checking or determining impact speed. Thus, the sum of damage energy to both impact partners can be checked against the energy loss predicted from dynamic momentum analysis. The physics and mathematics governing generalized twovehicle collisions has been adequately treated in the literature [Marquardt; Emori; PC CRASH]. Hand calculation methods can arrive at a reasonable estimate, but the arithmetic is extensive and laborious. Computer programs are available and are in widespread use to help with the calculations. The SMAC program and its derivatives integrates the equations of motion without reference to energy, but it requires an estimate of vehicle stiffnesses for its force balance operations [SMAC]. It is helpful to check SMAC results with independent calculations of energy. The CRASH program and its relatives employ an instantaneous impact model, but employ assumptions based on energy to achieve speed estimates [CRASH]. The PCCRASH program simply evaluates speed estimates supplied 
by the user, then provides instantaneous momentum accounting and run-out predictions, leaving the user to compare the dissipated energy to his own calculations of crush energy [PCCRASH]. Each program has its advantages, depending upon user objectives.

The kinetic energy involved during a single vehicle collision with a rigid, massive structure (utility pole, tree, bridge abutments etc.) can be expressed by

$\mathrm{KE}=\frac{1}{2} \mathrm{mv}_{\mathrm{i}}{ }^{2}=\frac{1}{2} \frac{\mathrm{W}}{\mathrm{g}} \mathrm{v}_{\mathrm{i}}{ }^{2}$

Where $\mathrm{m}=$ mass and $\mathrm{w}=$ weight of the moving vehicle, $\mathrm{g}=$ acceleration due to gravity, and $v_{i}=$ the velocity of the vehicle immediately prior to impact. The instant before impact, the vehicle can be idealized to possess energy only in this translational kinetic form. During impact, it also obeys rules of impulse and momentum, but these are not usually important tools in impacts against a massive or "fixed" barrier. Some of the energy the vehicle possessed prior to impact is dissipated by deforming structures, while some energy is retained in the form of post impact velocity (restitution) and/or rotation. Energy must be accounted for, as outlined in the mechanical energy equation:

$\mathrm{KE}_{\mathrm{i}}=\mathrm{KE}_{\mathrm{f}}+\mathrm{KE}_{\text {yaw }}+\mathrm{CE}$, 
where

$\mathrm{CE}=$ Crush energy

$\mathrm{KE}_{\mathrm{i}}=$ Initial translational energy $=\quad \mathrm{KE}_{\mathrm{i}}=\frac{1}{2} \mathrm{mv}_{\mathrm{i}}{ }^{2}$

$\mathrm{KE}_{\mathrm{f}}=$ final translational energy $=\quad \mathrm{KE}_{\mathrm{f}}=\frac{1}{2} \mathrm{mv}_{\mathrm{f}}^{2}$

$\mathrm{KE}_{\text {yaw }}=$ final yaw energy $=\quad \mathrm{KE}_{\mathrm{f}}=\frac{1}{2} \mathrm{I}_{\mathrm{f}}{ }^{2}$

When structures are deformed, they exhibit plastic and elastic behavior. The response of vehicle structures in a collision can be modeled many different ways. A traditional accounting method employs the concept of restitution to identify the restorative elastic properties of crush, by definition of rebound velocity as a fraction of approach velocity. This is discussed further below.

The structural deformation behavior of a deforming vehicle side structure has been defined in several ways, usually as some function of the crush stroke. The simplest model represents the deforming force as constant over the crush from an individual impact, $\mathrm{C}_{\mathrm{i}}$. It is one way of grasping the average force exhibited in an impact, and is represented by

$$
\overline{\mathrm{F}}_{\mathrm{i}}=\text { Constant. }
$$

The subscript " $i$ " is used here because in the application below, repeated impacts will be addressed at the same impact point, and an average constant force 
calculated based on total energy and crush from repeated applications of this simple representation, where crush energy is given by the product

$$
\begin{aligned}
& \mathrm{CE}_{\mathrm{i}}=\overline{\mathrm{F}}_{\mathrm{i}} \times \mathrm{C}_{\mathrm{i}} \\
& \mathrm{CE}_{\text {тот }}=\sum_{i} \mathrm{CE}_{\mathrm{i}}
\end{aligned}
$$

The simple model used here represents force as a linear function of crush, as $\mathrm{F}=\mathrm{kx}$.

Thus $\mathrm{CE}=\int_{\mathrm{c}} \mathrm{Fdx}=\frac{1}{2} \mathrm{kc}^{2}$

These relations apply to unit widths normal to the deformation on an idealized force transmission member. The linear model corresponds to the simple harmonic oscillator model. That model is applied in the SMAC program, by addressing the stiffness per unit width as $\mathrm{kv}=\mathrm{k} / \mathrm{w}$, and $\mathrm{F} / \mathrm{w}=[\mathrm{kv} / \mathrm{w}] \mathrm{x}$, where $\mathrm{w}$ is the small or unit width of application [SMAC]. This model, using kv, has become one of the standardized methods of correlating crush energy data. It is reported in the published data for many crash tests (See Appendix D).

The linear model was extended in the CRASH program to include a twoparameter representation of force and energy density as a point-slope form, wherein force per unit width takes the form 


$$
\frac{\mathrm{F}}{\mathrm{W}}=\mathrm{a}_{1}+\mathrm{b}_{1} \mathrm{x}
$$

This equation is equivalent to the representation of crush energy per unit width in the equation

$$
\sqrt{\frac{2 \mathrm{CE}}{\mathrm{W}}}=\mathrm{A}+\mathrm{BC}
$$

which is the model form used in the CRASH computer program formulation [CRASH manual]. The A and B "crush coefficients" are employed in published correlations of crash test data from public tests [Neptune, 1994].

In efforts to find better matches to existing crash data, some have proposed more elaborate models for the side crush layer, such as bilinear stiffnesses, a force saturation model, and various exponential and power-law forms [Strother, Woolley]. Without a large number of similar repeated tests to provide a good definition of behavior of individual or generalized structures with crush depth, the verification of elaborate models will be difficult. For the correlation of the pole crashes in this research, the simple linear models have been employed. The above energy principles also apply to multi-vehicle collisions, although we will only address single Ford Taurus collisions with fixed objects in this research. 


\subsection{The Velocity-Time Diagram}

The dynamics of impact are illustrated well on velocity-time coordinates. We define time zero as the moment of impact. In the case of a single vehicle pole impact, the moment initial contact is made between the moving vehicle and the stationary pole. Prior to impact, we consider the velocity of the vehicle $\left(\mathrm{v}_{0}\right)$ to be constant. Beginning at $\mathrm{t}=0$, the vehicle experiences a change in velocity $(\triangle \mathrm{V})$. The following diagram helps to illustrate a generic form of Velocity / Time (V/T) diagram that is useful in explaining a typical vehicle collision response. Its initial form is similar to the cosine curve which results from the integration of one quarter-wave (having duration of 0.085 seconds) of a simple harmonic oscillator which obeys the function in equation 2.11 as follows:

$$
m\left(\frac{d^{2} x}{d t^{2}}\right)+k x=0
$$




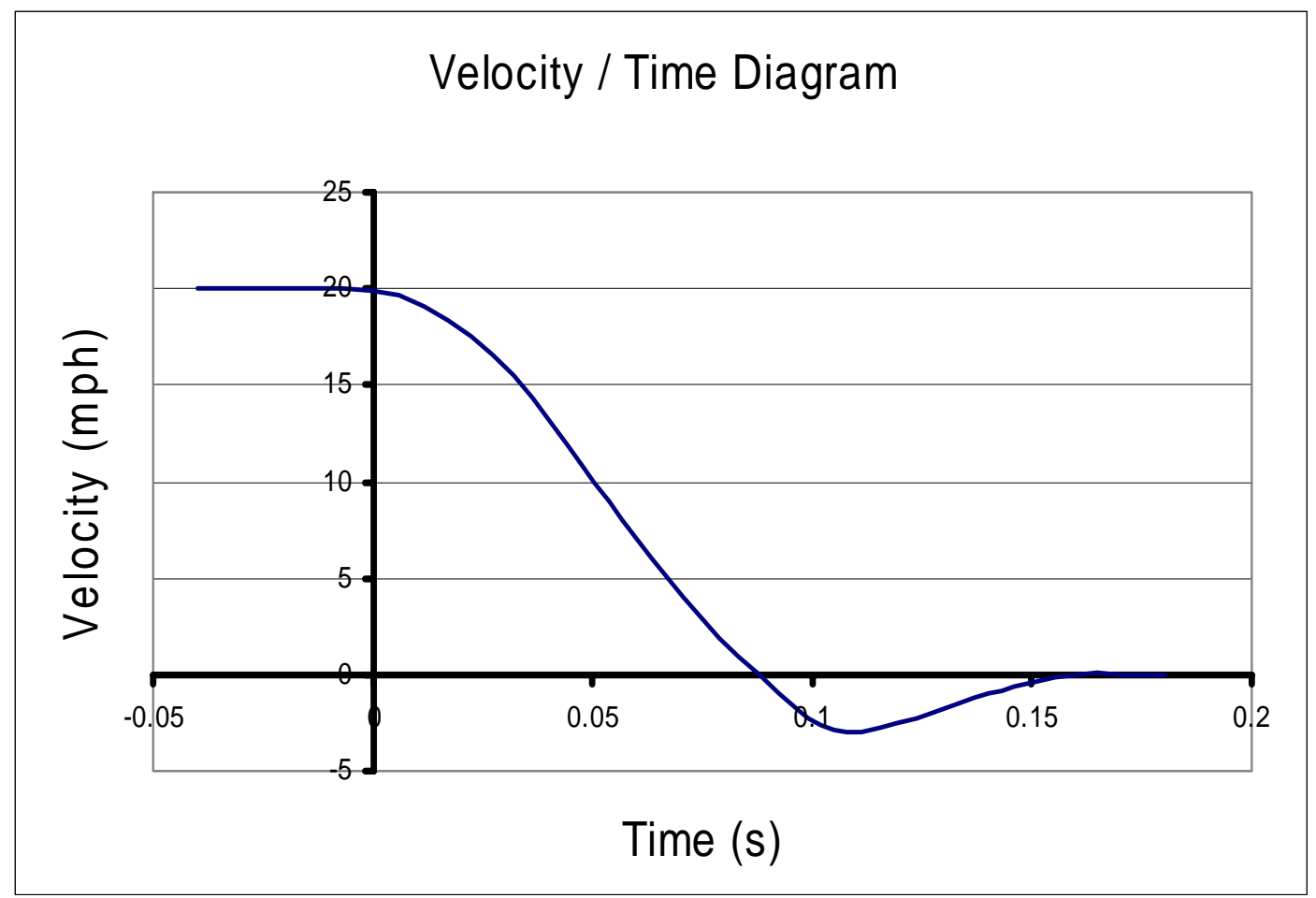

Figure 2.3 V-T Diagram for Central Impact

\subsection{Restitution}

The generic V/T curve of Figure 2.3 is representative of a central impact, where velocity passes zero at full crush, changing direction (velocity becomes negative) and vehicle structures restore part of their deformation. The area under the curve between 0 and 0.085 seconds represents distance absorbed as plastic deformation. The area below the horizontal axis between 0.085 and 0.15 seconds represents energy restored from elastic deformation, and is subtracted from the total residual kinetic energy in calculation of $\mathrm{CE}_{\mathrm{TOTAL}}$. Restitution is defined as 
the ratio of rebound velocity (Vr), divided by initial, or impact velocity (Vi) as follows:

$$
\varepsilon \equiv \frac{\mathrm{V}_{\mathrm{r}}}{\mathrm{V}_{0}}
$$

Technically, restitution is only defined for central impacts like billiard ball contacts or ball-into-flat wall contacts, although the concept has been extended by some researchers [Brach; Warner, 1998]. The application of restitution to noncentral collisions with complex structures like automobile bodies is not well understood. While it is clear that such bodies restore elastic energy after plastic collision, the application of the classical definition to largely offset collisions becomes very complex when rotational effects are involved. Fortunately, restitution in automobile crashes is usually quite small, typically less than $25 \%$. Further, it enters the energy balance as the square, so its effect on energy would usually be less than $10 \%$ and is often ignored in reconstruction calculations. It is included in this discussion to help separate the various energy effects.

\subsection{Rotation}

When a vehicle moves laterally into a fixed object, off-central forces will induce a yaw rate during the impact phase. Induced yaw rate $(\omega)$ will continue to 
increase as the vehicle structures are crushed to their maximum level. The resulting yaw energy must be subtracted from the total crush energy in calculating the energy absorbed by the deformed part of the vehicle. Impact-induced vehicle rotation may be divided into two phases:

Phase 1- $\quad$ Yaw of the vehicle mass around the impact point, (in this case, a pole) during contact, which increases in response to the impact moment.

Phase 2- $\quad$ Rotation of the vehicle immediately following separation from the pole, which decreases in response to tire forces interacting with the roadway surface. Impact induced yaw rate usually reaches a maximum value at the end of the impact phase, unless other rotational impulses are applied.

When calculating the planar Yaw Moment of Inertia for any finite object, including a rotating vehicle, two components of inertia are needed [Verat, 1999].

$\mathrm{I}_{0}=\mathrm{mk}^{2}$

$I_{p}=m\left(k^{2}+R^{2}\right)=\frac{w}{g}\left[k^{2}+R^{2}\right]$

In the equation, $\mathrm{m}=$ vehicle mass, $\mathrm{w}=$ vehicle weight, $\mathrm{h}=$ radius of gyration, and $\mathrm{R}=$ distance from the planar point of impact to the vehicle $\mathrm{CG}$, where $\mathrm{I}_{0}=$ The Yaw Moment of Inertia of a free rotating vehicle about its CG, and $I_{P}=$ the 
moment of inertia of a vehicle rotating around a point of impact a distance $\mathrm{R}$ from the CG.

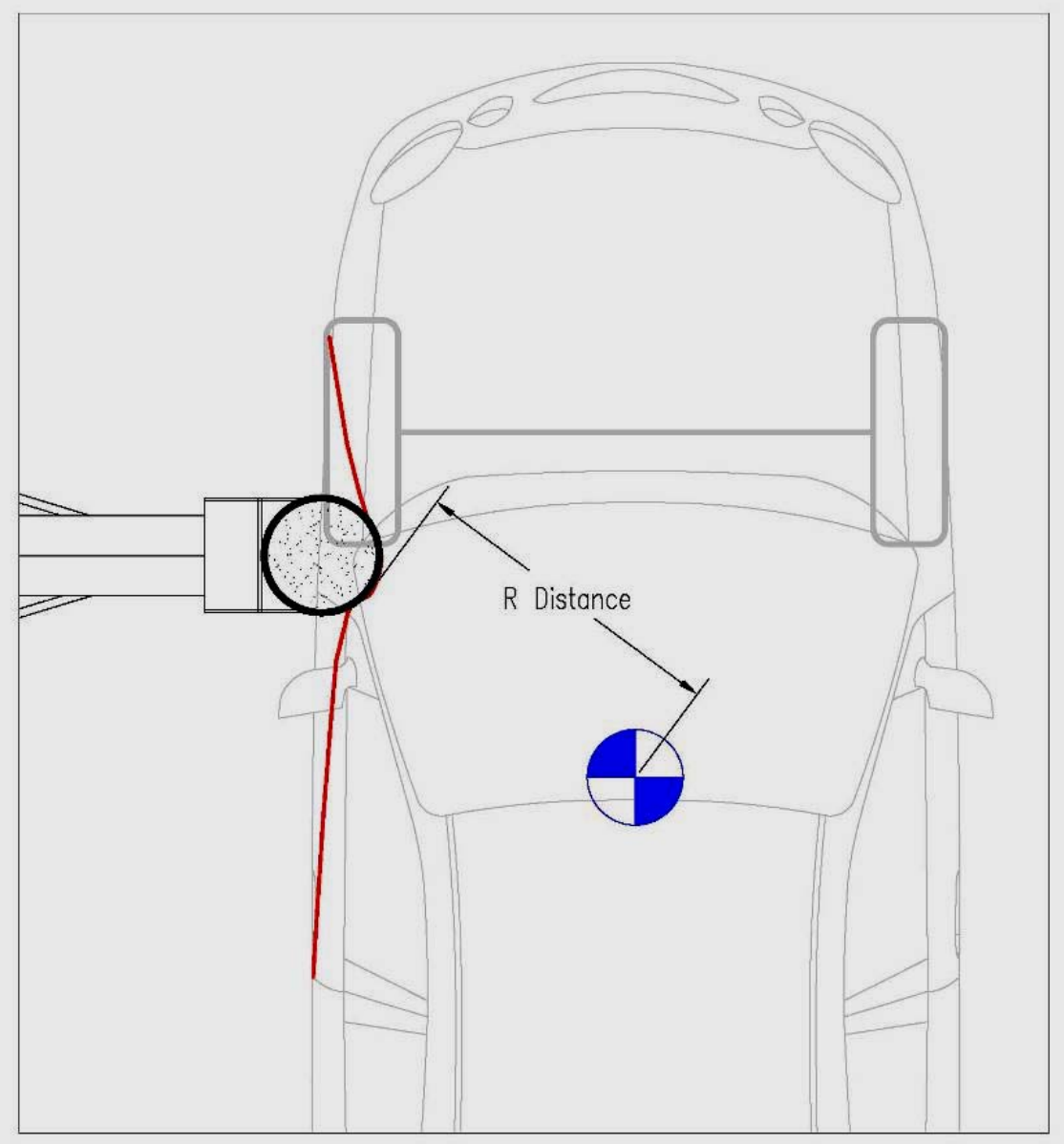

Figure 2.4 R distance from Pole Center of Rotation to $\mathrm{CG}$ 
In the specific case considered here, the rotation at separation is assumed to be around the $\mathrm{CG}$, since pole contact is lost at the instant restoration of impacted structures is complete.

Estimated values for Yaw Moment of Inertia for many vehicles are published in reference tables [NHTSA]. For this research the values of Yaw Moment of Inertia $\mathrm{I}_{0}$ for the test vehicle were obtained from measured values given for a similar vehicle reported by a NHTSA contractor and adjusted using the empirical formula [Appendix E].

The yaw energy is calculated using the established moment of inertia $\left(I_{0}\right)$ about the vehicle CG. The planar CG was located using individual tire weight measurements from the undamaged vehicle. Any shifts in $\mathrm{CG}$ position and $\mathrm{I}_{0}$ due to impact phase deformation were ignored. When the impact is longitudinally aligned with the vehicle $\mathrm{CG}, \mathrm{R}$ is simply the $\mathrm{Y}$ distance from the $\mathrm{CG}$ to the side of the vehicle. However, yaw velocities are very small, and rotational energies are generally negligible in central impacts.

Finally, the total rotational energy is subtracted from the net translational kinetic energy to obtain the energy absorbed in vehicle deformation, rearranging equation 2.2: 
$\mathrm{CE}=\left(\mathrm{KE}_{\mathrm{i}}-\mathrm{KE}_{\mathrm{f}}\right)-\mathrm{KE}_{\text {rot }}$

Figure 2.3 above represents the motion of the $\mathrm{CG}$ of a vehicle in central pole impact. One may schematically represent the CG motion for non-central pole impact in similar form, but the resulting motion will not be asymptotic to zero, but to the continuing speed of the $\mathrm{CG}$, with rotational effects considered. It will of course be complicated in general by tire force effects, but these may be ignored during the brief time of the impact, giving a motion of the form shown in figure 2.5 .

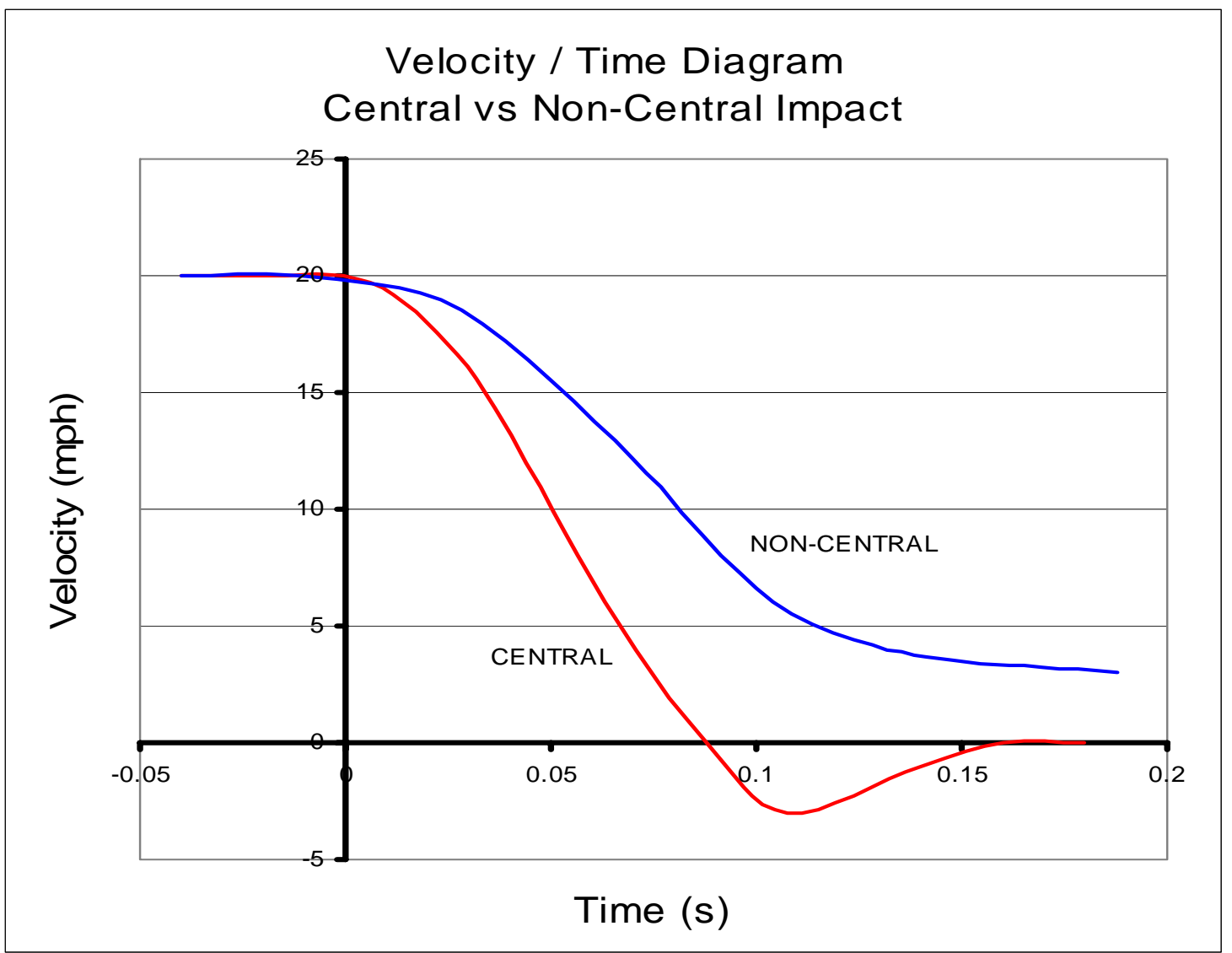

Figure 2.5 V-T Diagram For Non-Central Impact 


\subsection{Crush Energy as a Reconstruction Tool}

Calculation of crush energy based on vehicle deformation is a technique which has been developed and improved within the last 30 years. While sincere efforts have been made to develop methods for comparing standardized crash test results (including crush) to accident field data, the widely varying crush patterns exhibited, even between accidents of similar nature, highlight the difficulty in comparing test data to accident data. An accident is, by definition, an unusual event, and no two accidents are the same. Reconstruction attempts comparing "apples to oranges" have been made too often, as the researcher must often make gross generalizations in calculation of energy based on available data. More information is included in a brief, unpublished dialog by Dr. Charles Warner. It explains the development of various methods and tools related to crush energy (Appendix F).

\subsection{Review of Related Literature}

The use of crush energy in reconstruction originated with the pioneering work of Marquardt, Emori and Campbell and its application in the CRASH program and the crash files required to support it collated by the NHTSA [Marquardt, 1966; Emori, 1968; Campbell, 1974; McHenry, 1976]. In Europe, a similar approach called the EES (Energy Equivalent Speed) method was adopted 
[Zeidler, 1985]. The CRASH - III Manual provides rudimentary data related to structural behavior in the form of two-parameter "A and B coefficients" for a linear slope-intercept model relating the $[2 \mathrm{CE} / \mathrm{w}]^{1 / 2}$ and crush depth for the front, side, and rear of four vehicle classes. These early data were founded in interpretations of only about a dozen laboratory crashes [McHenry, 1976]. The dependent variable $[2 \mathrm{CE} / \mathrm{w}]^{1 / 2}$, while readily usable in calculations, lacks somewhat in its physical interpretability. Its relationship to the model for linear structural stiffness is discussed by Strother, et.al. [Strother, 1986; Prasad, 1990-1]. A new technique for better definition of crush models involving repeated crashes of the same vehicle was published by Warner, et.al. and applied extensively thereafter to frontal crashes by Prasad [Warner, 1986; Prasad, 1990-2]. Smith et.al. adapted frontal impact crush parameters to frontal pole crashes [Smith, 1987].

Side impact crash energy coefficients were not broadly published until FMVSS 214 dynamic testing began and injury reduction concepts were actively pursued [Warner, 1990]. Although side impact crash tests are now being conducted on four continents, emphasis is on occupant loadings, the crashes are almost never central, and the detailed measurements needed to separate rotation and restitution effects are seldom measured [NHTSA 214, NCAP, EuroNCAP]. As side impact crash test results were developed in compliance testing, they were included in published calculations of side crush coefficients, but without detailed accounting 
for localized effects [Neptune, 1994; Neptune, 1998]. Applications of side impact data in broad and narrow impacts were reviewed extensively by Strother, Varat, and others. More elaborate energy models were proposed. [Strother, 1998;

Neptune, 1999; Varat, 1999; Woolley, 2000; Woolley 2001; Asay, 2002].

Published testing of pole impacts into the side structures of vehicles has not been

documented to the extent needed to properly distinguish restitution and rotation

effects [FOIL, Escort, Asay]. 


\subsection{TEST METHOD DEVELOPMENT}

This section outlines the equipment, methods, and parameters utilized in this research. Testing was performed at facilities owned and operated by Delta V Technology, Inc. in Orem, Utah.

\subsection{The Rigid Barrier / Crash Test Facility}

A track-based guidance / acceleration system was employed, and vehicles were accelerated into a vertical, rigid $12 \% 3$ inch diameter pole barrier supported by a large concrete foundation.

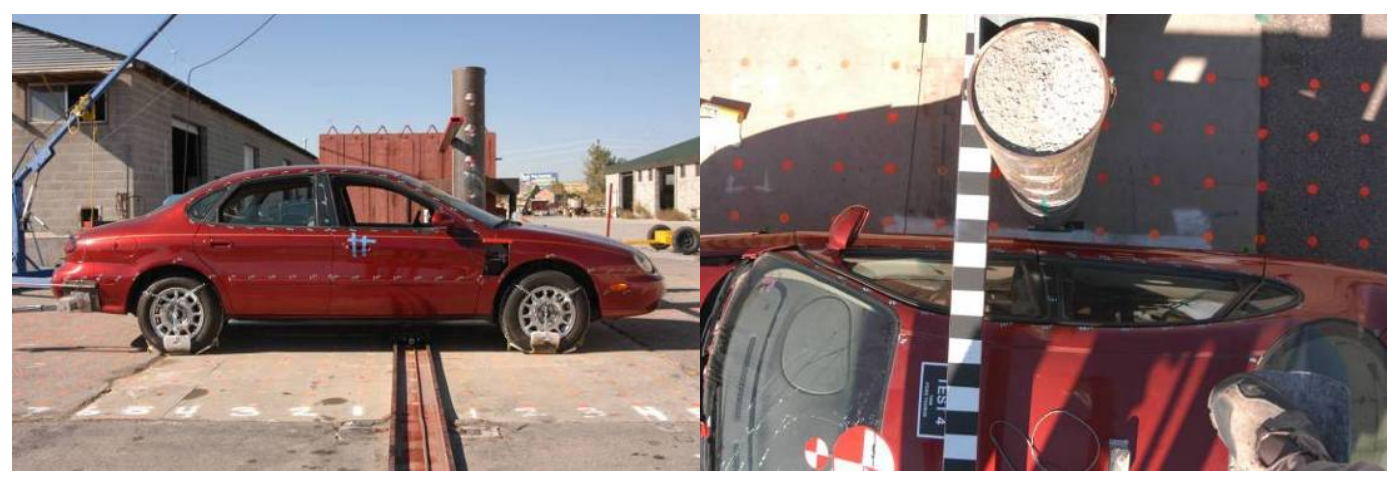

Figure 3.1 Photographs of Test Facility 
Lateral positioning of the pole barrier is facilitated by large attachment bolts. It was necessary to move and re-attach the pole for each impact location, as the guidance /acceleration track must guide the vehicle such that the $\mathrm{CG}$ remains aligned with the track..

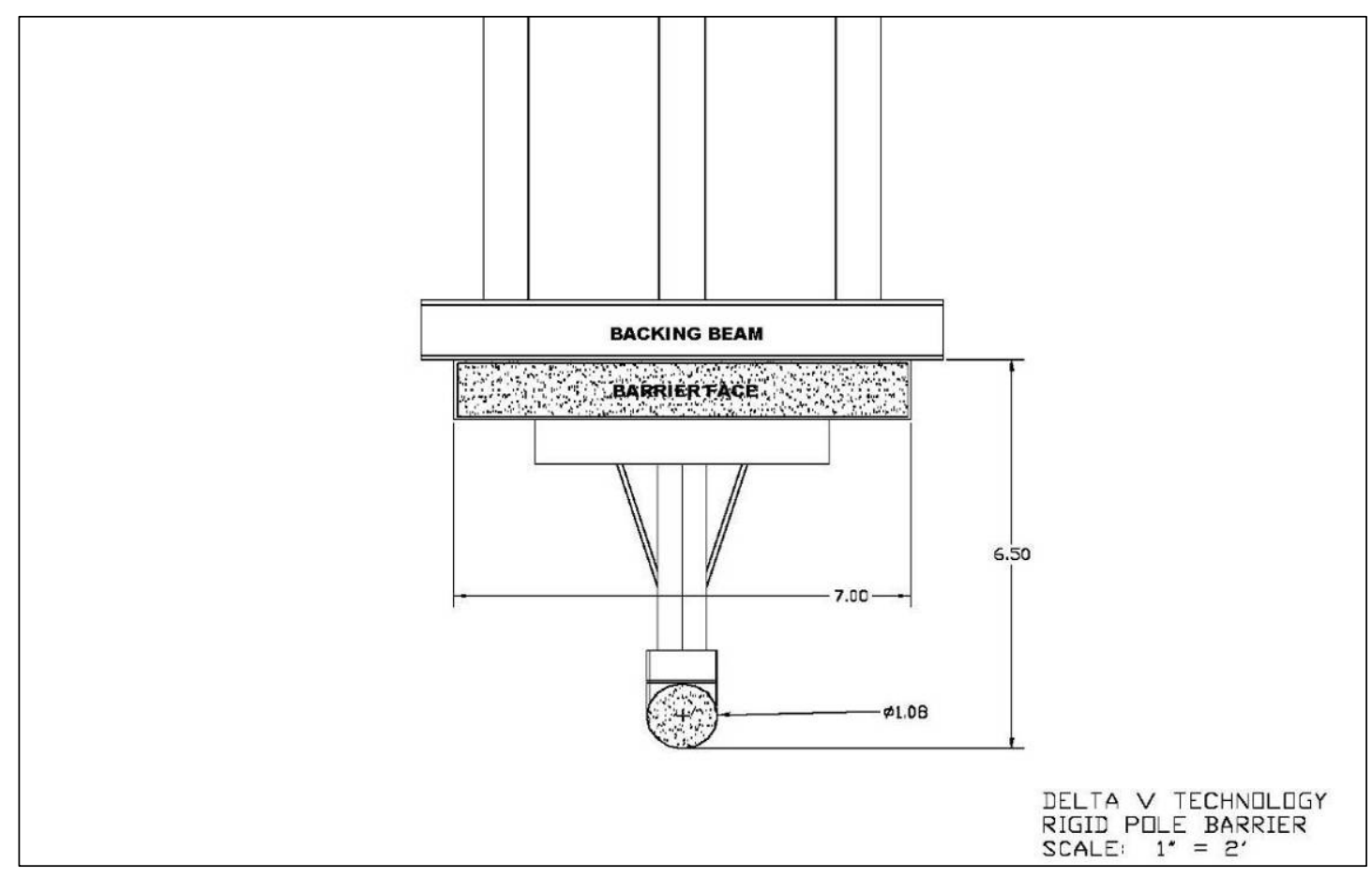

Figure 3.2 Pole Test Fixture

\subsection{Tow System}

A track-based tow system was used to accelerate and guide the vehicle for each test. The vehicle was attached to the tow cable by means of a tow chain or "tow yoke" connected to front and rear vehicle suspension members. The tow yoke was modified to ensure separation of the tow yoke upon release prior to 
impact. The tow yoke was connected at the "tow shoe" by means of a release pin which was driven out through the tow yoke ends just prior to impact with the pole. This mechanism worked without failure, and allowed the vehicle to slide into the pole and deform at the pole without tow yoke interaction.

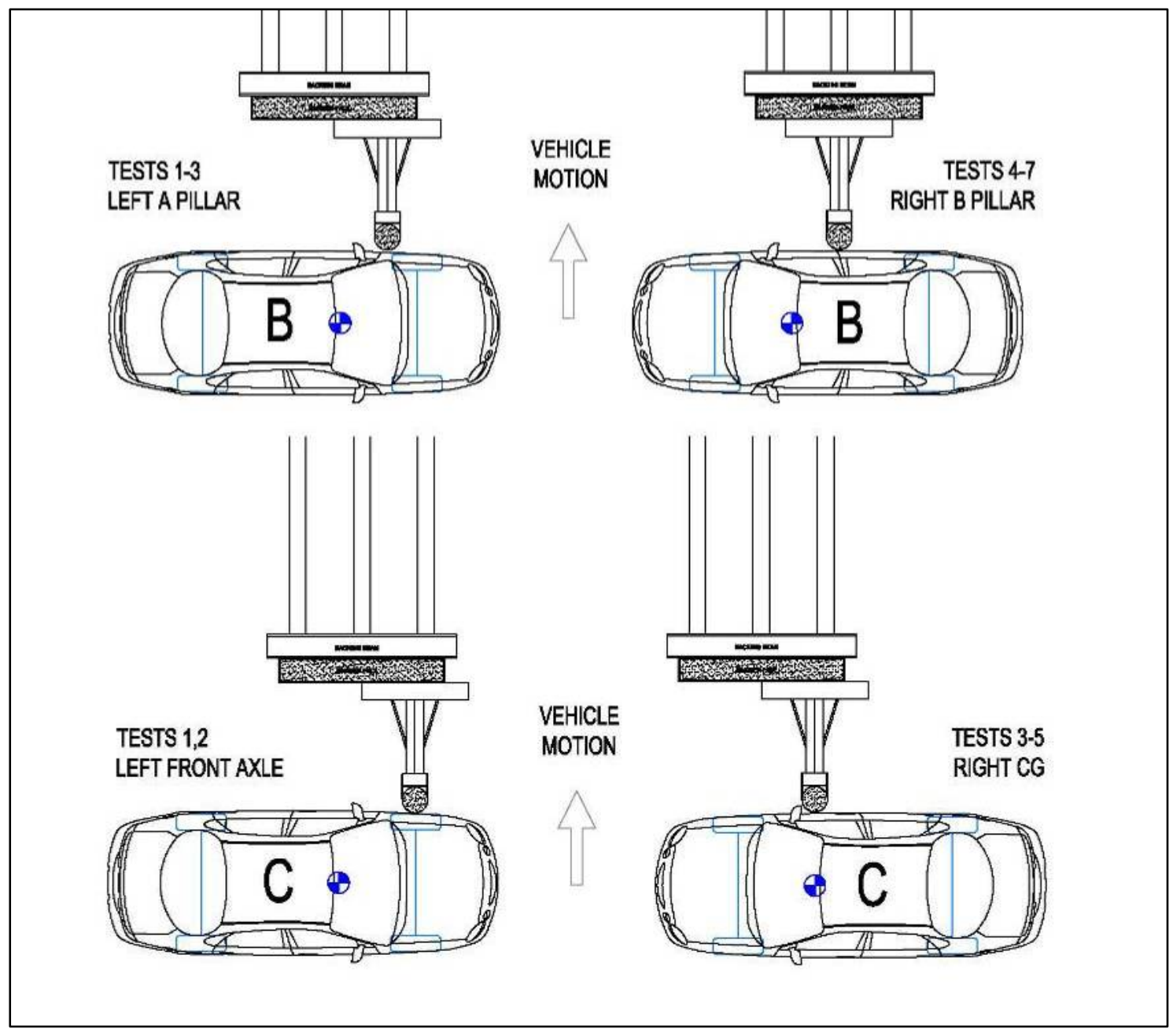

Figure 3.3 Impact Configuration and Location 
A "fifth wheel" was attached to the test vehicle, and used to measure vehicle velocity during approach. The fifth wheel transmitted real time velocity to the test controller through a radio telemetry system, as displayed on a plotter in the operator's booth.

\subsection{Speed Measurement}

Laser speed traps were used to record approach speed of the vehicle just prior to impact. Test vehicles were set near the pole in the intended impact configuration, and the speed trap fixture was positioned such that the traps were triggered within one foot of impact. The lasers were calibrated for each impact direction using a digital micrometer, and resulting speeds were compared to speeds calculated from high speed videotape analysis.

\subsection{Photography / Videography}

Test vehicles were photographed in impact configuration prior to each location series and following each impact at rest position. Overhead and horizontal video cameras were used to record vehicle motion prior to impact and during the impact phase. Mini DV cameras were used to document general motion from the side, and high speed video cameras were mounted overhead. Painted grid marks were applied at one foot intervals on the ground surrounding 
the pole, and an overhead measuring bar was installed with marks at 3 inch intervals. A matching series of 3 inch marks was applied directly beneath the vehicle and adjacent to the pole. Two high speed video cameras were mounted directly above the impact point on a stationary camera boom; one NAC model HSV 400 video camera recording 200 frames per second, and one JVC 9800 video camera recording 240 frames per second. The recorded images were instrumental in calculating restitution and aided in verification of post impact yaw rate.

\subsection{Side Impact Technique Development}

The most obvious difficulty when moving a vehicle laterally into a pole is the challenge of overcoming the lateral resisting force of the tires.

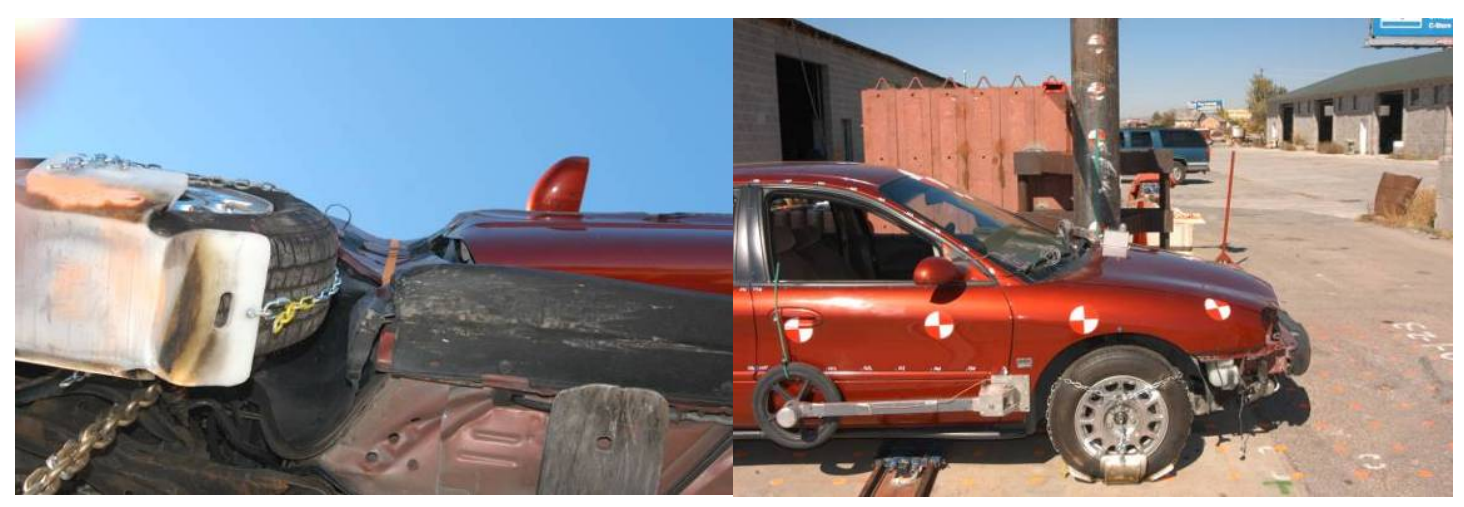

Figure 3.4 Photographs of Friction Shoes 
Some test facilities use large quantities of liquid soap spread over the track surface to reduce friction. This technique is cost-prohibitive, messy, environmentally unfavorable, and it attracts dirt. Experience with attached wheels, carts, and other devices led to experimentation with new methods. This work was accomplished by using plastic "friction shoes" attached to the tires of the test vehicle. The shoes are made of UHMW-PE (Ultra High Molecular Weight Polyethylene...similar in performance to Teflon ${ }^{\circledR}$ ) which allows the vehicle to slide sideways with a relatively low drag coefficient.

This technique has several advantages:

- No significant mass is added to the test vehicle (using a dolly or attaching wheels are some alternatives).

- The structure of the test vehicle is not altered.

- Attaching the friction pads is much less expensive and time-consuming than attaching a tow dolly.

The development of this technique involved several iterations or "shakedown tests" on vehicles other than the Ford Taurus test vehicles. Attaching rectangular UHMW-PE strips to vehicle tires proved to be a challenge. Subsequent experiments involved screwed-on rectangular UHMW-PE strips. Tires were filled with polyurethane foam (used for forklift tires), and self tapping screws were driven through the PE strips and into to tires directly. This technique 
worked well for attaching the strips, but added too much mass to the vehicle (added $70 \mathrm{lb}$ per tire) and was cost prohibitive due to the expense of the tire foam. The most effective means for attaching the friction shoes was to cut the material into a crossing-rectangle shape, then use a torch to form the shoe around the tire. A system of chains was assembled for each tire, then the tire was deflated, the chains were attached and the tire was re-inflated with the shoe in place.

Although reduced significantly from the level experienced without friction shoes, the increased pull force (compared to that of a rolling vehicle) caused increased tow cord stretch, and led to more difficult speed control than was anticipated. This made the use of repeated impacts more important, as comparable single data points based on speed or predicted energy were difficult to match.

\subsection{Test Vehicles}

The test vehicles were model year 1999 Ford Taurus sedans. The vehicles had been used previous to this research for unrelated low speed frontal crash testing, and had sustained minor front end damage. Residual damage profiles showing the vehicles as received and after testing are shown in figures 4.4.1 and 4.4.2. This previous damage was taken into account in calculation of potential bowing effects, but bowing was not found to be significant in relation to the localized pole impacts performed. 


\subsubsection{Pre-Test and Post-Test Geometric Documentation}

Each of the three test vehicles was cleaned and marked with a series of points to be used for three dimensional digitization, and the points were numbered sequentially. Prior to testing the vehicles were surveyed using a "Vulcan" surveying device, and the data was stored.

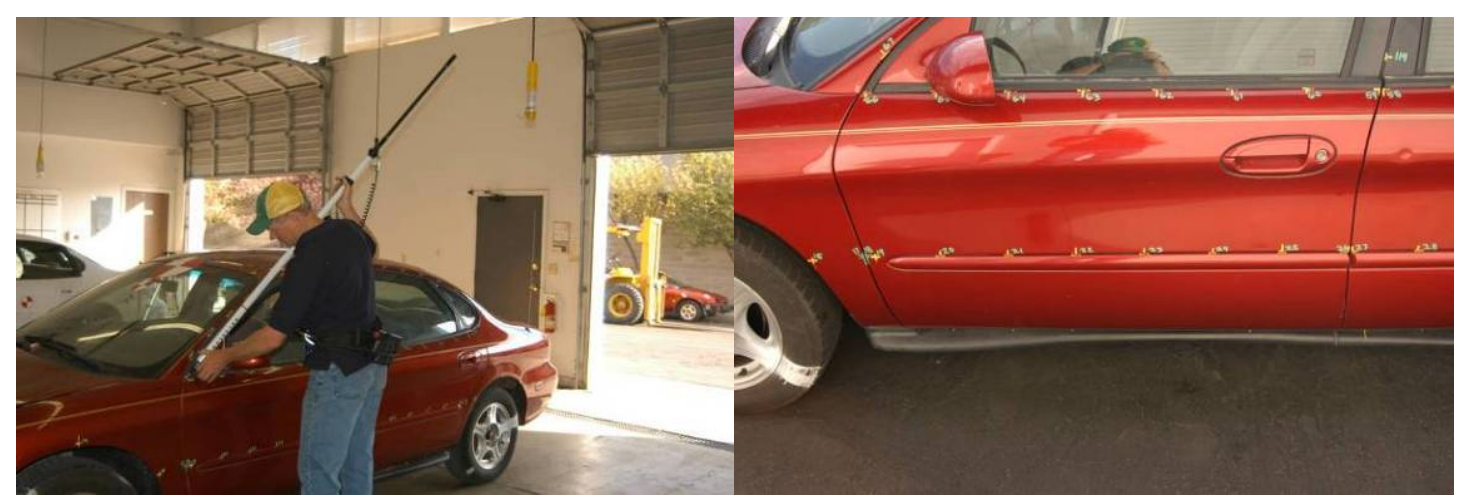

Figure 3.5 Photographs of Digital Surveying Technique

Following each impact, the same points were surveyed again and the data was overlaid and aligned using the AutoCAD ${ }^{\circledR}$ drawing program. Photographs were taken of each vehicle prior to initial testing and following each subsequent impact. 


\subsubsection{Vehicle Weight Measurement}

The test vehicles were weighed using an electronic scale system. Table 3.1 below lists vehicle weights at wheels, and shows calculated totals and percentages by location. Total vehicle weights (lbf) are used for energy calculations.

Table 3.1 Test Vehicle Weight Measurements

\begin{tabular}{|c|c|c|c|c|c|c|c|c|c|}
\hline & $\begin{array}{c}\text { VEHICLE } \\
\mathbf{A}\end{array}$ & & & $\begin{array}{c}\text { VEHICLE } \\
\mathbf{B}\end{array}$ & & & & $\begin{array}{c}\text { VEHICLE } \\
\mathbf{C}\end{array}$ & \\
\hline & TOTALS & & & & TOTALS & & & TOTALS & \\
\hline & $\%$ & & & & $\%$ & & & $\%$ & \\
\hline LF & 0.663217 & RF & LF & 0.675547 & RF & LF & 0.65782 & RF \\
\hline 1052 & $\mathbf{2 1 1 5}$ & 1063 & 1058 & $\mathbf{2 1 3 0}$ & 1072 & 1029 & $\mathbf{2 0 8 2}$ & 1053 \\
\hline & & & & & & & & & \\
\hline 0.505174 & $\underline{\mathbf{3 1 8 9}}$ & 0.494826 & 0.502696 & $\underline{\mathbf{3 1 5 3}}$ & 0.497304 & 0.500158 & $\underline{\mathbf{3 1 6 5}}$ & 0.499842 \\
\hline & & & & & & & & & \\
\hline LR & 0.336783 & RR & LR & 0.324453 & RR & LR & 0.34218 & RR \\
\hline 559 & $\mathbf{1 0 7 4}$ & 515 & & 527 & $\mathbf{1 0 2 3}$ & 496 & 554 & $\mathbf{1 0 8 3}$ & 529 \\
\hline
\end{tabular}

\subsubsection{Electronic Instrumentation}

The test vehicles were fitted with mounts for electronic accelerometers and yaw rate sensors at the CG. Where off central impacts were performed, the vehicles were fitted with mounts for an additional accelerometer opposite the 
point of impact on the vehicle. Accelerometer mounts were fabricated from 3/16" steel angle and plate, and welded to structural locations. The front axle test accelerometer mount was welded to the opposite side strut tower. A-pillar and Bpillar tests were welded to opposite side A and B-Pillar structures, respectively.

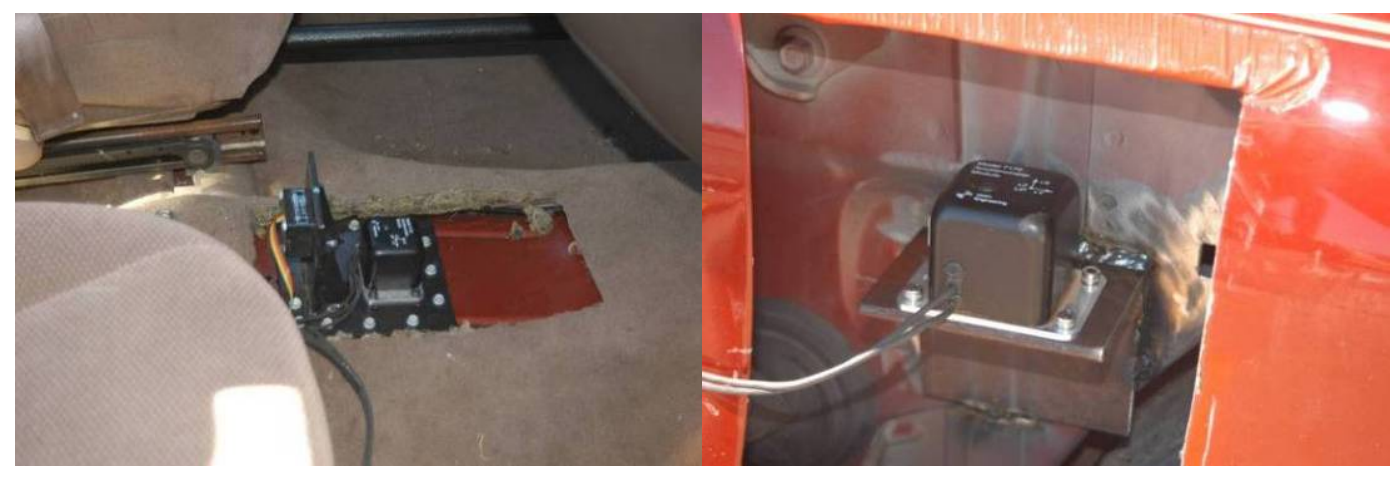

Figure 3.6 Photographs of Accelerometers and Yaw Rate Sensor 


\subsection{RESULTS}

\subsection{Test Locations and Velocities}

Plans to impact the test vehicles at multiple locations were developed well before the first impact occurred. It was important to be able to impact both sides of each test vehicle without disrupting integrity and making the vehicles unsuitable for further testing. Test speeds were chosen, with multiple impacts at each location.

Table 4.1 Impact Speed and Linear Crush

\begin{tabular}{|c|c|c|c|c|c|c|c|c|c|c|c|c|}
\hline Location & & $\begin{array}{c}\text { A } \\
\text { PILLAR }\end{array}$ & & \multicolumn{4}{|c|}{$\begin{array}{c}\text { B } \\
\text { PILLAR }\end{array}$} & \multicolumn{2}{|c|}{ LF WHEEL } & & CG & \\
\hline Test & B1 & B2 & B3 & B4 & B5 & B6 & B7 & $\mathrm{C} 1$ & $\mathrm{C2}$ & $\mathrm{C3}$ & C4 & C5 \\
\hline $\begin{array}{c}\text { IMPACT V } \\
\text { (mph) }\end{array}$ & 5.2 & 13.3 & 9.5 & 4.7 & 9.6 & 11.8 & 17.5 & 11.8 & 16.5 & 7.9 & 14.5 & 13 \\
\hline CRUSH (in) & 1.25 & 6 & 7.125 & 1 & 6.25 & 12 & 22 & 3.75 & 7 & 4.5 & 11 & 13.75 \\
\hline
\end{tabular}

\subsection{Restitution Documentation}

Rebound velocity $\left(\mathrm{v}_{\mathrm{r}}\right)$ at the vehicle CG was determined through analysis of high speed videotape by plotting the position of the CG over 100 millisecond 
(ms) increments in time. The center of the lens of the high speed video camera was positioned directly above the vehicle CG. With post-impact rotation a factor in most tests, the CG did not always rebound in the direction opposite to incoming velocity $\left(\mathrm{V}_{0}\right)$, as usually anticipated in the definition of central impacts. In lower speed impacts, rebound distance was often small. The restitution was inferred from vehicle $\mathrm{CG}$ position compared over equivalent time as follows:

$$
\varepsilon \equiv \frac{\mathrm{V}_{\mathrm{r}}}{\mathrm{V}_{0}} \approx \frac{\mathrm{X}_{\mathrm{r}}}{\mathrm{X}_{0}}
$$

Where $\varepsilon$ (epsilon) $=$ coefficient of restitution

$$
\begin{aligned}
& \mathrm{v}_{\mathrm{r}}=\text { the rebound velocity of the vehicle CG } \\
& \mathrm{v}_{0}=\text { the velocity at impact } \\
& \mathrm{x}_{0}=\text { the displacement of the vehicle CG between }-100 \mathrm{~ms} \text { and impact } \\
& \mathrm{x}_{\mathrm{r}}=\text { the displacement of the vehicle CG between } 100 \mathrm{~ms} \text { and } 200 \mathrm{~ms} \text { (post } \\
& \text { impact) }
\end{aligned}
$$

This technique was found to be superior to measuring equivalent distance over change in time, due to the small displacement of the CG post impact, and the difficulty in resolving small amounts of change over minimum time steps of $5 \mathrm{~ms}$ (video camera recording 200 frames / sec). Checks for parallax error showed negligible error for all subjects except those very near the edges of the camera 
view. The distance between the pole and deepest crush was also measured following each impact. This is termed the "run-out distance" and is used to estimate exit velocity by the skid mark method in comparing calculated restitution to measured restitution.

\subsection{Rotation Effects}

Yaw rate sensors attached at the $\mathrm{CG}$ of the test vehicle were used to record the yaw rate $(\Omega)$ during the impact phase. Integrated yaw rate plots were compared graphically to hand plots of videotape images spaced at 100 millisecond intervals, and were found to compare reasonably for all tests (See Figures 4.1 and 4.2). 


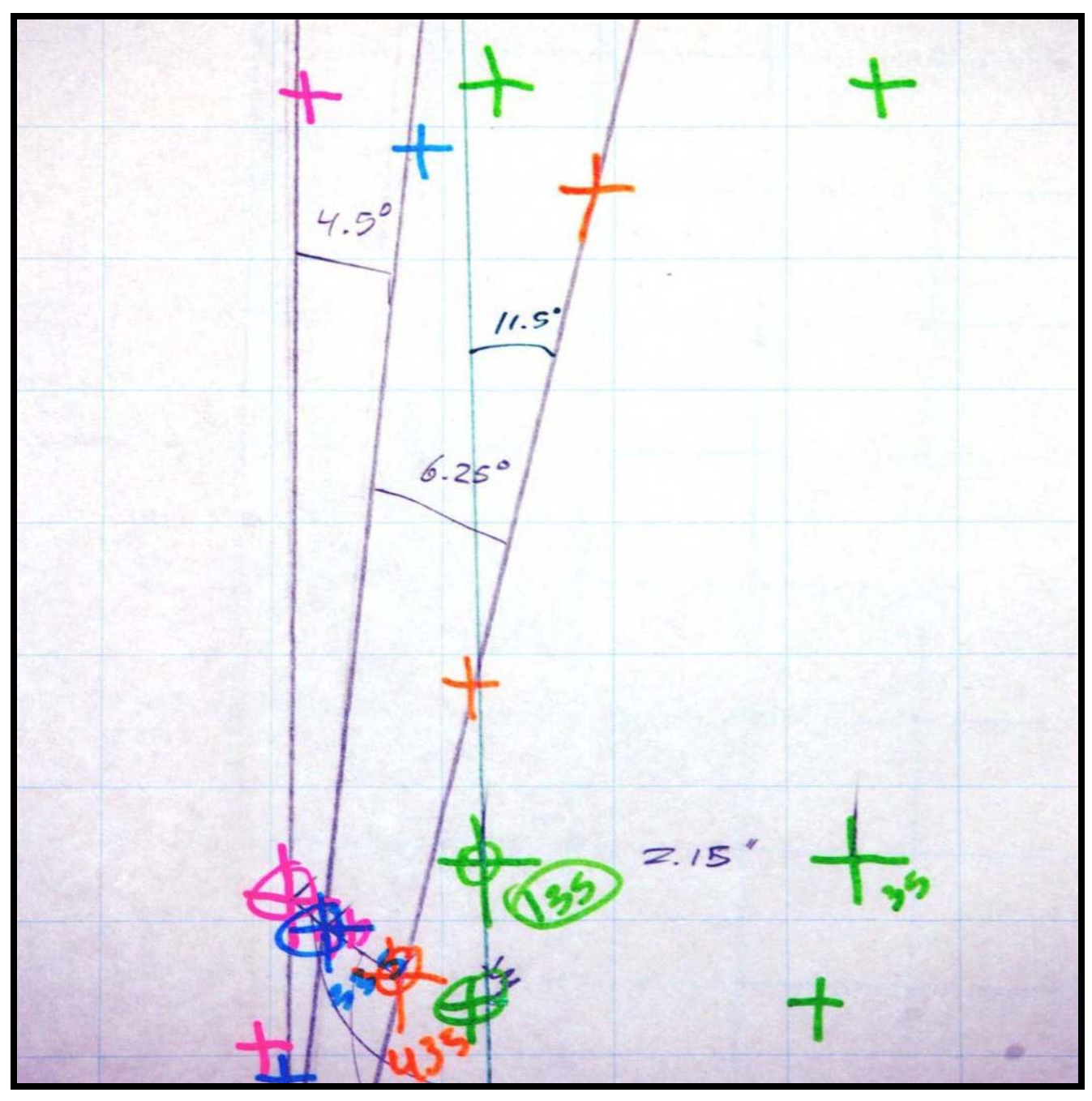

Figure 4.1 Vehicle Motion Analysis / Test B5 


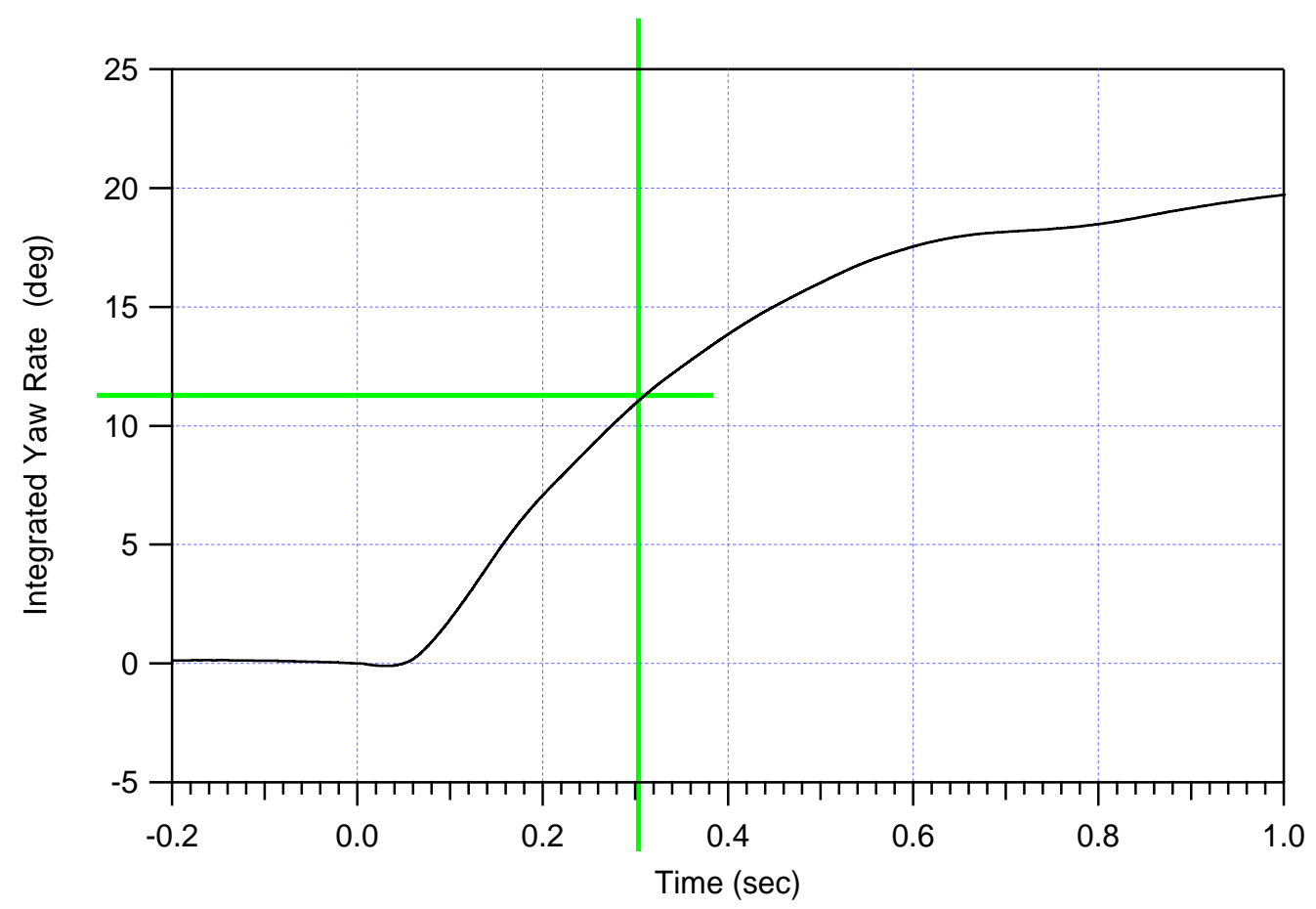

Figure 4.2 Integrated Yaw Rate / Test B5

The Y (lateral) acceleration trace was also integrated and plotted, providing a curve indicating the point in time when the vehicle CG velocity changed direction (see green lines on Figure 4.3 below). Analysis of the graphs at this point during the impact typically showed a peak yaw velocity between 100 and 200 milliseconds after first contact. 


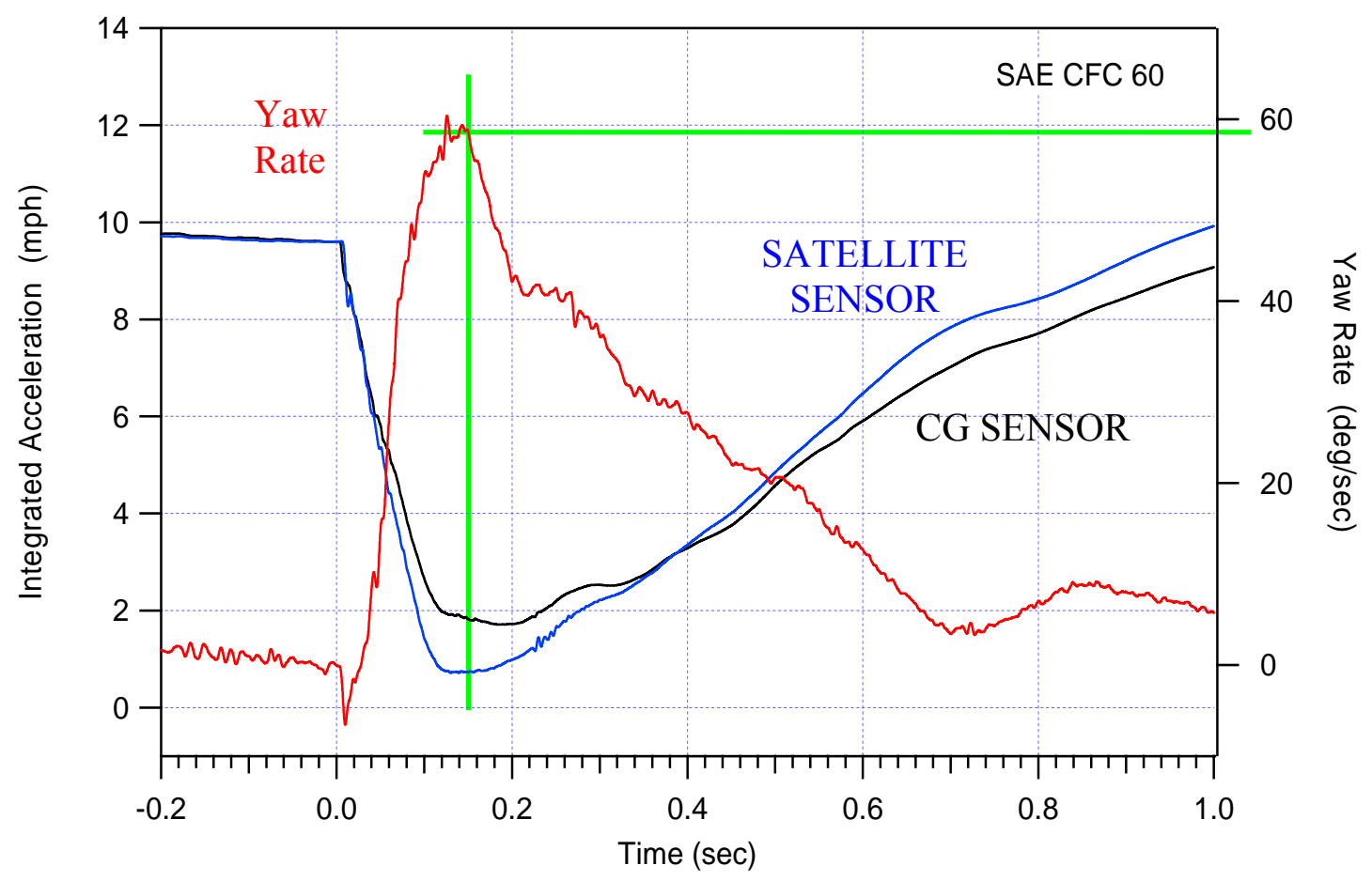

Figure 4.3 Integrated Acceleration overlaid with Yaw Rate / Test B5

\subsection{Crush Measurement}

Measurements of deepest crush were taken by tape measure following each impact, and added to the post test data sheets (an example test data sheet is found in appendix G). This measurement was used for preliminary energy calculations. Final crush measurements were taken from plan view CAD drawings produced using the survey data, and added to the calculation spreadsheet. 
Figures 4.4.1 and 4.4.2 show composite damage plots showing the crush at both locations impacted on vehicles B and C.

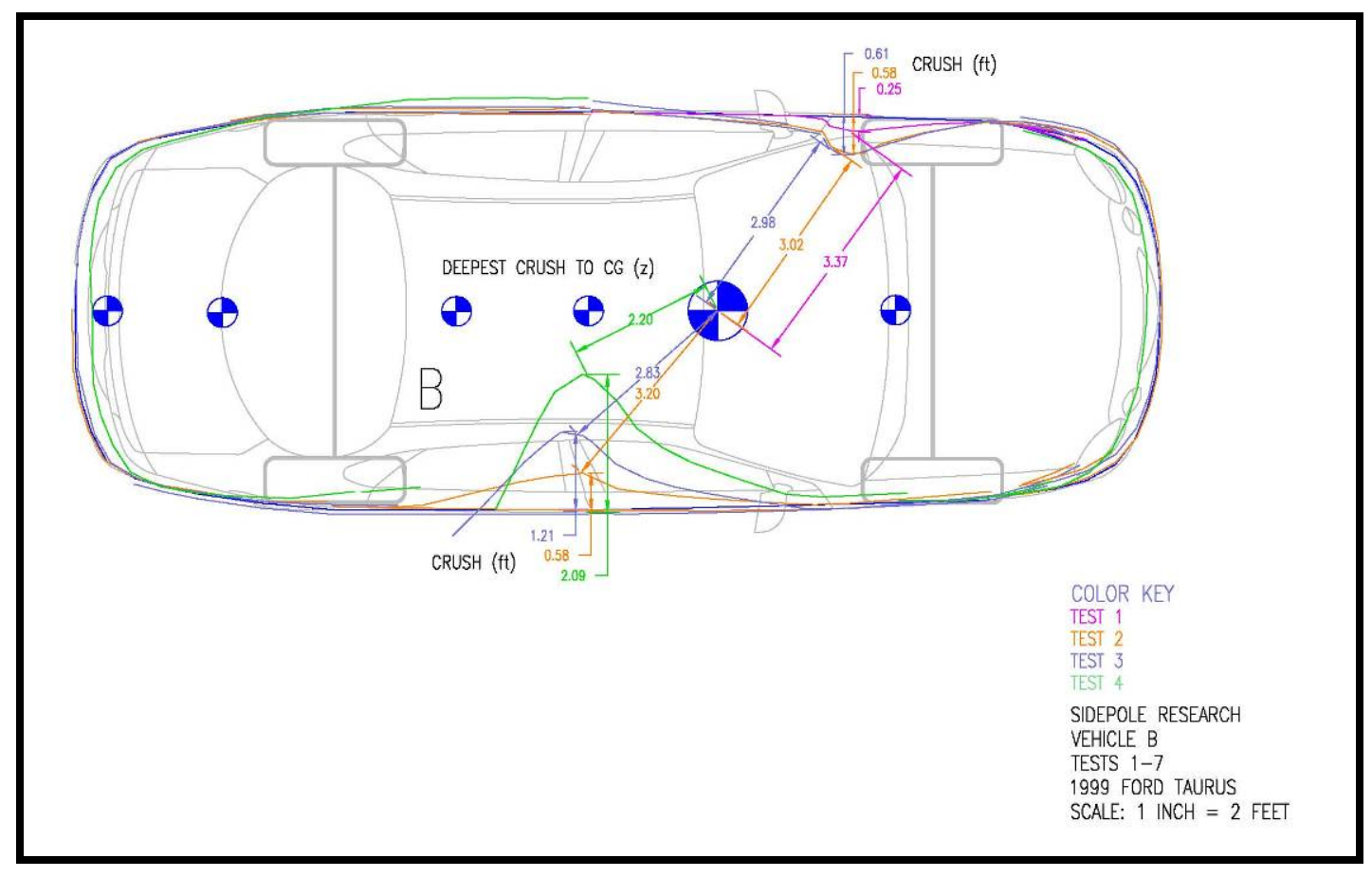

Figure 4.4.1 Composite Crush Map of Vehicle B 


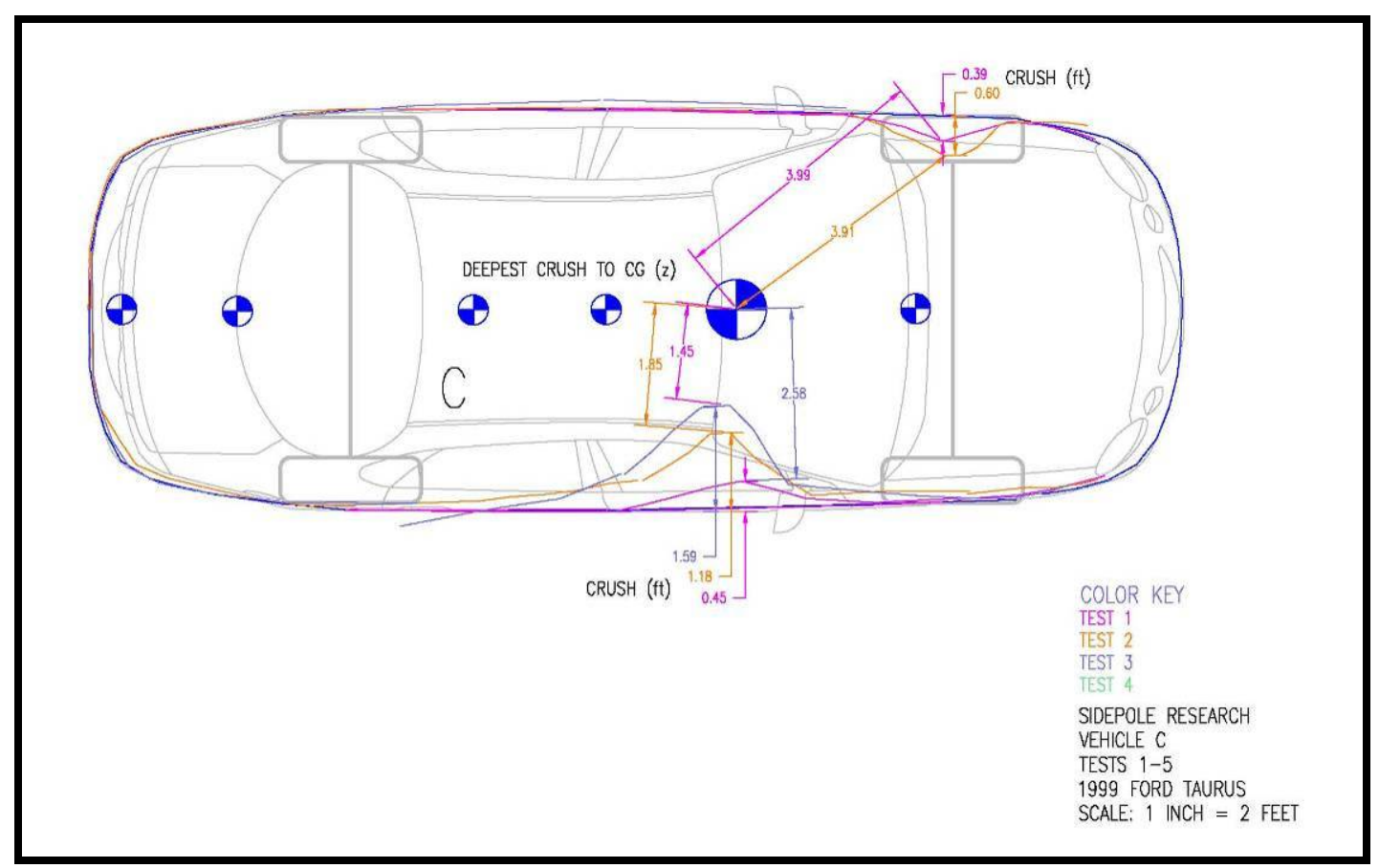

Figure 4.4.2 Composite Crush Map of Vehicle C

\subsection{Crush Energy Calculation}

\subsubsection{Planar Vehicle Yaw Rate}

As mentioned above, yaw rates were obtained by analyzing yaw rate sensor data as overlaid with integrated acceleration traces. These yaw rates were used in crush energy calculations as follows: 
$\Omega=$ Yaw rate (omega) in degrees/sec, converted to radians/sec for energy calculation

$I_{0}=$ Yaw moment of inertia for rotation about CG

$I_{p}=$ Yaw moment of inertia at the pole (center of vehicle rotation for impulse)

$\mathrm{kE}_{\text {yaw }}=\frac{1}{2} \mathrm{I}_{0} \Omega^{2}$

\subsubsection{Calculation of Total Crush Energy}

Crush energy was calculated as the total kinetic energy $\left(\mathrm{KE}_{\mathrm{i}}\right)$ of the vehicle prior to impact, minus the sum of the post-impact kinetic energy $\left(\mathrm{KE}_{\mathrm{f}}\right)$ and post impact rotational energy $\left(\mathrm{KE}_{\mathrm{rot}}\right)$, as shown in equation 4.3.

$\mathrm{CE}=\frac{1}{2}\left(\frac{\mathrm{w}}{\mathrm{g}} \mathrm{v}_{0}^{2}\right)-\frac{1}{2}\left(\frac{\mathrm{w}}{\mathrm{g}} \mathrm{v}_{\mathrm{r}}^{2}\right)-\frac{1}{2}\left(I_{\mathrm{f}} \Omega^{2}\right)$

Survey data recorded following each test were imported into the AutoCAD ${ }^{\circledR}$ drawing program, and linework was developed allowing comparison of the post test vehicle outline to the undamaged vehicle outline. Dimensions were transferred to an Excel $^{\circledR}$ spreadsheet where calculations were performed. 
Table 4.2 Crush Energy Calculation Matrix

\begin{tabular}{|c|c|c|c|c|c|c|c|c|}
\hline Repeat Test & Vo & $\Delta K E$ & Vr & $\Omega$ & KEYaw & $C_{i}$ & $C_{f}$ & СЕтот \\
\hline & $\begin{array}{c}\mathrm{V} \\
\text { Impact }\end{array}$ & Linear & $\begin{array}{c}\mathrm{V} \\
\text { rebound }\end{array}$ & $\begin{array}{c}\text { Yaw } \\
\text { Velocity }\end{array}$ & $\begin{array}{c}\text { Yaw } \\
\text { Energy }\end{array}$ & $\begin{array}{l}\text { Crush } \\
\text { Impact }\end{array}$ & $\begin{array}{l}\text { Crush } \\
\text { Total } \\
\end{array}$ & Cumulative \\
\hline & $\mathrm{mph}$ & $\mathrm{ft}-\mathrm{lbf}$ & $\mathrm{mph}$ & $\mathrm{rad} / \mathrm{s}$ & $\mathrm{ft}-\mathrm{lbf}$ & inches & inches & $\mathrm{ft}-\mathrm{lbf}$ \\
\hline A PILLAR 1 & 5.2 & 2757.7 & 1.0 & 0.3 & 116.9 & 3.0 & 3.0 & 2640.7 \\
\hline A PILLAR 2 & 13.3 & 18040.3 & 2.5 & 1.4 & 2231.8 & 4.0 & 7.0 & 18449.3 \\
\hline A PILLAR 3 & 9.5 & 8631.3 & 2.9 & 1.1 & 1811.4 & 0.4 & 7.3 & 25269.2 \\
\hline B PILLAR 1 & 4.7 & 2191.2 & 1.2 & 0.3 & 88.2 & 1.5 & 1.5 & 2103.0 \\
\hline B PILLAR 2 & 9.6 & 9091.9 & 2.5 & 0.9 & 809.9 & 5.5 & 7.0 & 10384.9 \\
\hline B PILLAR 3 & 11.8 & 13406.4 & 3.5 & 1.0 & 1034.2 & 7.6 & 14.5 & 22757.2 \\
\hline B PILLAR 4 & 17.5 & 31466.5 & 3.0 & 2.3 & 5817.0 & 10.6 & 25.1 & 48406.6 \\
\hline $\begin{array}{c}\text { FRONT AXLE } \\
1 \\
\end{array}$ & 11.8 & 14309.3 & 2.1 & 1.7 & 3251.9 & 4.7 & 4.7 & 11057.3 \\
\hline $\begin{array}{c}\text { FRONT AXLE } \\
2 \\
\end{array}$ & 16.5 & 27640.0 & 3.5 & 2.4 & 6373.8 & 2.5 & 7.2 & 32323.6 \\
\hline CG 1 & 7.9 & 6214.2 & 2.0 & 0.3 & 130.1 & 5.4 & 5.4 & 6084.1 \\
\hline CG 2 & 14.5 & 20934.6 & 3.6 & 0.8 & 718.3 & 9.2 & 14.6 & 26300.3 \\
\hline CG 3 & 13.0 & 16999.7 & 3.0 & 0.4 & 150.3 & 4.5 & 19.1 & 43149.7 \\
\hline
\end{tabular}

Calculated values of crush energy were plotted against crush depth (energy vs. crush). These calculated values form a good basis for comparison. It is worth repeating that these data are corrected for rotation, and that the total crush energy absorbed in vehicle structures can be a fairly small percentage of the total kinetic energy of the vehicle prior to impact. For example, crush energy calculated for the second impact at the front axle location is $32324 \mathrm{ft}-\mathrm{lbf}$. The energy attributed to post impact rotation was $6374 \mathrm{ft}-\mathrm{lbf}$ (Table 4.2). 


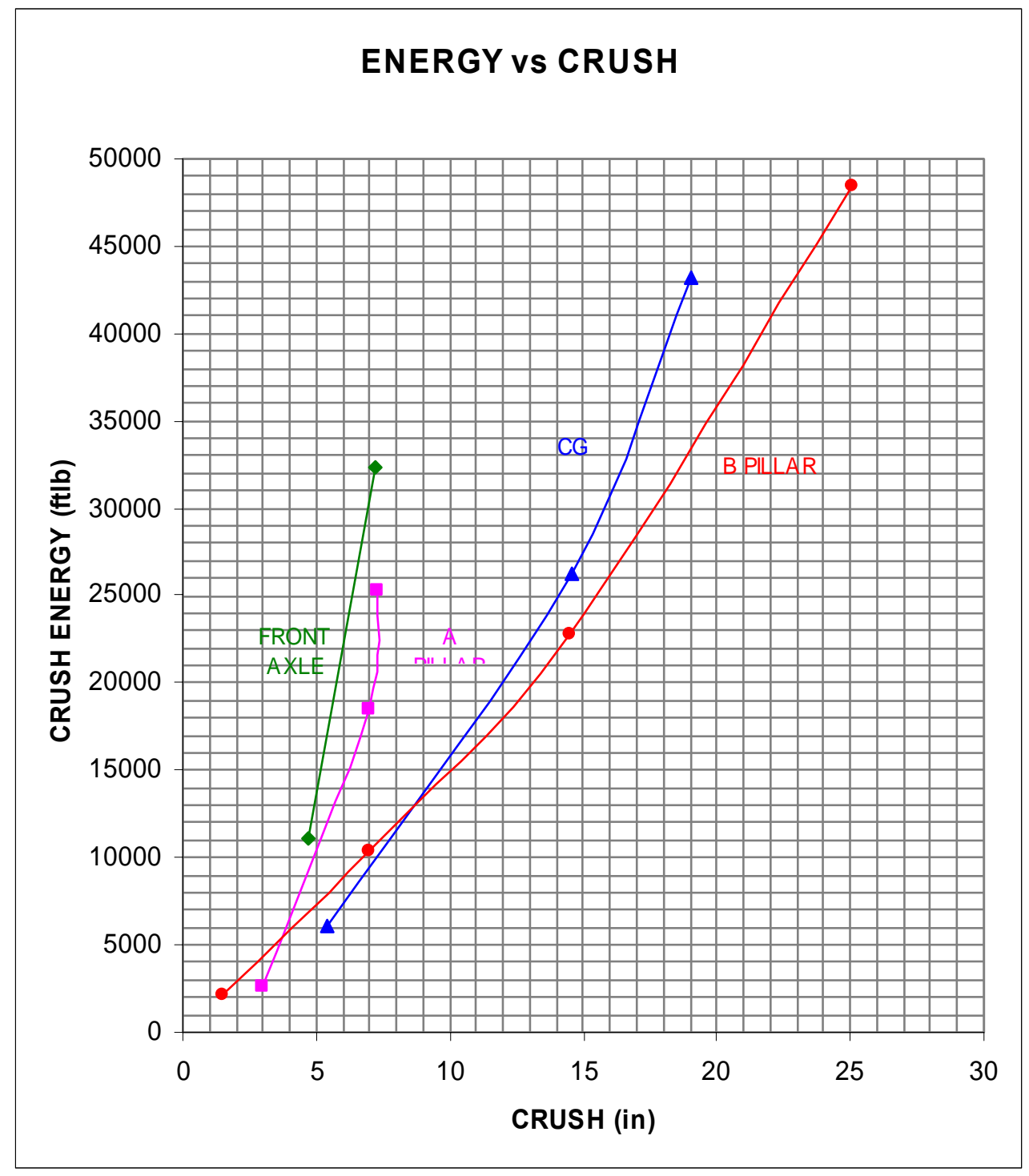

Figure 4.5 Energy / Crush Distance Correlations

It should be obvious that models which fail to account for rotational energy should not be relied upon for non-central impacts. In Figure 4, The slope of the line connecting data points for each test is seen to increase as total energy and crush depth increase. This is reasonable, as we expect structures to increase in 
stiffness with increasing deformation up to a point where the structure becomes completely crippled. In cases of very high crush, a force saturation may occur, as reported for some vehicles by Strother, et.al. [Strother, 1998]. Such saturation behavior was not manifest in the crush levels recorded in the present research. Deeper levels of crush involve more vehicle structures, and the ability of structures to collapse prior to crippling or rupture becomes more limited with depth. Only two or three data points are available for stiffness characterizations at each location. Budget and time limited the number of crash tests which were devoted to this study.

\subsection{Crush Energy as a Function of Width}

The use of the SMAC model to calculate an effective "k" or spring stiffness has become a common industry tool for comparing crush energy from accident field data to crash test data. A frequently used source for this data is Neptune Engineering [Appendix D], where thousands of crash test data from various entities are compiled and sold through an on-line ordering system [Appendix C]. As shown, available side crash data for the similar body type Ford Taurus was purchased from Neptune Engineering for comparison with our test results. The vertical axis in the plots is $[2 \mathrm{CE} / \mathrm{w}]^{1 / 2}$. In the case of the Neptune data, the impactor width is the measured barrier face width of a little more than 5 feet. This does not account for the width of the induced damage pattern, just the crush depth as compared to the width of the impactor. 
For comparison purposes, a plot of the resulting crash test data overlaid with the Neptune data is shown below. The Neptune data is centered at the point $(12.5,100)$, and is shown in black. These data are taken from 5 side impact tests with similar test conditions, producing points in the graph that are overlaid at this point. The green data series mark the points from pole tests at the CG performed in this study. A trendline was added using a linear regression fit of the data, and forced through the $\mathrm{x}, \mathrm{y}$ intercept at zero. The slope of the lines represents the value of $\mathrm{k}_{\mathrm{v}}$, or the equivalent spring constant, relating to the given data group.

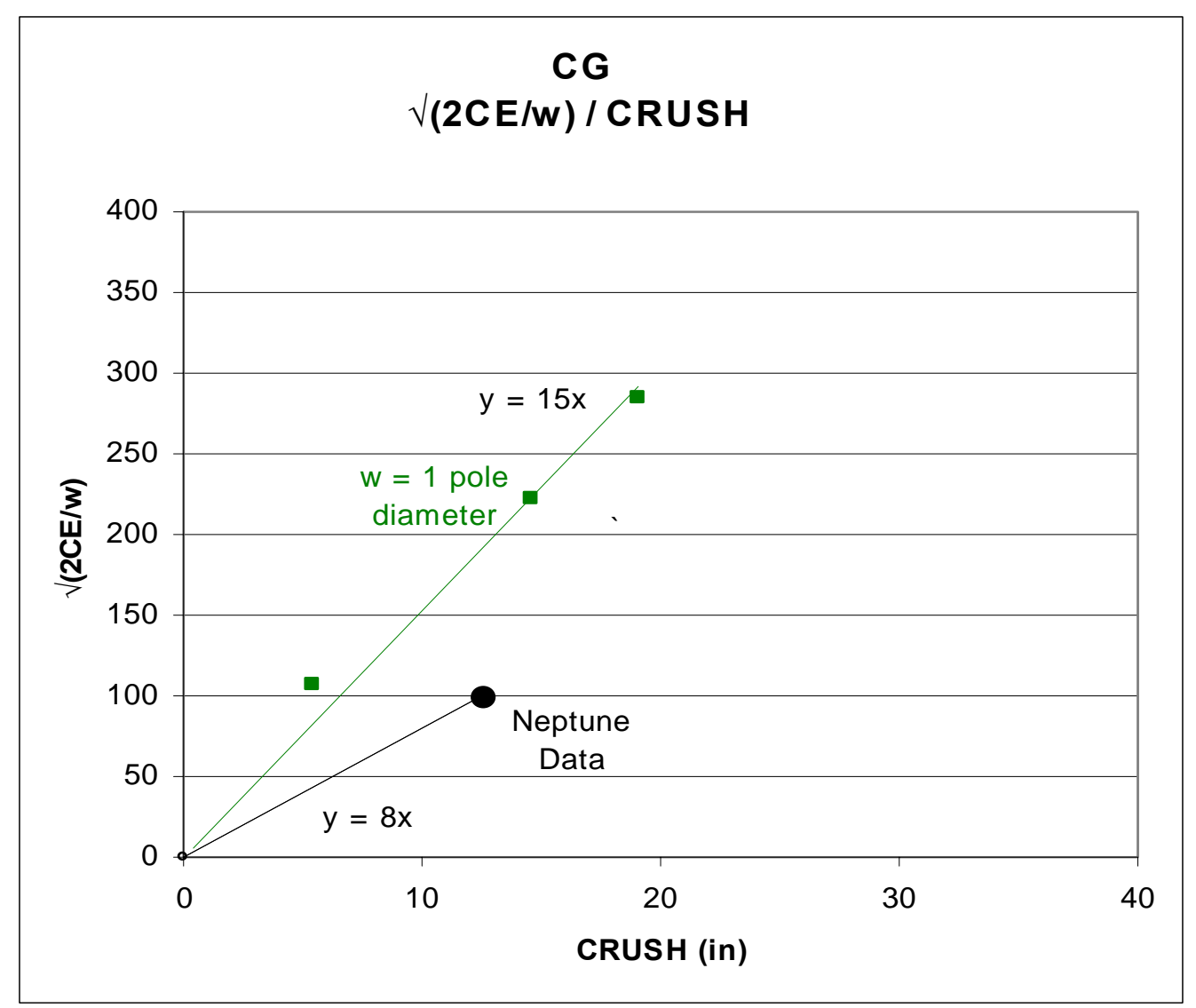

Figure 4.6 CG Test And Neptune Data 


\subsection{Bowing and Effective Width}

In cases of deep deformation and/or high energy side impacts, the vehicle longitudinal centerline begins to exhibit bowing. Test and accident vehicles exhibiting high levels of bowing often have ruptured door latch mechanisms and other component failures associated with the structural integrity of the vehicle. NHTSA field reconstruction standards mandate an adjustment of energy calculations by using a "bowing constant" when the undeformed side of the vehicle is bowed more than 4 inches. Minor bowing was present in all tests except those performed at the left front axle spin axis, but none exceeded 4 inches. Please refer to Appendix $\mathrm{H}$ for the NHTSA protocol for measuring sideimpacted vehicle crush. 


\subsection{DISCUSSION}

\subsection{Barrier Width}

Figure 5.1 (below) helps to illustrate the variation in energy absorption characteristics a given vehicle will exhibit, based on the width of the impactor. This comparison may lead us back to a discussion comparing apples to oranges, but since no other basis for comparison is available, we will stay with impactor width. An argument could be made that the width of the pole applied to the side of a vehicle bears little relationship to the width of a NHTSA 214 barrier face. This research supports such an argument, but for the lack of other proven data to compare against, we will use the Neptune data, as gleaned from NHTSA 214 tests. In plotting of $[2 \mathrm{CE} / \mathrm{w}]^{1 / 2}$ for the $\mathrm{CG}$ test data, the width of the pole $(12.75$ inches diameter) is compared to the width of the NHTSA 214 test barrier face (66 inches). 


\subsection{Barrier Width as a function of Pole Width}

For impacts at the $\mathrm{CG}$, the exact number of pole widths needed to overlay the Neptune data is 3.55 , or 45.3 inches. This does not correlate to the Neptune data based on barrier width, and it should not be expected to correlate.

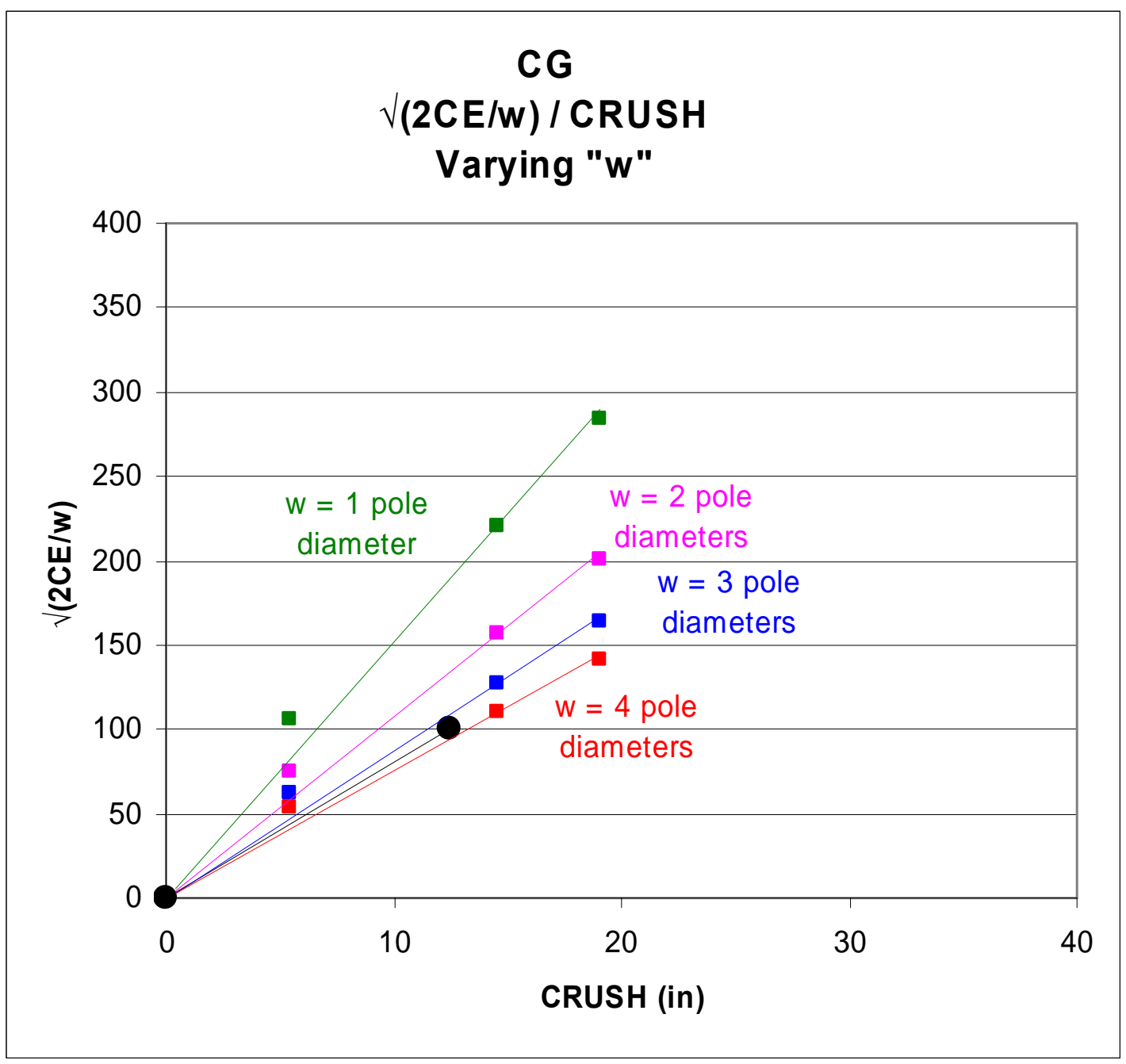

Figure 5.1 CG: Varying Pole Widths Compared to Neptune Data 
The Neptune data is based upon test data from NHTSA 214 tests, where barrier width is 66 inches, the barrier face is deformable, and test conditions are significantly different from those employed here. Graphs showing varying pole widths help to demonstrate these differences. Plotting test data from the other 3 locations (Front axle, B-pillar, A-pillar), gives some insight into the energy absorbed at these locations. At the B-pillar location, the data fits best at 2.65 times pole width, 33.8 inches wide, and the others as shown in the following table:

Table 5.1 Pole Width Correlations

\begin{tabular}{|l|c|c|c|c|}
\hline LOCATION & FRONT AXLE & A PILLAR & CG & B PILLAR \\
\hline MULTIPLES OF POLE WIDTH & 16.5 & 12 & 3.55 & 2.65 \\
\hline INCHES & 210.4 & 153 & 45.3 & 33.8 \\
\hline
\end{tabular}

In addition to the difficulty comparing widths in the $[2 \mathrm{CE} / \mathrm{w}]^{1 / 2}$ equation, we must deal with the fact that yaw energy is not fully accounted for in the NHTSA 214 test data. Plots of Front axle, A-pillar and B-pillar comparisons are shown below. 


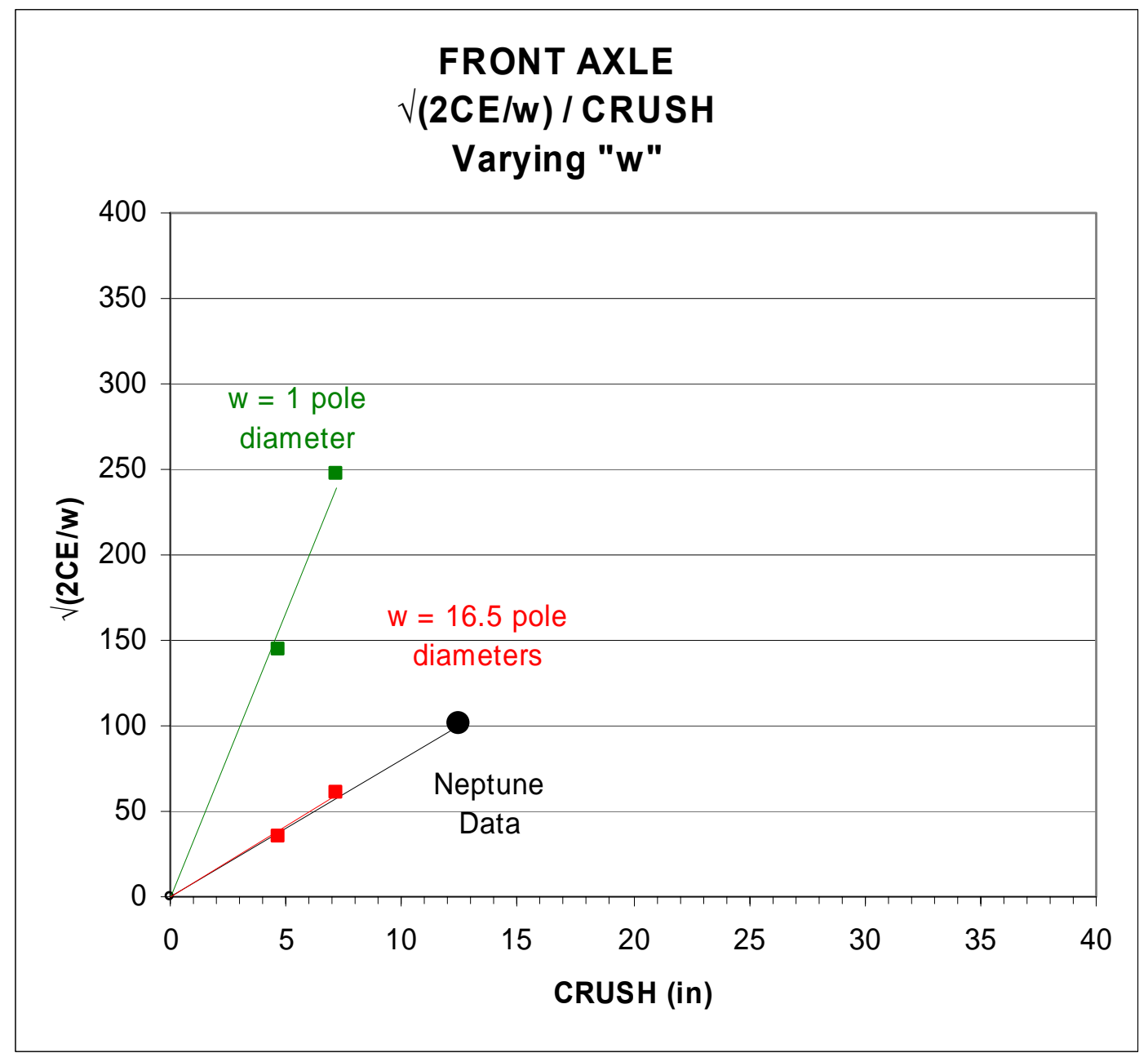

Figure 5.2 Front Axle: Varying Pole Widths / Neptune Data 


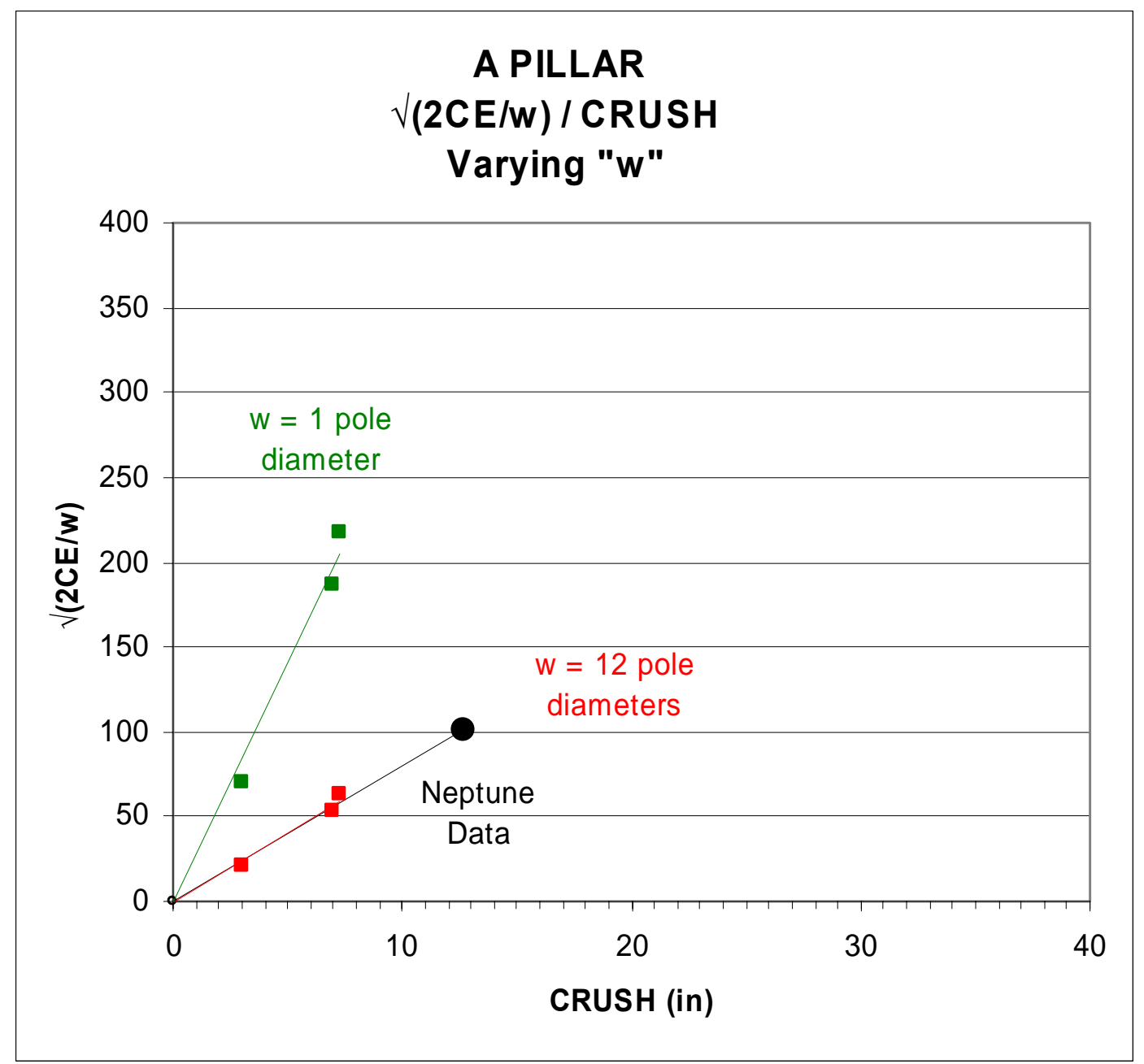

Figure 5.3 A Pillar: Varying Pole Widths / Neptune Data 


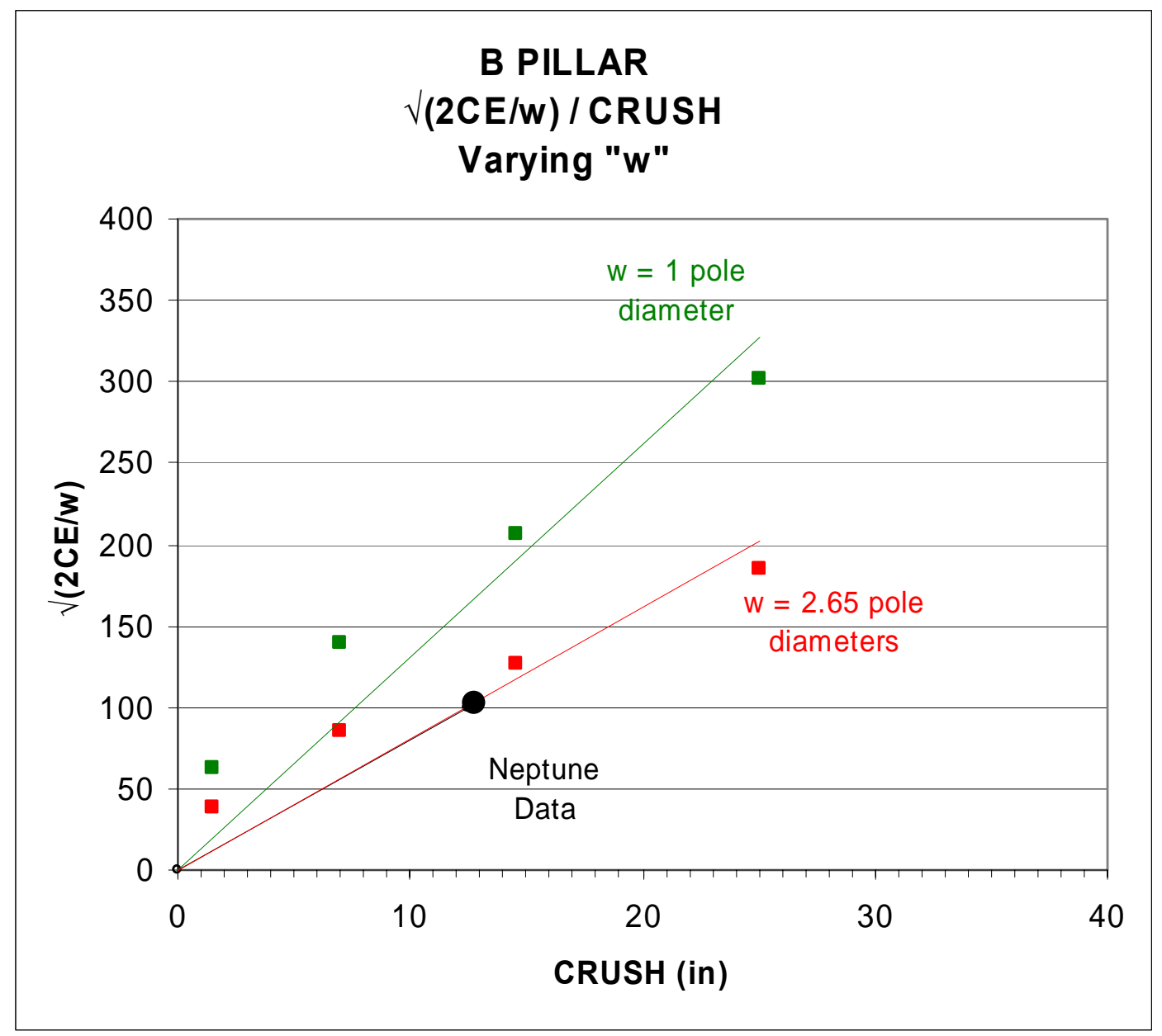

Figure 5.4 B Pillar: Varying Pole Widths / Neptune Data

Variation in structural stiffness between multiple locations along a vehicle side can be characterized through analysis of crash test data at the different locations. This research allows conclusions to be drawn and predictions to be made for the Ford Taurus vehicle platform based upon the comparison of similar test or accident conditions to this testing. Generalizations relating narrow object test or accident conditions in locations other than at or close to the locations tested here, 
in angled tests, or with barrier types or widths of different types should not be made. Test data exist wherein results are calculated inclusive of rotational energy, in addition to data where these calculations are not included. The researcher should use care in use of crash test data and results, including those presented here.

\subsection{Yaw Energy}

Calculation of yaw energy, and accounting for such energy must be performed for impacts where post impact yaw is present. In a case where the center of an impulse is offset more that a few inches from the vehicle CG, this energy can be a large percentage of the total energy. For example, in the tests at the vehicle CG, the total yaw energy is $998 \mathrm{ft}-\mathrm{lbf}$, less than $3 \%$ of the total crush energy, whereas the yaw energy at the front axle is 9625 , nearly $30 \%$ of the total crush energy (Table 5.2).

Table 5.2 Highlighted Crush Energy Calculations

\begin{tabular}{|c|c|c|c|c|c|c|c|c|}
\hline Repeat Test & $\mathbf{V o}$ & $\mathbf{\Delta K E}$ & $\mathbf{V r}$ & $\mathbf{\Omega}$ & $\mathbf{K E Y a w}$ & $\mathbf{C}_{\mathbf{i}}$ & $\mathbf{C}_{\mathbf{f}}$ & $\mathbf{C E}_{\text {TOT }}$ \\
\hline & $\begin{array}{c}\mathrm{V} \\
\text { Impact }\end{array}$ & Linear & $\begin{array}{c}\mathrm{V} \\
\text { rebound }\end{array}$ & $\begin{array}{c}\text { Yaw } \\
\text { Velocity }\end{array}$ & $\begin{array}{c}\text { Yaw } \\
\text { Energy }\end{array}$ & $\begin{array}{c}\text { Crush } \\
\text { Impact }\end{array}$ & $\begin{array}{c}\text { Crush } \\
\text { Total }\end{array}$ & Cumulative \\
\hline & $\mathrm{mph}$ & $\mathrm{ft}-\mathrm{lbf}$ & $\mathrm{mph}$ & $\mathrm{rad} / \mathrm{s}$ & $\mathrm{ft}-\mathrm{lbf}$ & inches & inches & ft-lbf \\
\hline $\begin{array}{c}\text { FRONT AXLE } \\
1\end{array}$ & 11.8 & 14309.3 & 2.1 & 1.7 & $\mathbf{3 2 5 1 . 9}$ & 4.7 & $\underline{4.7}$ & 11057.3 \\
\hline $\begin{array}{c}\text { FRONT AXLE } \\
2\end{array}$ & 16.5 & 27640.0 & 3.5 & 2.4 & $\mathbf{6 3 7 3 . 8}$ & 2.5 & 7.2 & $\mathbf{3 2 3 2 3 . 6}$ \\
\hline CG 1 & 7.9 & 6214.2 & 2.0 & 0.3 & $\mathbf{1 3 0 . 1}$ & 5.4 & $\underline{5.4}$ & 6084.1 \\
\hline CG 2 & 14.5 & 20934.6 & 3.6 & 0.8 & $\mathbf{7 1 8 . 3}$ & 9.2 & 14.6 & 26300.3 \\
\hline CG 3 & 13.0 & 16999.7 & 3.0 & 0.4 & $\mathbf{1 5 0 . 3}$ & 4.5 & 19.1 & $\mathbf{4 3 1 4 9 . 7}$ \\
\hline
\end{tabular}




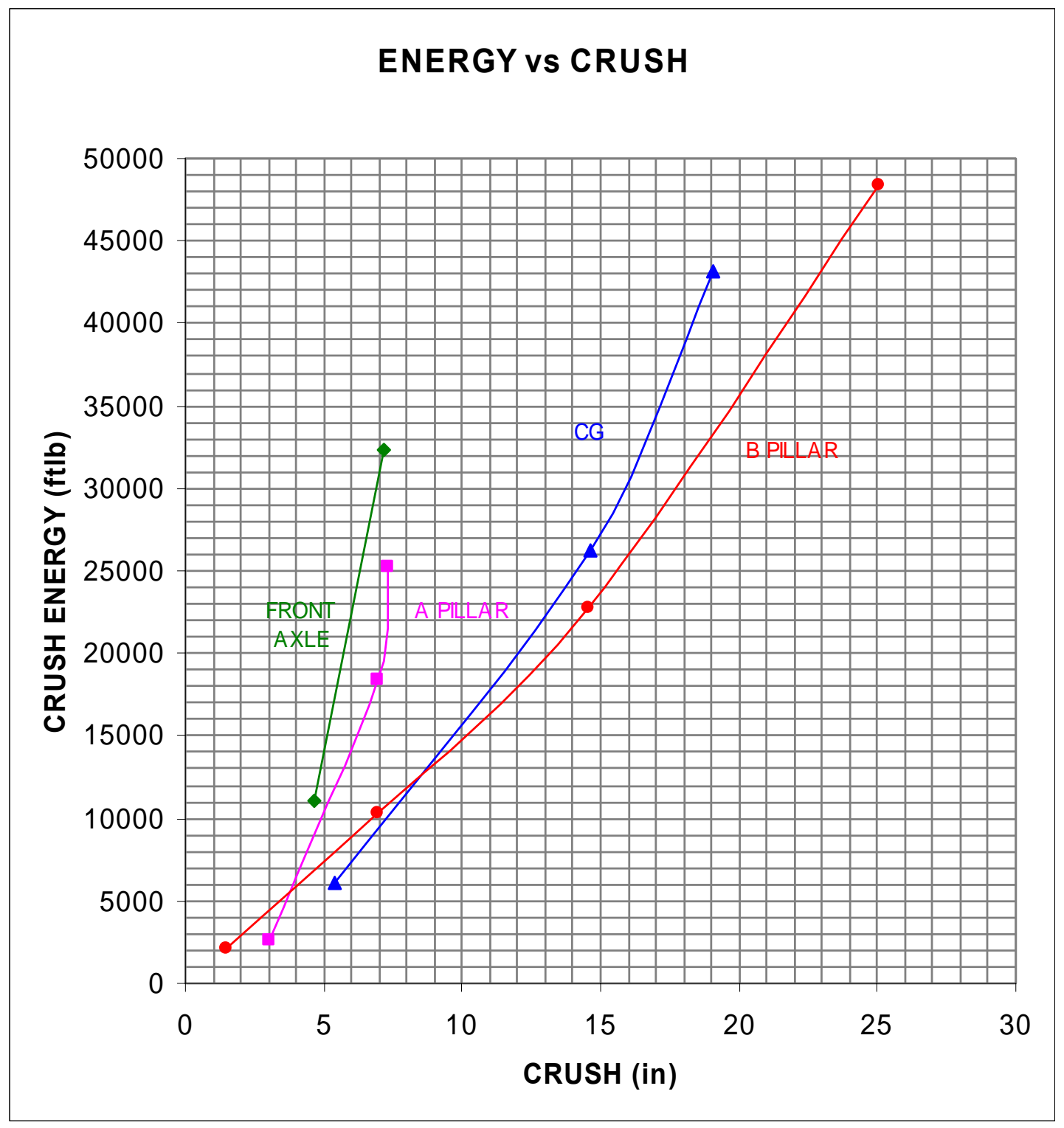

Figure 5.5 Comparison of Crush Energy / Linear Crush Distance 


\subsection{Energy Comparisons Based upon Impact Location}

One of the goals of this work was to ascertain how well impacts between the stiffest and softest locations on a vehicle exhibit behavior consistent with averaging the distance between points of equal force on the energy/displacement curve. For example, using a crush energy basis of 20,000 ft-lbf, we can compare crash deformation and stiffness between the A-Pillar and B-Pillar locations noting the intersection of each curve, and checking the deformation in inches. The results of this example give a deformation comparison of 7.2 at the A-Pillar vs. 13.5 inches at the B-Pillar. The challenge comes when one tries to interpolate between points. If we attempt to use the $\mathrm{CG}$ data as a mid point between the $\mathrm{A}$ and B Pillars, we find it crosses the $20,000 \mathrm{ft}-1 \mathrm{bf}$ line at 12 inches. This method does not allow for reliable linear interpolation prediction of structural behavior between points, but a physical understanding of the structures involved at the various impact locations can lead to rational justification of these results.

When applying these data to another vehicle with side impact deformation, the researcher must apply good judgment in comparing stiff locations to soft locations. The behavior of the crush data at the CG location during this test series was particularly difficult to predict. The term "Transition Zone" may be used to describe a location that is between a hard and soft spot. Repeated impacts at the CG of the Ford Taurus test vehicles presented a behavior that was unanticipated. 
The crush pattern had a tendency to drift toward the softer area of the vehicle side structure, yielding in a pattern that forced the vehicle to move longitudinally to some degree during the impact phase. It is likely that a given vehicle will exhibit this behavior in several locations. More research is needed to compare behavior of these transition zones, and to compare repeated impacts to higher speed single impact tests. It is anticipated that this diagonal drifting will be evident in both repeated and single impacts, but that the drifting will be more difficult to account for using an energy basis in repeated testing. 


\subsection{CONCLUSIONS}

\subsection{Multiple Impact Location Test Technique}

A method for impacting a test vehicle at multiple locations along the side has been developed. Comparing calculated crush energy from test data at multiple impact locations provides the researcher with a better understanding of the variation in stiffness along the vehicle side. Though not practical as a tool in every circumstance, this technique should be considered when side impact crush energy absorption characteristics are key to the outcome of an accident reconstruction.

\subsection{Variations in Stiffness Between Impact Locations}

The results of this study allow a generalization relating energy absorption properties at different locations along the vehicle side. These tests show that front axle and A pillar locations are much stiffer than $\mathrm{CG}$ and $\mathrm{B}$ pillar locations in response to rigid, narrow pole impacts, and that equivalent energy is absorbed over roughly half the crush distance as compared to $\mathrm{CG}$ and B pillar locations. 
Conversely, the front axle and A pillar locations absorb about twice the energy for a given linear crush distance.

\subsection{Importance of Yaw Energy in Calculating Crush Energy}

Calculation of yaw energy, and accounting for such energy must be performed for impacts where post impact yaw is present. In a case where the center of an impulse is offset more that a few inches from the vehicle CG, yaw energy can be a large percentage of the total energy.

\subsection{Transition Zones}

In areas between stiff and soft spots on the vehicle side, interaction of the rigid pole barrier created a source of longitudinal deflection as it interacted with vehicle structures. This behavior was noticed at the CG of the Ford Taurus test vehicle, and was accentuated in repeated impact tests. The resultant forces experienced by the vehicle during impact were not purely lateral as would be modeled in many accident simulation programs. 


\subsection{Pole Impact Data Compared to NHTSA 214 Test Data}

Comparison of these test data to NHTSA 214 test data show significant differences in vehicle side structure response. This is to be expected, as NHTSA 214 test data are taken from application of a wide deformable barrier face and crabbed moving barrier. The researcher should use discretion when comparing narrow object impacts to NHTSA 214 test data.

\subsection{Applications}

In cases where a pole or tree impact has occurred and residual crush has displaced structures laterally into the side of a vehicle, these data can be referenced and used as an aid to accident reconstruction. Only vehicle structures similar to the late model Ford Taurus should be compared.

Modern automobiles are constructed is such a way as to maximize convenience and usefulness to the consumer, while providing needed performance and safety. The results of this study may be misinterpreted by some to conclude that vehicles of the type tested here are "too soft" in the areas surrounding the passenger compartment. Stiffness and energy absorption properties relating to occupant motion and protection are complex issues not discussed here. 


\subsection{RECOMMENDATIONS FOR FUTURE RESEARCH}

An important goal of any research should be the advancement of state-ofthe-art techniques for analysis or method. This work has presented many problems and solutions in terms of crash test technique and methodology, and some of the solutions have come as a result of post test analysis.

Recommendations for future work of this type are as follows:

1. Pole contact area as applied to the vehicle body surface should be measured following each impact. Some correlation between the pole surface area, or simply the circumferential contact distance, with the crush and stiffness calculations may be discovered.

2. The characterization of "transition zones" along the vehicle side should be explored. Experience here shows that repeated impact techniques in transition zones will be less dependable for calculation of crush energy in these locations. 
3. Comparable peer vehicles should be tested using similar test conditions and impact parameters, allowing more general comparisons of this test data to other vehicle makes and models.

4. Verification tests are needed to confirm the accuracy of the repeated impact technique on vehicle side structures. Multiple impact tests need to be compared to single impact tests of equal energy. 


\section{REFERENCE MATERIALS}

[Asay 2002]

Brach 1987]

[Bradsher 2002]

[Brown 1998]

[BuzemanJewkes 1999]

[Campbell 1974]

[Canada]

[Chen 2004]

[De Coo 1998]
Asay, Alan F., Dagmar Buzeman-Jewkes, and Ronald L. Woolley, "Narrow Object Impact Analysis \& Comparison with Flat Barrier Impacts", Paper \# 2002-01-0552, Society of Automotive Engineers, Warrendale, Pennsylvania, 2002.

Baumann, K.H., L. Groesch, H. Holtze, and W. Schwede, "Frontal Offset Crash Testing for Approx. 15 Yrs: Results, Experiences \& Consequences", Paper \# 900413, Society of Automotive Engineers, Warrendale, Pennsylvania, 1990.

Brach, Raymond M., "Energy Loss in Vehicle Collisions", Paper \# 871993, Society of Automotive Engineers, Warrendale, Pennsylvania, 1987.

Bradsher, Keith, High and Mighty, New York: PublicAffairs, 2002.

Brown, Christopher M., "1994 Ford Explorer XLT Broadside Collision with a Narrow Fixed Object: Foil Test No. 98S005", Publication No. FHWA-RD-98-150, USDOT, Federal Highway Administration, McLean, Virginia, Oct. 1998.

Buzeman-Jewkes, Dagmar G., Per Lövsund, and David C. Viano, "Use of Repeated Crash Tests to Determine Local Long \& Shear Stiffness of the Veh Front with Crush", Paper \# 1999-01-0637, Society of Automotive Engineers, Warrendale, Pennsylvania, 1999.

Campbell, Kenneth L., "Energy Basis for Collision Severity", Paper \# 740565, Society of Automotive Engineers, Warrendale, Pennsylvania, 1974.

Canada, "Test Method 214 - Side Door Strength", Ottawa, Ontario, November 14, 1996.

Chen, H. Fred, C. Brian Tanner, Nicholas J. Durisek, and Dennis A. Guenther, "Pole Impact Speeds Derived from Bilinear Estimations of Maximum Crush for Body-OnFrame Constructed Vehicles", Paper \# 2004-01-1615, Society of Automotive Engineers, Warrendale, Pennsylvania, 2004.

De Coo, P.J., A.K. Roberts, A. Seeck, and D. Cesari, "Test Methods for Evaluating and Comparing the Performance of Side Impact Barrier Faces", $16^{\text {th }}$ ESV Conference, Abstract Paper \# 98-S8-O-02, Windsor, Canada, June 1998. 
[Digges 1999] Digges, K., A. Eigen, and J. Harrison, "Application of Load Cell Barrier Data to Assess Vehicle Crash Performance and Compatibility", Paper \# 1999-01-0720, Society of Automotive Engineers, Warrendale, Pennsylvania, 1999.

[Durisek 2004] Durisek, Nicholas J., C. Brian Tanner, H. Fred Chen, and Dennis A. Guenther, "Vehicle Characterization Through Pole Impact Testing, Part I: Vehicle Response in Terms of Acceleration Pulses", Paper \# 2004-01-1210, Society of Automotive Engineers, Warrendale, Pennsylvania, 2004.

[Emori 1968] Emori, Richard I., "Analytical Approach to Automobile Collisions", Paper \# 680016, Society of Automotive Engineers, Warrendale, Pennsylvania, 1968.

[Emori] Emori, Richard I., "Mechanics of Automobile Collisions", Conf.

[EuroNCAP 2003] "Pole Side Impact Testing Protocol", European New Car Assessment Programme, Version 4, Jan. 2003.

[Fleck 1996] Fleck, John, NHTSA Crash Test V2483, Report No. 214D-MGA-97-04 New Car Assessment Program Side Impact Testing Passenger Cars, 1977 Ford Taurus 4-door Sedan, MGA Proving Ground, Burlington, Wisconsin, Dec. 11, 1996.

[FMVSS 214] US Dept of Transportation Laboratory Test Procedure for FMVSS 214, August 2, 1999.

[Fonda 1990] Fonda, Albert G., "Crush Energy Formulations and Single-Event Reconstruction", Paper \# 900099, Society of Automotive Engineers, Warrendale, Pennsylvania, 1990.

[Gadberry 1998] Gadberry, Chad, NHTSA Crash Test V2975, Report No. 214-MGA-99-02 Safety Compliance Testing for FMVSS No. 214 "Side Impact Protection", 1999 Ford Taurus 4-door, MGA Proving Ground, Burlington, Wisconsin, Dec. 21, 1998.

[Gorski 1991] Gorski, Zygmunt, "Practical Problems Related to Side Impact Field Data Accuracy \& Its Importance to Side Impact Protection Assessments", Paper \# 910317, Society of Automotive Engineers, Warrendale, Pennsylvania, 1991.

[Grimes 1997] Grimes, Wesley D., Ronald Heusser, John Hunter, and James A. Neptune, "Developing a Crush Profile Estimate by Balancing Impact Forces", Paper \# 970942, Society of Automotive Engineers, Warrendale, Pennsylvania, 1997.

[IIHS 2001] "Head Protection in Side Impacts", Status Report, Insurance Institute for Highway Safety, Jan. 6, 2001

[IIHS 2002] "Side Impact Crash Test Protocol (Version I)", Insurance Institute for Highway Safety, Dec. 2002.

[IIHS 2003] "Side Impact Crash Test Protocol (Version II)", Insurance Institute for Highway Safety, Oct. 2003. 
[IIHS 2004]

[Jones 1978]

[Kamal 1970]

[Kent 1998]

[Kerkhoff 1993]

[Kosloske 2000a]

[Kosloske 2000b]

[Lim 1972]

[Long 1999]

[Mak 1981]

[Mak 1981]

[Marquard 1966]
"Side Impact Crash Test Results: Camry and Accord with Side Airbags Rated Good, Malibu Acceptable; 10 Other Mid-sized Cars Rated Poor in Tests Simulating Crash With SUV", Insurance Institute for Highway Safety, April 18, 2004.

Jones, lan S., and A. Stephen Baum, "An Analysis of the Urban Utility Pole Accident Problem", American Association of Automotive Medicine, San Francisco, California, 1978.

Kamal, M.M., "Analysis and Simulation of Vehicle to Barrier Impact", Paper \# 700414 Society of Automotive Engineers, Warrendale, Pennsylvania, 1970.

Kent, Richard W. and Charles E. Strother, "Wooden Pole Fracture Energy in Vehicle Impacts", Paper \# 980214, Society of Automotive Engineers, Warrendale, Pennsylvania, Warrendale, Pennsylvania, 1998.

Kerkhoff, John F., Stein E. Husher, Michael S. Varat, Alison M. Busenga, and Kevin Hamilton, "An Investigation into Vehicle Frontal Impact Stiffness, BEV and Repeated Testing for Reconstruction", Paper \# 930899, Society of Automotive Engineers, Warrendale, Pennsylvania, 1993.

Kosloske, Dave and David Winkelbauer, NHTSA Crash Test V3445, ES-2 Full Scale Vehicle Tests, Report No. 2, Testing for EU 96/27/EC European Side Impact, 1996 Ford Taurus 4-door, MGA Proving Ground, Burlington, Wisconsin, Aug. 15, 2000.

Kosloske, Dave and David Winkelbauer, NHTSA Crash Test V3522, ES-2 Full Scale Vehicle Tests,

Report No. 4, FMVSS No. 214 "Side Impact Protection", 1996 Ford Taurus 4-door, MGA Proving Ground, Burlington, Wisconsin, Nov. 8, 2000.

Kosloske, Dave and David Winkelbauer, NHTSA Crash Test V3482, ES-2 Full Scale Vehicle Tests, Report No. 3, FMVSS No. 214 "Side Impact Protection", 1996 Ford Taurus 4-door, MGA Proving Ground, Burlington, Wisconsin, Aug. 20, 2000.

Lim, G.G., "Crash Data Analysis", Paper \# 720496, Society of Automotive Engineers, Warrendale, Pennsylvania, 1972.

Long, Timothy J., "A Validation Study for the Force Balance Method in Determination of

Stiffness Coefficients", Paper \# 1999-01-0079, Society of Automotive Engineers, Warrendale, Pennsylvania, 1999.

Mak, King K., John J. Labra, and J. Thomas Noga, "A Procedure for The Reconstruction

of Pole Accidents", American Association of Automotive Medicine, San Francisco, California, 1981.

Mak, King K., and Robert L. Mason, "Selected Characteristics of Pole Impacts", American Association of Automotive Medicine, San Francisco, California, 1981.

Marquard, E., "Progress in the Calculations of Vehicle Collisions", Automobiltechnische Zeitschrift, Jahrq. 68, Heft 3, 1966, pp. 74-80. 
[McHenry 1975] McHenry, R.R., "The CRASH Program - A Simplified Collision Reconstruction Program", Paper prepared for the Motor Vehicle Collision Investigation Symposium, Calspan Corporation, Buffalo, New York, October 1975.

[Monson 1999] Monson, Kenneth, "Determination of Mechanisms of Motor Vehicle Structural Restitution from Crash Test Data", Paper \# 1999-01-0097, Society of Automotive Engineers, Warrendale, Pennsylvania, 1999.

[Morgan 1987] Morgan, James R. and Don L. Ivey, "Analysis of Utility Pole Impacts", Paper \# 870607, Society of Automotive Engineers, Warrendale, Pennsylvania, 1987.

[Neptune 1992] Neptune, James A., George Y. Blair, and James E. Flynn, "A Method for Quantifying Vehicle Crush Stiffness Coefficients", Paper \# 920607, Society of Automotive Engineers, Warrendale, Pennsylvania, 1992.

[Neptune 1994] Neptune, James A. and James E. Flynn, "A Method for Determining Accident Specific Crush Stiffness Coefficients", Paper \# 940913, Society of Automotive Engineers, Warrendale, Pennsylvania, 1994.

[Neptune 1998] Neptune, James A. and James E. Flynn, "A Method for Determining Crush Stiffness Coefficients from Offset Frontal and Side Crash Tests", Paper \# 980024, Society of Automotive Engineers, Warrendale, Pennsylvania, 1998.

[Neptune 1999] Neptune, James A., "A Comparison of Crush Stiffness Characteristics from PartialOverlap and Full-Overlap Frontal Crash Tests", Paper \# 1999-01-0105, Society of Automotive Engineers, Warrendale, Pennsylvania, 1999.

[Nystrom 1991] Nystrom, Gustav A., Garrison Kost, and Stephen M. Werner, "Stiffness Parameters for Vehicle Collision Analysis", Paper \# 910119, Society of Automotive Engineers, Warrendale, Pennsylvania, 1991.

[Nystrom 1992] Nystrom, Gustav A. and Garrison Kost, "Application of the NHTSA Crash Database to Pole Impact Predictions", Paper \# 920605, Society of Automotive Engineers, Warrendale, Pennsylvania, 1992.

[PC Crash] $\quad$ PC Crash User manual, Version 6.2

[Prasad 1981] Prasad, Priyaranjan, "Static-to-Dynamic Amplification Factors for use in Lumped-Mass Vehicle Crash Models", Paper \# 810475, Society of Automotive Engineers, Warrendale, Pennsylvania, 1981.

[Prasad 1990] Prasad, Aloke Kumar, "CRASH3 Damage Algorithm Reformulation for Front and Rear Collisions", Paper \# 900098, Society of Automotive Engineers, Warrendale, Pennsylvania, 1990.

[Prasad 1990] Prasad, Aloke K., "Energy Dissipated in Vehicle Crush - A Study Using the Repeated Test Technique", Paper \# 900412, Society of Automotive Engineers, Warrendale, Pennsylvania, 1990.

[Prasad 1991] Prasad, Aloke K., "Energy Absorbed by Vehicle Structures in Side-Impacts", Paper \# 910599, Society of Automotive Engineers, Warrendale, Pennsylvania, 1991. 
[Robinson 2000]

[Samaha 1998]

[Schreier 1987]

[Seyer 1998]

[SMAC]

[Smith 1987]

[Stolinski 1998]

[Strother 1986]

[Strother 1998]

[Strother 1990]

[Tumbas 1988]

[Ueno 1998]

[Varat 1994]
Robinson, Edward L., "Derivation of Closing Speed as a Function of Dissipated Energy", Paper \# 2000-01-1318, Society of Automotive Engineers, Warrendale, Pennsylvania, 2000.

Samaha, Randa R., Louis N. Molino, and Matthew R. Maltese, "Comparative Performance Testing of Passenger Cars Relative to FMVSS 214 and the EU 96/EC/27 Side Impact Regulations: Phase I", $16^{\text {th }}$ ESV Conference, Abstract Paper \#98-S8-O-08, Windsor, Canada, June 1998.

Schreier, Hans-Herbert and Wilton D. Nelson, "Applicability of the EES-Accident Reconstruction Method with MacCAR", Paper \# 870047, Society of Automotive Engineers, Warrendale, Pennsylvania, 1987.

Seyer, K., M. Terrell, Brian Fildes, D. Dyte, and K. Digges, "Development and Benefits of a Harmonised Dynamic Side Impact Standard", $16^{\text {th }}$ ESV Conference, Abstract Paper \# 98-S8-O-04, Windsor, Canada, June 1998.

SMAC User manual, 1994

Smith, Gregory C., Michael B. James, Thomas R. Perl, and Donald E. Struble, "Frontal Crush Energy \& Impulse Analysis of Narrow Object Impacts", Paper \# 87WA/SAF-5, The American Society of Mechanical Engineers, New York, New York, 1987.

Stolinski, Richard, Raphael Grzebieta, and Brian Fildes, "Vehicle Far-Side Impact Crashes", $16^{\text {th }}$ ESV Conference, Abstract Paper \# 98-S8-W-23, Windsor, Canada, June 1998.

Strother, Charles E., Ronald L. Woolley, Michael B. James, and Charles Y. Warner, "Crush Energy in Accident Reconstruction", Paper \# 860371, Society of Automotive Engineers, Warrendale, Pennsylvania, 1986.

Strother, Charles E., Richard W. Kent, and Charles Y. Warner, "Estimating Vehicle Deformation Energy for Vehicles Struck in the Side", Paper \# 980215, Society of Automotive Engineers, Warrendale, Pennsylvania, 1998.

Strother, Charles E., Charles Y. Warner, Ronald L. Woolley, and Michael B. James, "The Assessment of the Societal Benefit of Side Impact Protection", Paper \# 900379, Society of Automotive Engineers, Warrendale, Pennsylvania, 1990.

Tumbas, Nicholas S. and Russell A. Smith, "Measuring Protocol for Quantifying Vehicle Damage from an Energy Basis Point of View", Paper \# 880072, Society of Automotive Engineers, Warrendale, Pennsylvania, 1988.

Ueno, Masanori, Takeshi Harigae, Haruo Ohmae, Takahiko Uchimura, and Eiji Fujiwara, "Development of Moving Deformable Barrier in Japan - Part 2", $16^{\text {th }}$ ESV Conference, Abstract Paper \# 98-S8-W-25, Windsor, Canada, June 1998.

Varat, Michael S., Stein E. Husher, and John F. Kerkhoff, "An Analysis of Trends of Vehicle Frontal Impact Stiffness", Paper \# 940914, Society of Automotive Engineers, Warrendale, Pennsylvania, 1994. 
[Varat 1999] Varat, Michael S. and Stein E. Husher, "Vehicle Crash Severity Assessment in Lateral Pole Impacts", Paper \# 1999-01-0100, Society of Automotive Engineers, Warrendale, Pennsylvania, 1999

[Warner 1978] Warner, Charles Y. and Thomas R. Perl, "The Accuracy and Usefulness of SMAC", Paper \# 780902, Society of Automotive Engineers, 22 ${ }^{\text {nd }}$ STAPP Car Crash Conference, Ann Arbor, Michigan, 24-26 October 1978.

[Warner 1986] Warner, Charles Y., "A Repeated-Crash Test Technique for Assessment of Structural Impact Behavior", Paper \# 860208, Society of Automotive Engineers, Warrendale, Pennsylvania, 1986.

[Warner 1989] Warner, Charles Y., Charles E. Strother, Michael B. James, Donald E. Struble, and Timothy P. Egbert, "Crash Protection in Near-Side Impact - Advantages of a Supplemental Inflatable Restraint", Paper \# 890602, Society of Automotive Engineers, Warrendale, Pennsylvania, 1989.

[Warner 1990] Warner, Charles Y., Charles E. Strother, Michael B. James, "A Perspective on Side Impact Occupant Crash Protection", Paper \# 900373, Society of Automotive Engineers, Warrendale, Pennsylvania, 1990.

[Warner 1990] Warner, Charles Y., Charles E. Strother, and Ronald L. Woolley, "Application of Kinematic Concepts to Side Impact Injury Analysis", Paper \# 900375, Society of Automotive Engineers, Warrendale, Pennsylvania, 1990.

[Welsh 1999] Welsh, Kevin, "Crush Energy and Structural Characterization", Paper \# 1999-01-0099, Society of Automotive Engineers, Warrendale, Pennsylvania, 1999.

[Winkelbauer Winkelbauer, David, NHTSA Crash Test V2340, Report No. 214-MGA-96-003 Safety 1995] Compliance Testing for FMVSS 214 "Side Impact Protection - Passenger Cars", 1996 Ford Taurus GL 4-door, MGA Proving Ground, Burlington, Wisconsin, Nov. 14, 1995.

[Wood 1992] Wood, Dennis, "Collision Speed Estimation Using a Single Normalised Crush DepthImpact Speed Characteristic", Paper \# 920604, Society of Automotive Engineers, Warrendale, Pennsylvania, 1992.

[Wood 1993] Wood, Denis P., Mark Doody, and Stephen Mooney, "Application of a Generalised Frontal Crush Model of the Car Population to Pole and Narrow Object Impacts", Paper \# 930894

Society of Automotive Engineers, Warrendale, Pennsylvania, 1993.

[Wood 1997] Wood, Denis P. and Stephen Mooney, Modelling of Car Dynamic Frontal Crush", Paper \#

970943, Society of Automotive Engineers, Warrendale,Pennsylvania, 1997.

[Wood 1998] Wood, Denis P., "Comparison of Modelled and Actual Car Dynamic Frontal Crush", Paper \# 980027, Society of Automotive Engineers, Warrendale, Pennsylvania, 1998. 
[Woolley 1991] Woolley, Ronald, Charles E. Strother, and Michael B. James, "Rear Stiffness Coefficients

Derived from Barrier Test Data", Paper \# 910120, Society of Automotive Engineers, Warrendale, Pennsylvania, 1991.

[Woolley 2000] Woolley, Ronald L., Alan F. Asay, and Dagmar Buzeman-Jewkes, "Crash Testing with a Massive Moving Barrier as an Accident Reconstruction Tool", Paper \# 2000-010604, Society of Automotive Engineers, Warrendale, Pennsylvania, 2000.

[Woolley 2001] Woolley, Ronald L., "Non-Linear Damage Analysis in Accident Reconstruction", Paper \# 2001-01-0504, Society of Automotive Engineers, Warrendale, Pennsylvania, 2001.

[Zeidler 1985] Zeidler, F., H.H. Schreier, and R. Stadelmann, "Accident Research and Accident Reconstruction by the EES-Accident Reconstruction Method", Paper \# 850256, Society of Automotive Engineers, Warrendale, Pennsylvania, 1985. 
APPENDIX

I. FMVSS 214 "Dynamic" Side Impact Protection 74

J. European Side Impact Test 78

K. Excerpts from Neptune Engineering, Inc. Website 80

L. Neptune Crash Data for 1999 Taurus Side 87

M. Yaw Moment of Inertia for 1999 Taurus 88

N. Charles Y. Warner Brief Regarding Energy Models 89

O. Selected Test Vehicle Photographs 97

P. NHTSA Bowing Protocol 103 
TP-214D-05

August 2, 1999

\section{U.S. DEPARTMENT OF TRANSPORTATION}

NATIONAL HIGHWAY TRAFFIC SAFETY ADMINISTRATION

\section{LABORATORY TEST PROCEDURE}

\section{FOR}

FMVSS NO. 214 "DYNAMIC"

SIDE IMPACT PROTECTION

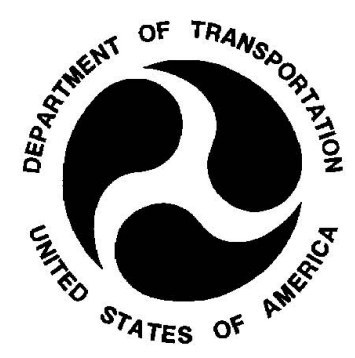

August 1999

SAFETY ASSURANCE

OFFICE OF VEHICLE SAFETY COMPLIANCE ROOM 6111, NSA-30

400 SEVENTH STREET, SW

WASHINGTON, DC 20590 
1. PURPOSE AND APPLICATION $\ldots \ldots \ldots \ldots \ldots \ldots \ldots \ldots \ldots \ldots$

2. GENERAL REQUIREMENTS $\ldots \ldots \ldots \ldots \ldots \ldots \ldots \ldots \ldots \ldots \ldots$

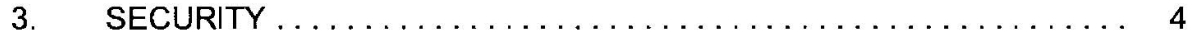

4. GOOD HOUSEKEEPING $\ldots \ldots \ldots \ldots \ldots \ldots \ldots \ldots \ldots \ldots \ldots$

5. TEST SCHEDULING AND MONITORING $\ldots \ldots \ldots \ldots \ldots \ldots \ldots$

6. FACILITY AND EQUIPMENT $\ldots \ldots \ldots \ldots \ldots \ldots \ldots \ldots \ldots \ldots \ldots$

6.1 SIDE IMPACT TEST SURFACE $\ldots \ldots \ldots \ldots \ldots \ldots \ldots \ldots \ldots$

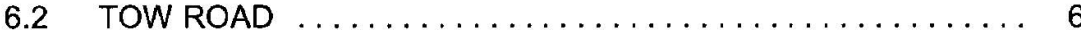

6.3 TEST VEHICLE PREPARATION BUILDING $\ldots \ldots \ldots \ldots \ldots \ldots 6$

6.4 MOVING DEFORMABLE BARRIER (MDB) $\ldots \ldots \ldots \ldots \ldots \ldots . \ldots$

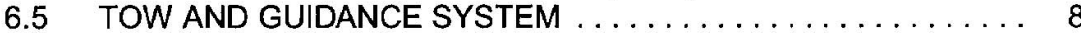

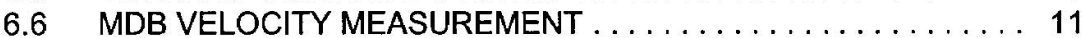

6.7 MDB BRAKE ABORT SYSTEM $\ldots \ldots \ldots \ldots \ldots \ldots \ldots \ldots \ldots \ldots . \ldots \ldots$

6.8 ALUMINUM HONEYCOMB BARRIER FACE UNITS . . . . . . . 12

6.9 NOTIFICATION OF COTR ..................... 12

7. GOVERNMENT FURNISHED PROPERTY (GFP) . . . . . . . . 13

7.1 TEST VEHICLES $\ldots \ldots \ldots \ldots \ldots \ldots \ldots \ldots \ldots \ldots \ldots \ldots$

7.2 SIDE IMPACT DUMMIES (SIDs) $\ldots \ldots \ldots \ldots \ldots \ldots \ldots \ldots \ldots$

8. INSTRUMENTATION AND CALIBRATION REQUIREMENTS . . . . . . . 14

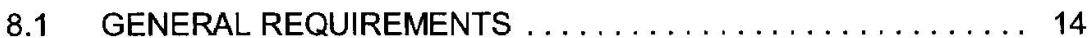

8.2 SID INSTRUMENTATION ...................... 16

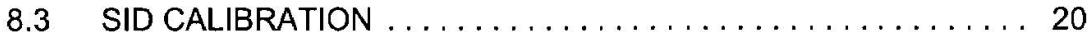

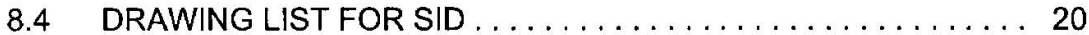

8.5 TEST VEHICLE INSTRUMENTATION $\ldots \ldots \ldots \ldots \ldots \ldots \ldots \ldots$

8.6 MDB INSTRUMENTATION ................... 25 
TABLE OF CONTENTS....Continued

9. PHOTOGRAPHIC DOCUMENTATION $\ldots \ldots \ldots \ldots \ldots \ldots \ldots \ldots 27$

9.1 GROUND BASED CAMERAS $\ldots \ldots \ldots \ldots \ldots \ldots \ldots \ldots, 28$

9.2 MDB CAMERAS .............................. 29

9.3 TEST VEHICLE ON-BOARD CAMERAS $\ldots \ldots \ldots \ldots \ldots \ldots \ldots 29$

9.4 PAINT AND CHALKING REQUIREMENTS $\ldots \ldots \ldots \ldots \ldots \ldots 29$

9.5 REAL TIME PHOTOGRAPHIC COVERAGE ............ 30

$9.6 \quad$ IMPACT EVENT MARKERS $\ldots \ldots \ldots \ldots \ldots \ldots \ldots \ldots \ldots \ldots \ldots \ldots \ldots$

9.7 PHOTOGRAPHIC TARGETS AND TAPE $\ldots \ldots \ldots \ldots \ldots \ldots, 31$

9.8 VEHICLE INFORMATION PLACARDS $\ldots \ldots \ldots \ldots \ldots \ldots, 33$

9.9 CRASH FILM HEADING AND SEQUENCE $\ldots \ldots \ldots \ldots \ldots \ldots \ldots, 34$

9.10 STILL PHOTOGRAPHS $\ldots \ldots \ldots \ldots \ldots \ldots \ldots \ldots \ldots, 36$

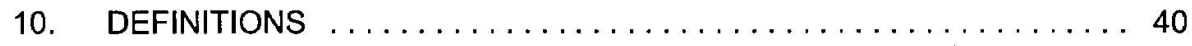

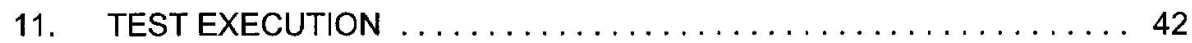

11.1 TEST VEHICLE PREPARATION $\ldots \ldots \ldots \ldots \ldots \ldots \ldots \ldots 42$

11.2 DUMMY PREPARATION, POSITIONING

AND PLACEMENT $\ldots \ldots \ldots \ldots \ldots \ldots \ldots \ldots \ldots \ldots \ldots, 47$

11.3 SIDE IMPACT TEST CONDITION .................. 53

11.4 HONEYCOMB FACE WELDING ROD ALIGNMENT ........ 54

11.5 MOVING DEFORMABLE BARRIER IMPACT FACE

CRUSH MEASUREMENTS $\ldots \ldots \ldots \ldots \ldots \ldots \ldots \ldots \ldots$

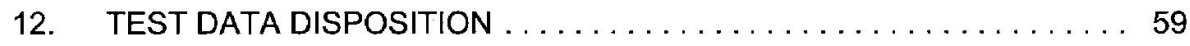

12.1 PERFORMANCE REQUIREMENTS $\ldots \ldots \ldots \ldots \ldots \ldots \ldots . \ldots$

12.2 DATA PROCESSING $\ldots \ldots \ldots \ldots \ldots \ldots \ldots \ldots \ldots \ldots \ldots, 61$

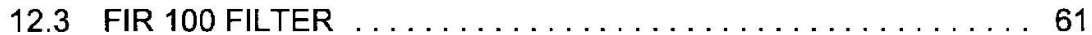

12.4 COMPUTER DATA TAPE $\ldots \ldots \ldots \ldots \ldots \ldots \ldots \ldots \ldots \ldots \ldots \ldots \ldots \ldots \ldots \ldots$

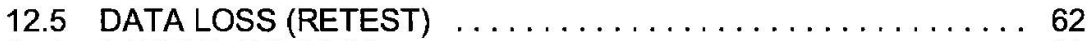

12.6 PARTIAL PAYMENT $\ldots \ldots \ldots \ldots \ldots \ldots \ldots \ldots \ldots \ldots \ldots \ldots \ldots \ldots \ldots$

12.7 DATA RETENTION BY CONTRACTOR ............. 63 
TABLE OF CONTENTS....Continued

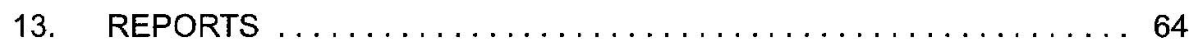

13.1 MONTHLY STATUS REPORTS .................. 64

13.2 LABORATORY NOTICE OF TEST FAILURE

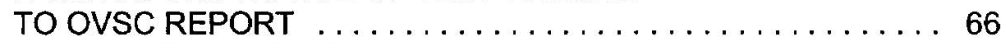

13.3 FINAL TEST REPORT $\ldots \ldots \ldots \ldots \ldots \ldots \ldots \ldots \ldots \ldots \ldots \ldots$

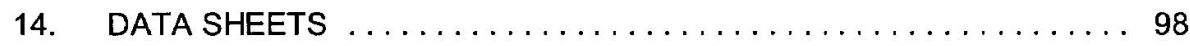

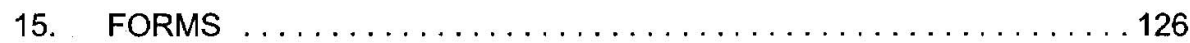

APPENDICES:
A. Laboratory Configuration and Performance Verification Procedure
B. Positioning Procedure for SID
C. Aluminum Honeycomb Crush Strength Certification
D. User's Manual for SID
E. Data Acquisition System Qualification Requirements and Test Procedure 


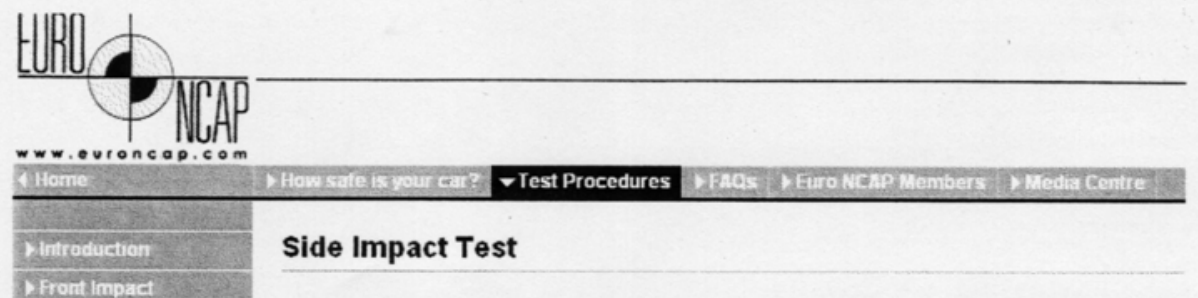

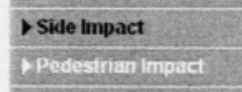

P. Pole Test

Phect the diners

Protocols

P rechinicalpapers

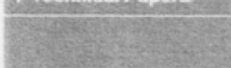

Impact takes place at $50 \mathrm{kph} 30 \mathrm{mph}$. Trolley fitted with a deformable front is towed into the driver's side of the car to simulate a side-on crash.

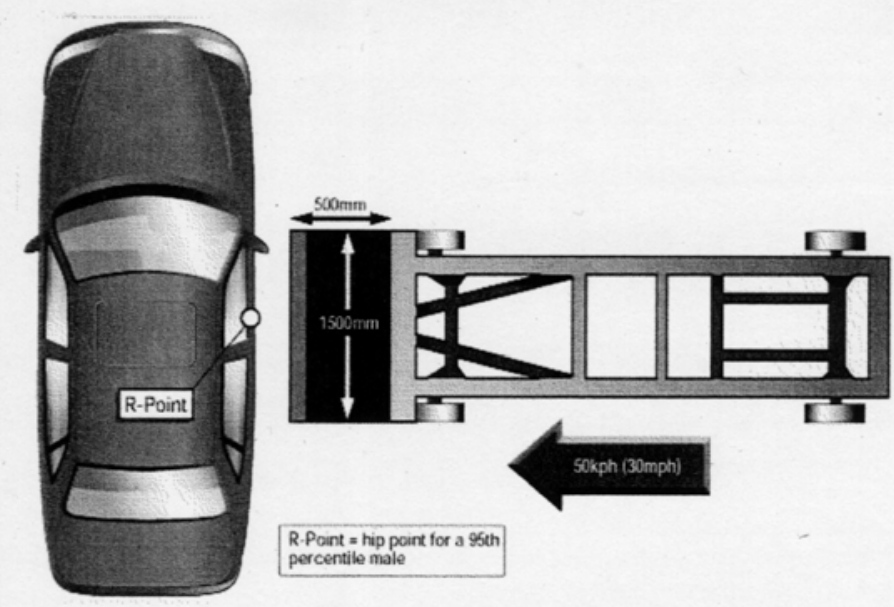

Readings taken from dummies are used to assess protection given to front occupant.

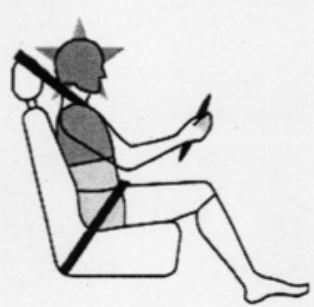

Protection:

Good

Adequate

Marginal

圈Weak

댈 Poor 


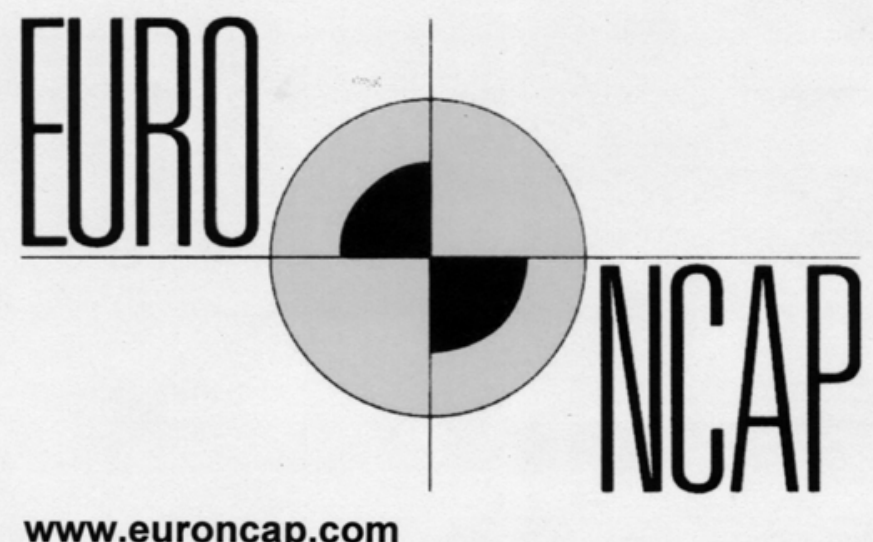

www.euroncap.com

EUROPEAN NEW CAR ASSESSMENT PROGRAMME

(EuroNCAP)

SIDE IMPACT

TESTING PROTOCOL 


\section{Nome \\ Products}

\section{NEI Home Page}

\section{Company Profile}

Neptune Engineering, Inc. is a service company that provides data on motor vehicles. Currently, Vehicle Crush Stiffness Coefficients, Motor Vehicle Manufacturers (MVM) Specification/Brochure Documents, NHTSA \& Transport Canada Crash Test Reports, Vehicle Static Stability Factor Reports and a Sisters \& Clones Listing are available.

"What's New!"

July 7,2004

Crash Test Reports (w/ photographs)

140 Crash Test Reports bave been added to our collection.

These new documents, from NHTSA, are for 1996-2004 model year vehicles.

June 29, 2004

Changes to the NEI Data Store

Circumstances have caused a policy change regarding e-mail messages at Neptume Engineering, Inc. Effective immediately any e-mail messages received by NEI that do not originated from the NEI web site Feedback page will be returned to the sender unopened. To contact NEI via e-mail, please go to the NEI web site Feedback page, fill out the form and submit it. NEI apologizes for any inconvenience this procedure may cause.

In addition, all e-mail messages originating from NEI will have DolotReply.NEI@neptuneeng.com as the return address. The following footer will be located at the bottom of the e-mail message:

DO NOT REPLY TO THIS E-MAIL MESSAGE. This e-mail message has been sent from an address that will not accept incoming messages. To send e-mail messages to Neptune Enginering Inc., please use the Feedback page located at our web site. The following link will connect you to the Feedback page: hrtp//www.neptuneeng.com/feedback.cfm.

Should you receive such a Iressage, you will not be able to respond via e-mail using a nomal 'Reply' procedure. The return e-mail address will not accept incoming messages. To respond via email, please use the NEI web site Feedback page.

May 28, 2004

Motor Vehicle Manufacturers Specification Document/Brochures

306 MVM Spec Document/Brochures have been added to our collection.

These new documents are for 1992-2004 model year vehicles.

One manufacturer (Scion) has been added.

Please visit our MVM Specs Information Page to discover more about this great deal and view example data.

February 13, 2004

MAJOR Changes to the NEI Data Store

New Toolbar

New toolbar allows direct entry into the NEI Data Store.

Customer Accounts with Login

Access the last 60 days of E-Invoices with Download. Login with your e-mail address \& a user assigned password

Optional User Reference Field 
An optional Reference field has been added to the E-Invoice to assist in tracking purchases. When purchasing data, you may enter reference information into this field on the Order Form.

New Download Mechanism

No need to 'right click' to start the downioad. A normal 'left click' will cause a 'File Download' box to appear. You can then choose to 'Open' or 'Save' the file.

No Off-Line Purchase Option

The Off-Line purchase option has been removed from the web site. All purchases are now On-Line and require a credit card.

Segrch Engine at the NEI Data Store

Use 'make', 'model' and a 'year range' to search for data. The search produces a single web page that

list ALL the data matching the search criteria. The matching data is grouped by type, i.e. Static

Stability Factor reports, Crash Test reports, MVM Specification/Brochure documents, and Crush

Stiffness Coefficients. The traditional Master Directory structure also is available.

January 5, 2004

Changes to the NEI Data Store

The NHTSA and Transport Canada crash test report directories have been combined together. The combined directory structure provides a quicker 'lookup' for crash test reports.

The source of the report can be determined by the filename. NHTSA reports have filenames that

begin with 'Nhtsa' (i.e. Nhtsa2440). Transport Canada reports have filenames that begin with

'TC' (i.e. TC98220).

Crash Test Reports (w/ photographs)

451 Crash Test Reports have been added to our collection.

These new documents, from both NHTSA and Transport Canada, are for 1981-2003 model year vehicles.

October 24, 2003

New Crush Stiffness Dat

412 crush stiffness files have been created/updated. That's 885 crush stiffness files created/updated this year to date. The crash tests results were 'Air-Gap' adjusted as required. Click here for more information on the 'Air-Gap' Problem.

Transport Canada Crash Test Reports (w/ photographs)

27 Canadian Crash Test Reports have been added to our collection.

These new documents are for 2002-03 model year vehicles.

\section{Contact Information}

Telephone

(559) 297-1593

FAX

(559) 298-2465
Postal Address

P.O. Box 1597

Clovis, CA 93613-1597

Electronic Mail

Feedback

Please send teedback with questions or comments about this web site

Copyright O 2004 Neptune Engineering, Inc.
Lant modified: February 13, 2004 


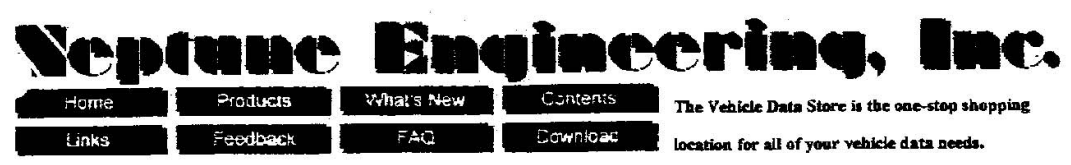

\section{Crush Stiffness Coefficients Introduction}

The stiffness coefficient tables contain data from approximately 3000 crash tests, 439 of which are low speed collisions where the impact speed was less than 15 miles per hour. CRASH plots were used to determine the stiffness coefficients for 404 vehicle structures where multiple crash test data was available. Damage onset speeds (b0) were determined for the front end structures of 126 vehicle and the rear end structures of 52 vehicles. A damage onset speed is the maximum speed of a vehicle at impact with a non-energy absorbing fixed barrier that will not produce any residual crushing of the vehicle structure. The onset of residual crush occurs after an amount of kinetic energy has been absorbed by the vehicle structure. The magnitude of the damage onset kinetic energy is determined from the CRASH plot best fit line intercept with the $y$-axis.

The damage onset kinetic energy and the weight of the test vehicle from the low speed collisions were used to calculate the damage onset speeds for the vehicle structures. In the past, the average weight of all the test vehicies in a crash plot was used to calculate the damage onset speed. It was felt that this new procedure would more accurately determine the damage onset speed. This is due to the low speed data having mostly been obtained from the Insurance Institute for Highway Safety (IIHS), which impacts the vehicles essentially at their curb weights. The weights of the high speed test vehicles, on the other hand, generally varying from 0 to 1000 pounds heavier than their respective curb weights.

The distribution of the frequency of occurrence for the damage onset speeds 2 for both front and rear structures was found to be centered around a damage onset speed of approximately 4.5 miles per hour.

The damage onset speeds for the individual high speed crash tests have been corrected for weight. This procedure resulted in a damage onset speed for each individual test vehicle that, although not numerically the same, was equivalent to the curb weight based damage onset kinetic energy.

During 1992 the IIHS changed its procedures for conducting low-speed crash tests. The IIHS no longer reports the depth of the damage sustained by the test vehicles. If the test vehicles sustained damage, only an estimation of the cost of repair is reported. To use this new data it was decided that when the test vehicle was reported as not having sustained any residual damage, then a zero crush depth would be entered into the tables of the manual. When damage was reported, however, a uniform equivalent crush depth of 0.1 inches would be entered into the data tables.

The width of the damage profiles for the side impacts obtained from the NHTSA have been standardized. The damage profiles that included induced damage were reduced to the width of the direct damage only. This generally was the width of the face of the impactor. As a resuit, the stiffness coefficients for side structures should be applied to a direct damage only profile on the subject vehicle in a reconstruction of a traffic accident.

Front and rear crash tests that reported only two crush measurements (left \& right side 
only) have been corrected to account for the curvature of the end of the vehicle. The crush profile was redefined by using the two reported measurements in conjunction with the distance which the nose of the bumper extended beyond the bumper tips. This resulted in crush profiles that are defined by five crush depths.

Most of the damages sustained by the test vehicles resulted in non-uniform crush profiles. These crush profiles were a combination of direct-damage and induced-damage. ONLY THE DIRECT DAMAGE PORTION OF THE CRUSH PROFILES WERE USED IN THE CALCULATION OF CRUSH STIFFNESS COEFFICIENTS.

The proper use of the data contained in this manual requires a thorough understanding of vehicle dynamics. The user should recognize that there is a degree of variance in the level of damages sustained by "identical" vehicles during controlled barrier collisions. This variance can be seen in the scatter of data points in the CRASH plots and SMAC plots. The user also should recognize that the potential variance in the level of damages sustained during a "real-world" collision is even greater. Sound engineering judgment, therefore, should be used when applying the enclosed data in the reconstruction of "real-world" accidents.

THE USE AND RELIANCE ON THE INFORMATION CONTAINED HEREIN IS SUBJECT TO THE LLABILITY DISCLAIMER.

\author{
Please send feedbagk with questions or comments about this web sixe. \\ Copyright o 2003 Nepture Engineering, Loc.
Last modified: Oetober 24, 2003
}




\section{\begin{tabular}{l} 
Home \\
\hline Pinks \\
\hline Fedikds
\end{tabular}}

\section{Crush Stiffness Coefficients Data Sources}

A Office of Vehicle Research, National Highway Traffic Safety Administration, U.S. Department of Transportation, Washington, D.C

B. Compliance Engineering and Vehicle Testing, Road Safety and Motor Veticle Regulation Directorate, Transport Canada, Ottawa, Ontario, Canada.

C. Insurance Institute For Highway Safezy, Arlington, Virginia

D. "Energy Dissipated in Vehicle Crush-A Study Using the Repeated Test Technique", Prasad, A.K., SAE Paper $900412,1990$.

E. "Rear Stiffness Cocfficients Derived from Barrier Test Data", Woolley, RL., Strother, C.E. and James, M.B.

Collision Safety Engineering, SAE Paper 910120, 1991.

F. "Controlled Impact Investigations, Head-On Impacts Of Four Similar Cars From Different Speeds Against A

Rigid Barrier", Neilson, 1.D., NTIS No. PB 179 866, 1968.

G. "A Repeated Crash Test Technique For Assessment Of Structurai Impact Betravior", Wamer, Chardes Y., Allsop, Douglas and Germane, Geoff J., SAE Paper No. 860208, 1986.

H. "The Estimation of Accidest Impact Speed", Masoo, $R$ and Whitcomb, D., Cornell Aeronantical L.aboratory Inc., Report No. YB-3109-V-1, 1972.

I "Basic Research In Crashworthiness II, Low Speed Impact Tests of Unmodified Vehicles", Naab, Kenneth N., NTIS No. PB 212 924, 1972.

J. "Crashworthiness Of The Subcompact Veticle", Tanner, Richard B., NTIS No. PB 258 293, 1976.

K. "Consumer Infonmation Crash Test Program Prediction Of Dynamic Crash Responses For Veticle And Occupants", Volume I \& II, Shoemaker, N.E., NTIS No. PB 258 130, 1976.

L. "Frontal And Side Impact Crashworthiness-Compact Cars", Wingenbach, William J., NTIS No. PB 231 561 , 1974

M. "Classification Of Automobile Frontal StiffnessiCrashworthiness By Impact Testing", Ryder, Melvin O. NTIS No. PB 258302,1976

N. "Development Of A Test Methodology For Evaluating Crash Compatibility And Aggressiveness Volume II, Yee, R., NTIS No. PB 80-130685, 1979

O. "Safety Compliance Text Program FMVSS 212, 219, 301-75, NCAP, Accident Investigation Division Data",

Carison, Lloyd E., NTIS No. PB 80-166051, 1979.

P. Consumer Reports, Consumers Union of U.S. Inc., 101 Truman Avenue, Yonkess, NY 10703-1057.

Q. "An Investigation into Vehicle Frontal Impact Stifiness, BEV, and Repeated Testing for Reconstruction ", Kerkoff, J.F., Husher, S.E. and Varat, M.S., SAE Paper 930899, 1993.

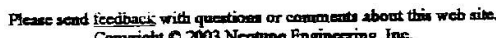

Copyrighte 0 2003 Noptmon Enginocing. In 


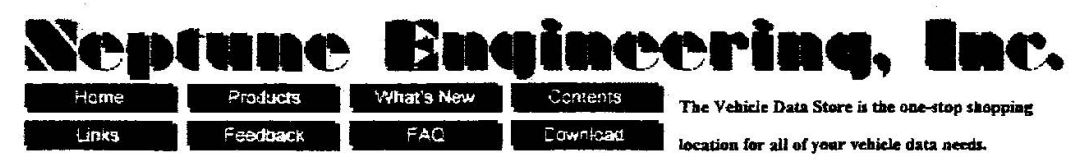

\section{Crush Stiffness Coefficients \\ References}

1. Nepture, J. A., "A Comparison of Crush Stiffess Characteristics from Partial-Overlap and Full-Overlap Frontal Crash Tests", SAE Paper 1999-01-0105, 1999.

2. Nepune, J. A., and J. E.. Flynn, "A Method for Determining Crush Stiffness Ccefficients from Offset Frontal and Side Crash Tests", SAE Paper $980024,1998$.

3. Neptume, J. A., "Cnush Stiffness Coefficients, Restitution Constants, And a Revision of CRASH3 \& SMAC",

SAE Paper $980029,1998$.

4. Neptune, J. A., "Overview of an HVE Vehicle Database", SAE Paper 960896, 1996.

5. Neprane, J. A., J. E. Flynn, H.W. Underwood and P.A. Chavez, "Irrpact Analysis Based Upon the

CRASH3

Damage Algorithom ", SAE Paper 950358, 1995.

6. Neptune, J. A., and J. E. Flynn, "A Method for Determining Accident Specific Crush Stiffness Coefficients",

SAE Paper $940913,1994$.

7. Neptume, J. A., G. Y. Blair and J. E.. Flynn, "A Method for Quantifying Vehicle Crush Stiffness Coefficients", SAE Paper $220607,1992$.

8. Strother, C., R. Woolley and M James, "A Comparison Between NHTSA Crash Test Data and CRASH3 Frontal Stiffiness Coefficients", SAE Paper 900101,1990

9. Day, T.D. and R.I. Hargens, "An Overview of the Way EDCRASH Computes Delta-V", SAE Paper 870045 ,

1987.

10. "CRASH3 User's Guide and Technical Manual", U.S. Deparment of Transportation, NHTSA National Center For Statistics and Analysis, Accident Investigation Division, Washington, D.C., 1986.

11. Wamer, C., D. Allsop and G. Germane, "A Repeated-Crash Test Technique for Assessment of Structural Impact Behavior", SAE Paper 860208, 1986.

12. Strother, C., R. Wooiley, M. James and C. Wamer, "Crush Energy in Accident Reconstruction", SAE Paper 860371, 1986.

13. Campbell, K. L., "Energy Basis for Collision Severity", SAE Paper 740565, 1974.

Please send fitedback with quescions or conments about this web site.

Copyright o 2003 Neptine Engineering Ine.
Last modifiet- Oetober 24, 2003 


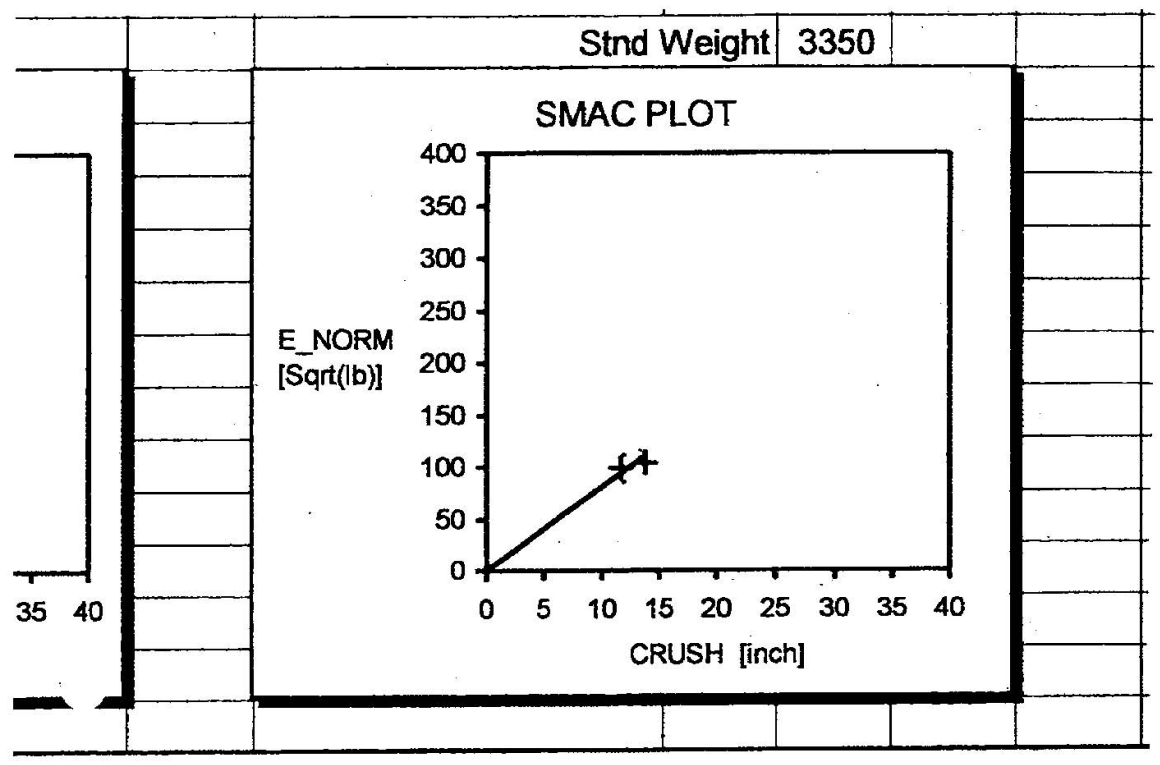


Vehicle Crush Stil....ess Coefficients

Neptune Engineering, Inc

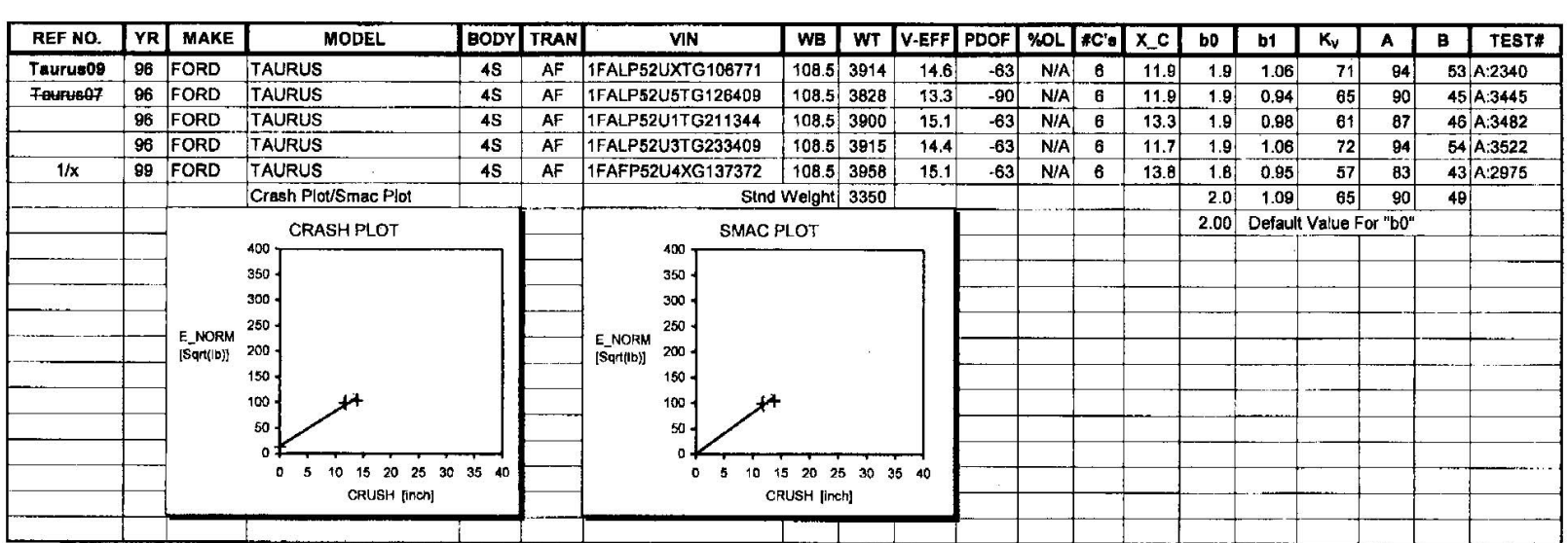

Liability Disclaimer

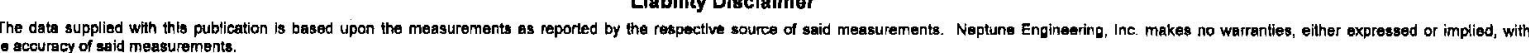

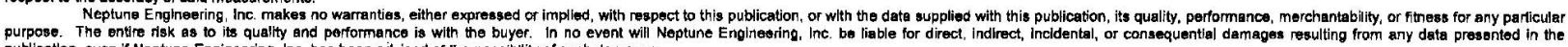

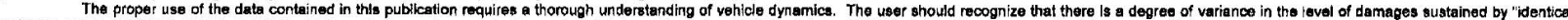

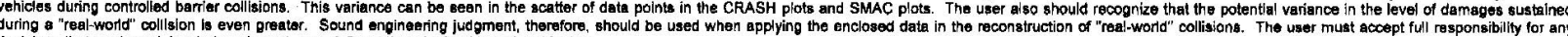

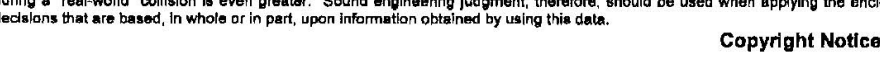

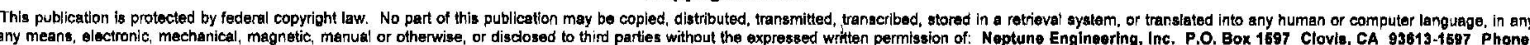

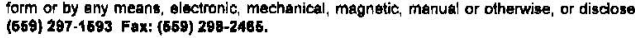




\section{NHTSA INERTIAL DATABASE}

Wheel- Track Width Roof

Model Vehiclt Vehi Veh. IPMD Veh. Occu- Ballast Drive base Front Rear Height'ei Fuct

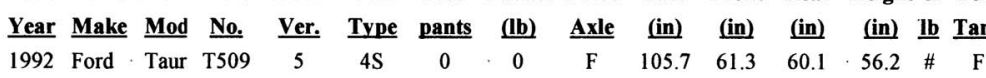

CG Location (in Moments of Inertia Roll/Yar Tilt Static

From Above (ft-lb-sec ${ }^{\wedge}$ ) Produc Table Stability mm ront AxGround Pitch oll Yaw

Test Run Length Date No. (in 
Notes Regarding Energy Models

A Dialog by Dr. Charles Y. Warner, Senior Engineer / Collision Safety

Engineering

The widespread use of crush energy as a tool for accident reconstruction depends upon structural performance data from appropriate surrogate structures. This has been attempted in various ways since the method first gained prominence following the accumulation of a small number of crashes which served as a basis for the CRASH II computer program, fostered by the NHTSA about 1974 as a basis for "automated" reconstruction for field accident data teams. The CRASH (Calspan Reconstruction of Accident Speeds on the Highway) program was based on a user-interactive approach in an era where punched card data input was just giving way to desktop computers. This approach allowed the NHTSA's relatively non-technical field investigators to answer standardized questions and arrive at an answer for traveling speed and velocity change. It gave the NHTSA a way to accumulate data on crash severity in a standardized and repeatable way, and served as the reconstruction basis for the National Crash Severity Study (NCSS) and National Accident Sampling System (NASS). Although the program was never intended for precision work, CRASH II's energy methods were quickly 
adopted by the reconstruction community because the computer program allowed a kind of "cookbook" approach.

Since the inception of the FMVSS crash testing program, thousands of FMVSS compliance and NCAP crash tests have been performed and reported by government, research and manufacturer agencies, patterned to prove or disprove performance of occupant protection strategies related to legal requirements. This has led to the development of a kind of "cottage industry" wherein government test results have been catalogued and massaged in the form of energy coefficients first utilized for the CRASH II computer program and its predecessor, the Simulation Model for Automotive Collisions (SMAC) program. The continuing enlargement of this crash data base has proven to be both a blessing and a curse to the crash reconstruction community. It is an obvious blessing because it has provided access to real structural and restraint system performance data and thereby helped to enlighten the community regarding vehicle and occupant motion and injury causation. Its negative effects are related to the false sense of security which comes from repetition of many very similar tests around a single test condition and generalization of that condition to other untested situations. FMVSS, NCAP and EuroNCAP requirements have specific test conditions that are seldom seen that specifically in real accidents. Vehicles have thus been characterized on the basis of these many repetitions of the same test condition, but much of the structural detail for more limited force application and for different 
impacts speeds is masked in these generalizations. This was obviously true of the first single-parameter modeling of the entire vehicle circumference by the same single-parameter crush stiffness (kv) in the SMAC program. This first approximation was designed around a linear spring-mass model in an attempt to provide a time-based solution of the crash phase. The stiffness $\mathrm{kv}$ was intended to indicate the linear force-deflection constant which would result from compression of a unit width of a vehicle having homogeneous crush character similar to a foam block, so it had the dimensions of a classical stiffness, i.e. lb/ft, written per unit crush width. Hence, $\mathrm{kv}$ had the units of $(\mathrm{lb} / \mathrm{ft}) / \mathrm{ft}$; resembling a pressure. Aside from applications to cases where significant shear angles, corners, and multiple impacts were applied on various sides of the same vehicle, the approximations remained physically intelligible. (An early through review of the literature of the SMAC program and some of its applications was given by Warner and Perl, 1978.)

The introduction of the CRASH filled some of the technical blanks left in the SMAC formulation, but created others in its turn. Much of our current reconstruction work still carries the physical paradigms introduced by SMAC and CRASH, but many of their oversimplifications remain to bedevil the practitioners and confuse the physical interpretation of their structural models and results. CRASH retained the unit-height representation of vehicle structures introduced in SMAC. In this regard, neither program offers complete reconstruction of the 
general under-over-ride accident scenario. CRASH, moving toward the purpose of improving the modeling ability of the crushing structures, introduced a twoparameter $(\mathrm{A}+\mathrm{Bx})$ slope-intercept characterization of the crush layer formerly represented in SMAC by the single stiffness parameter kv. Hence the CRASH model allows a representation of the displacing structures in slope-intercept form. The reconstruction tables and charts produced from crash tests typically report both characterizations, i.e. the kv for the SMAC model and the A and B for the CRASH model. Thus, the reconstruction community has available tables of kv, A, and B coefficients for the fronts, rears, and sides of various makes and models of automobiles, mostly structured from crash tests related to FMVSS requirements. These are seldom adequate to justify the sophistication of even a two-parameter model, since the severity range and crush data are clustered around a single test condition. In practice, many attempt to salvage the appearance of accuracy by assuming a no-damage impact level (the energy level at which permanent plastic deformation remains), but this is seldom based on real crash data for the vehicle represented.

It is fortunate that many of the inaccuracies in the tabulated data are masked by the squared function that generally governs the calculation of crush energy and crash intensity, so that many of the inaccuracies are of little consequence in serious crashes. Since the majority of reconstruction applications are directed to injury-producing crashes involving significant delta- $\mathrm{V}$, the nuances 
of lower-severity crush behavior may not be important. Hence the emphasis on more elaborate crush models may be somewhat wasted, except for modeling of crashes where limited crush is involved.

One method which has been used successfully to address structural crush behavior involves repeated testing of the same structures [Warner; Prasad]. While this approach cannot offer much insight into replication of occupant motion, it has been shown to give reasonable approximations of crush energy responses and has been used in many applications.

Data limitations arising from the limited test scope are often ignored in the application of these tabulated coefficients. For instance, it is often assumed that the "pressure" exerted upon a crushing structure is uniform across the width of application. Of course, the width of application is fixed in FMVSS testing, but real crashes have varying widths. That assumption is implied in all of the tabulated coefficients, but it is obviously unjustified in localized crashes like pole impacts and in situations where stiff structures "telescope" past each other. It is often necessary to conduct specific testing to evaluate structural conditions encountered in practice.

Definition of crush width and of impact location become very significant in side impact [Strother, et.al. 1998]. The tabulated crash data available to the 
public is largely based upon the FMVSS 214 Crabbed Deformable Moving Barrier (CMDB) crash testing at $33 \mathrm{mph}$ and $39 \mathrm{mph}$. Tabulated A, B, and kv values are usually founded upon assumptions regarding barrier face energies and rotational effects, and the width denominator in the calculations is large. FMVSS 214 tests generally involve deformation of A and B pillars, door, and rocker panel structures as a system responding to the broad homogeneous barrier face. It is clear that these structures will resist crushing differently when loaded independently. This has been documented for broad-faced barrier impacts against front axles as compared to occupant compartments, for example, and has been the subject of a few reported test conditions [Woolley, et.al.].

The A and B coefficients used to derive estimates of crush energy in the CRASH model establish a slope-intercept linear approximation for an energy parameter $[2 \mathrm{CE} / \mathrm{w}]^{1 / 2}$. This model has become the standard method of presentation of crash test data. It is discussed at length in earlier publications [Woolley, et.al., 198 ]. As discussed above, the coefficients A and B are generally inferred from clusters of test data near the same severity as that of the FMVSS compliance requirements; the intercept parameter assumed by reference to low-speed damage thresholds [Neptune]. While the $[2 \mathrm{CE} / \mathrm{w}]^{1 / 2}$ formulation may seem more satisfying for some applications, and has been used as a matter of convention in many publications, I have chosen to use the simpler more satisfying physical interpretation of a linear spring for the reduction of the narrow object 
impact data in my research. I believe that this will simplify the process of sorting out the rotation, restitution, and crash width issues with which I am faced in this analysis. The result should allow the reader to more easily interpret the observations. This is consistent with the presentation and analysis of Varat, et.al. [Varat, 1999]. Application of more elaborate force-deflection models for these localized structures will be left for further future work.

The repeat-crash method for these narrow pole impacts calls into question the proper width to be employed in the pressure model. It is customary to employ the volume of direct and induced crush in application of test data, as usually represented by the respective planar areas and the assumed unit height of the vehicles. The most appropriate volume has not yet been proven for narrow pole impacts. It was assumed for the purposes of this study that the induced crush may be neglected. This is consistent with the standard practice relative to the broad impacts reported from CDMB tests reported in the literature [Neptune, 2003].

In general, repeated crashes in the same structure will produce an array of points in which $[2 \mathrm{CE} / \mathrm{w}]^{1 / 2}$ may be defined by linear functions of crush, C.. The slope of the curve passing through the origin and the regression of these data points will be termed $\mathrm{k}$, and is comparable to the overall $\mathrm{kv}$ coefficients reported for side impacts in the literature. The literature itself does not present much data for narrow, non-central side impacts. Crush characterizations are mostly related 
to the CDMB setup of the FMVSS 214 compliance tests. Indeed, the documentation of post-impact rotation effects is very limited. Such tests as are reported and acknowledge the importance of rotation supply poor documentation of its effects.

Varat and Husher reported crush energy prediction errors as high as $357 \%$ based on interpretations of flat barrier data for a Ford Escort, having included an accounting for the rotational effects [Varat, 1999]. Asay, Jewkes, and Woolley report two repeated 90-degree side pole impacts into a 1988 Ford Taurus with significant rotational moment, but do not make clear how they may have accounted for the average crush bowing effects, or rotational energy [Asay, 2002]. 

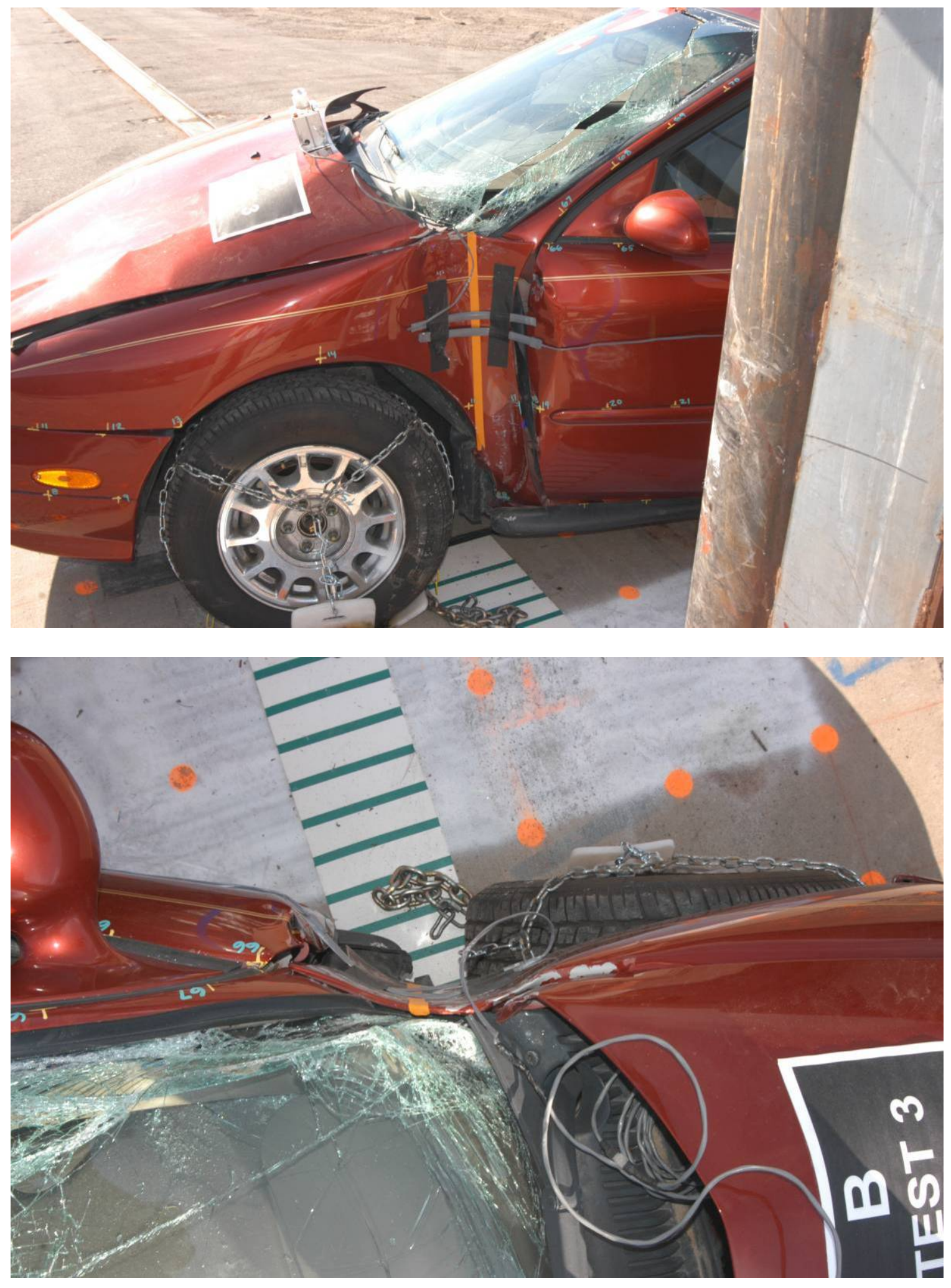

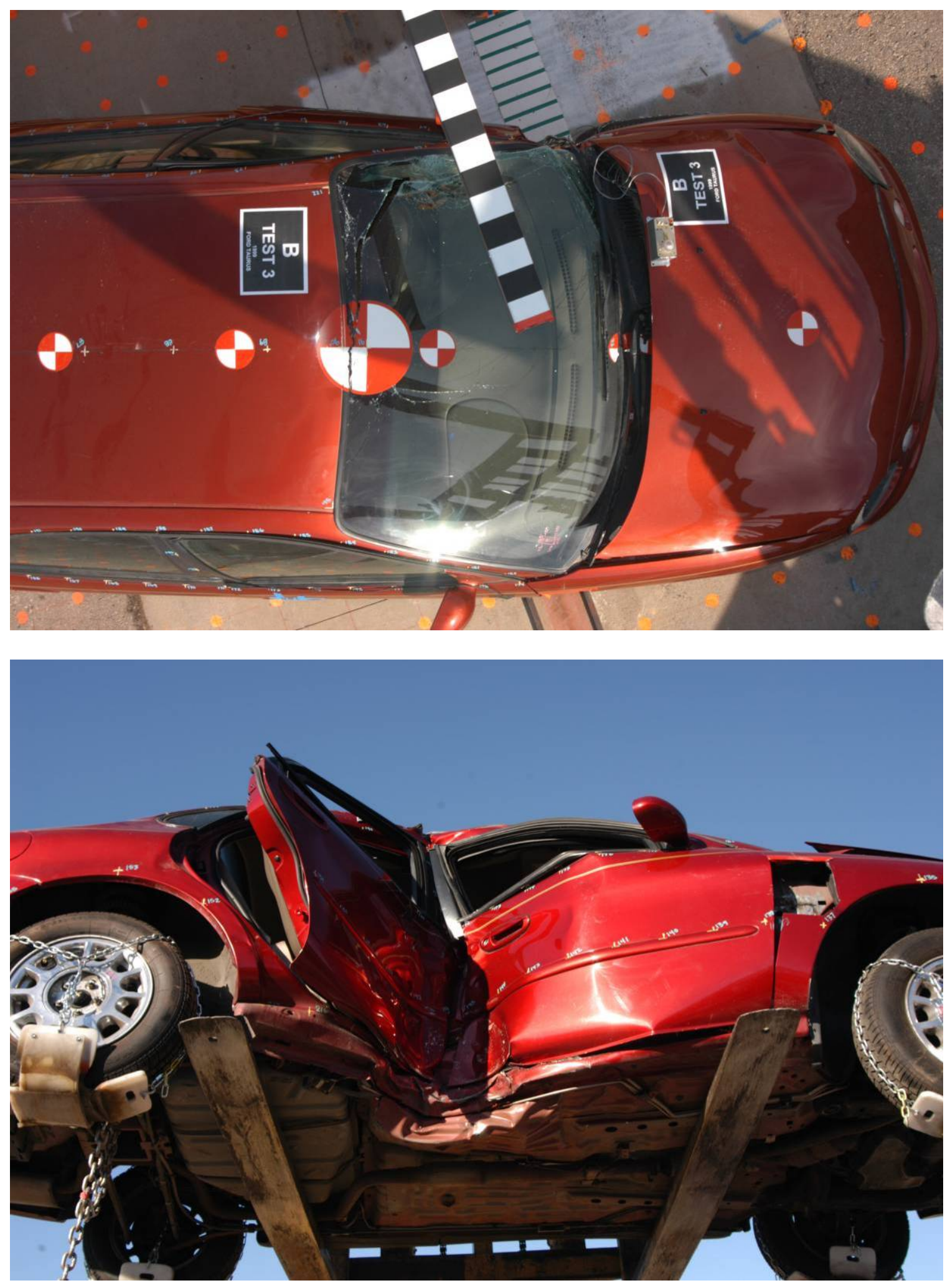

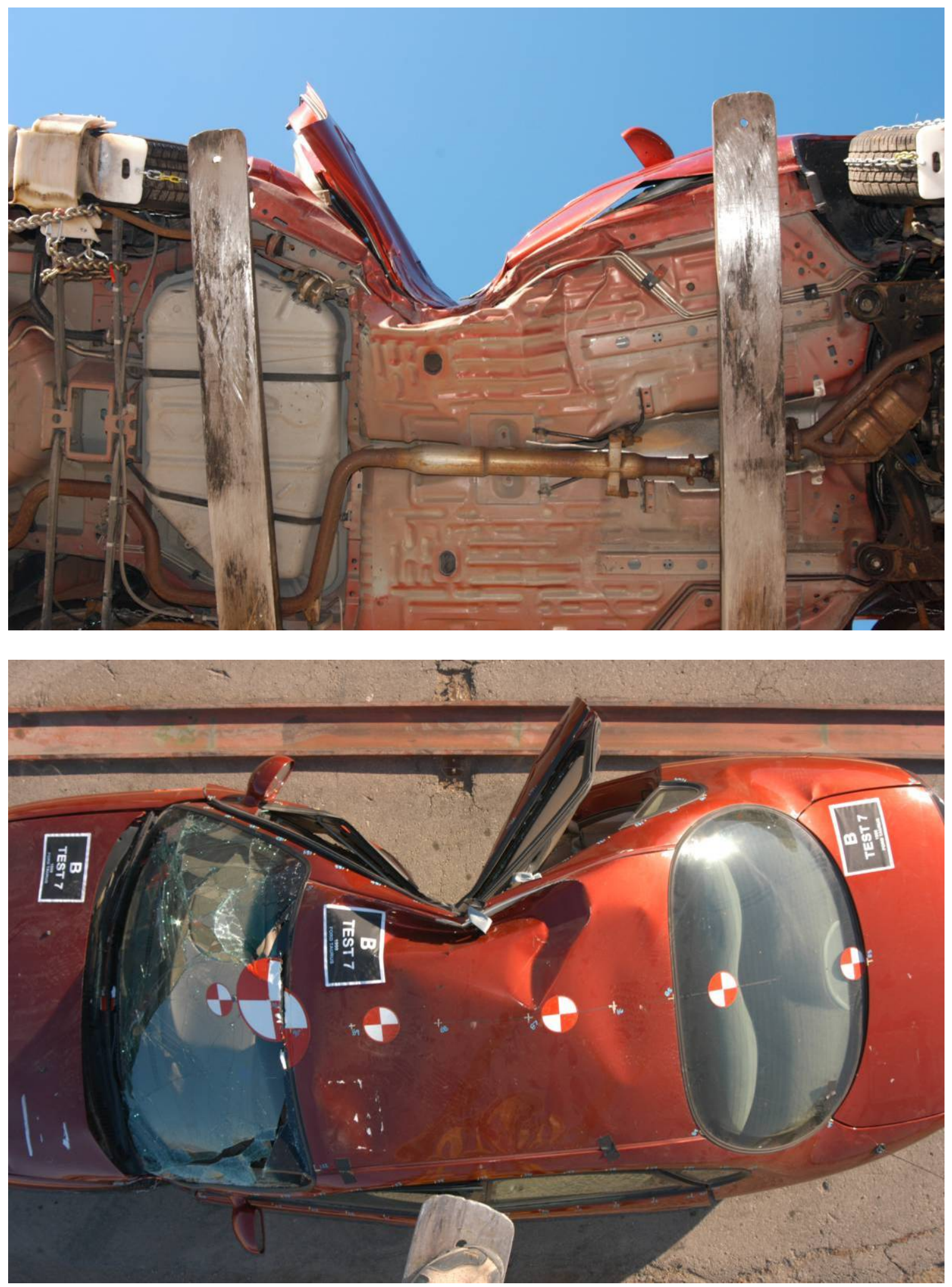

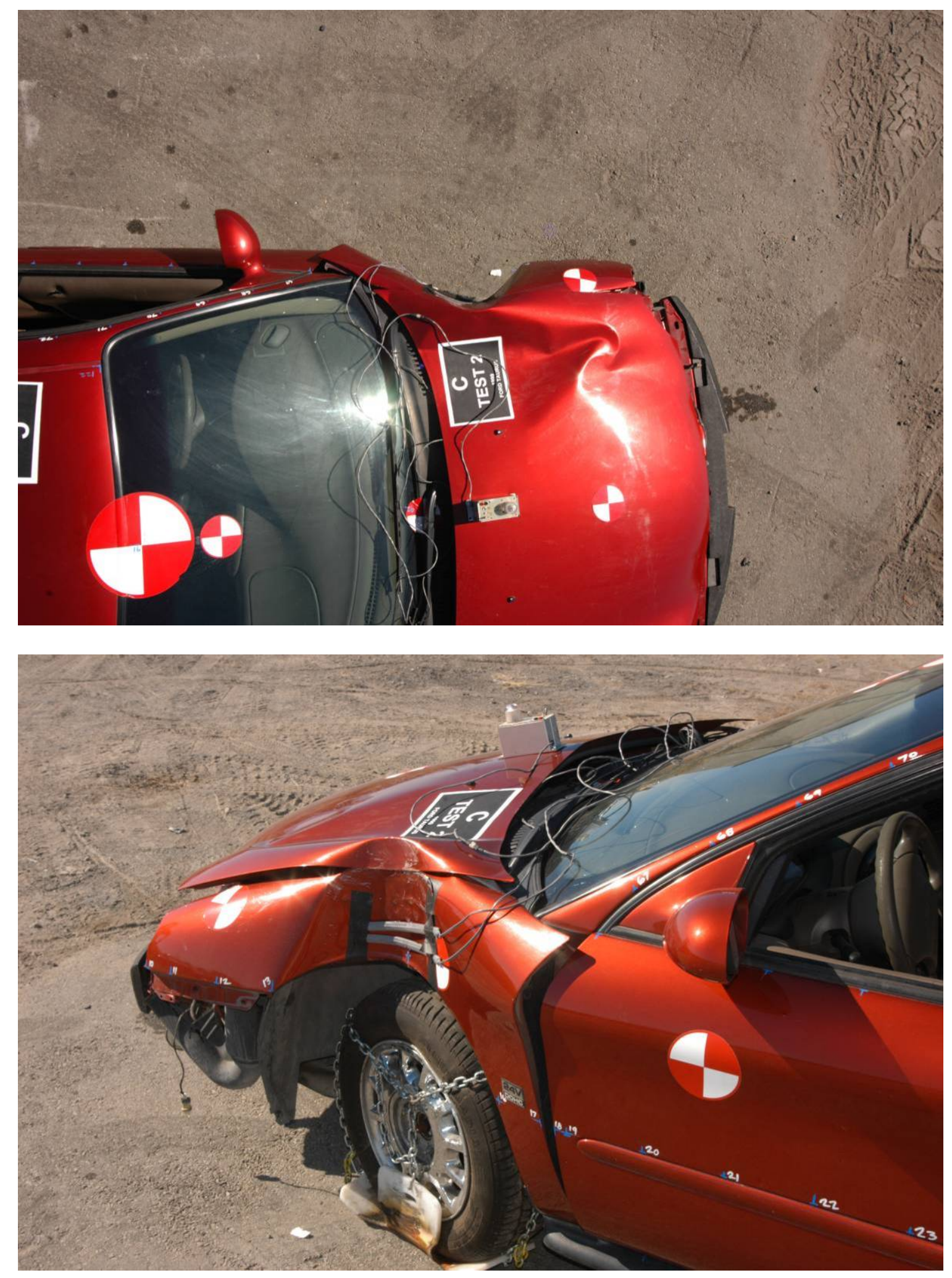

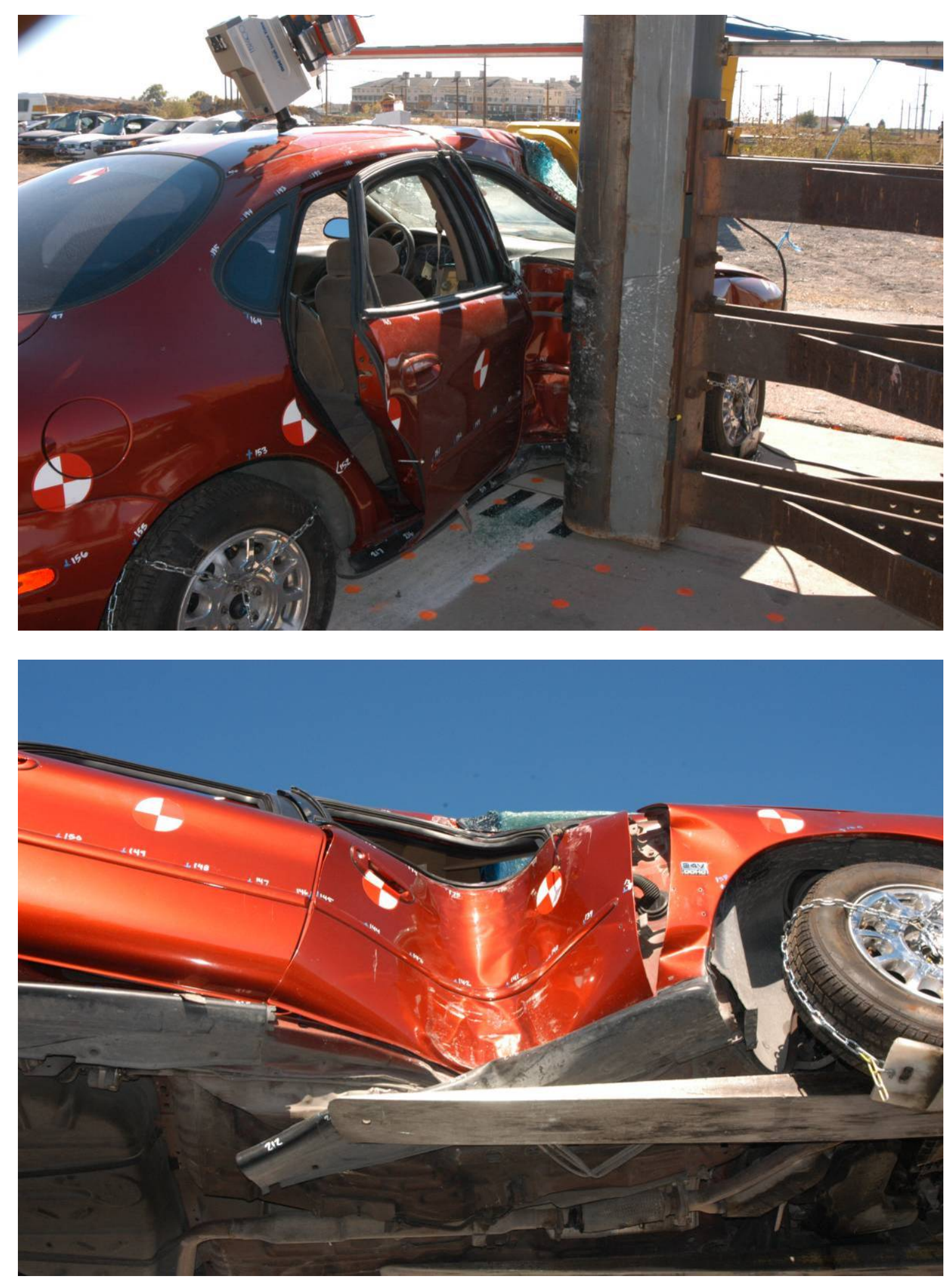


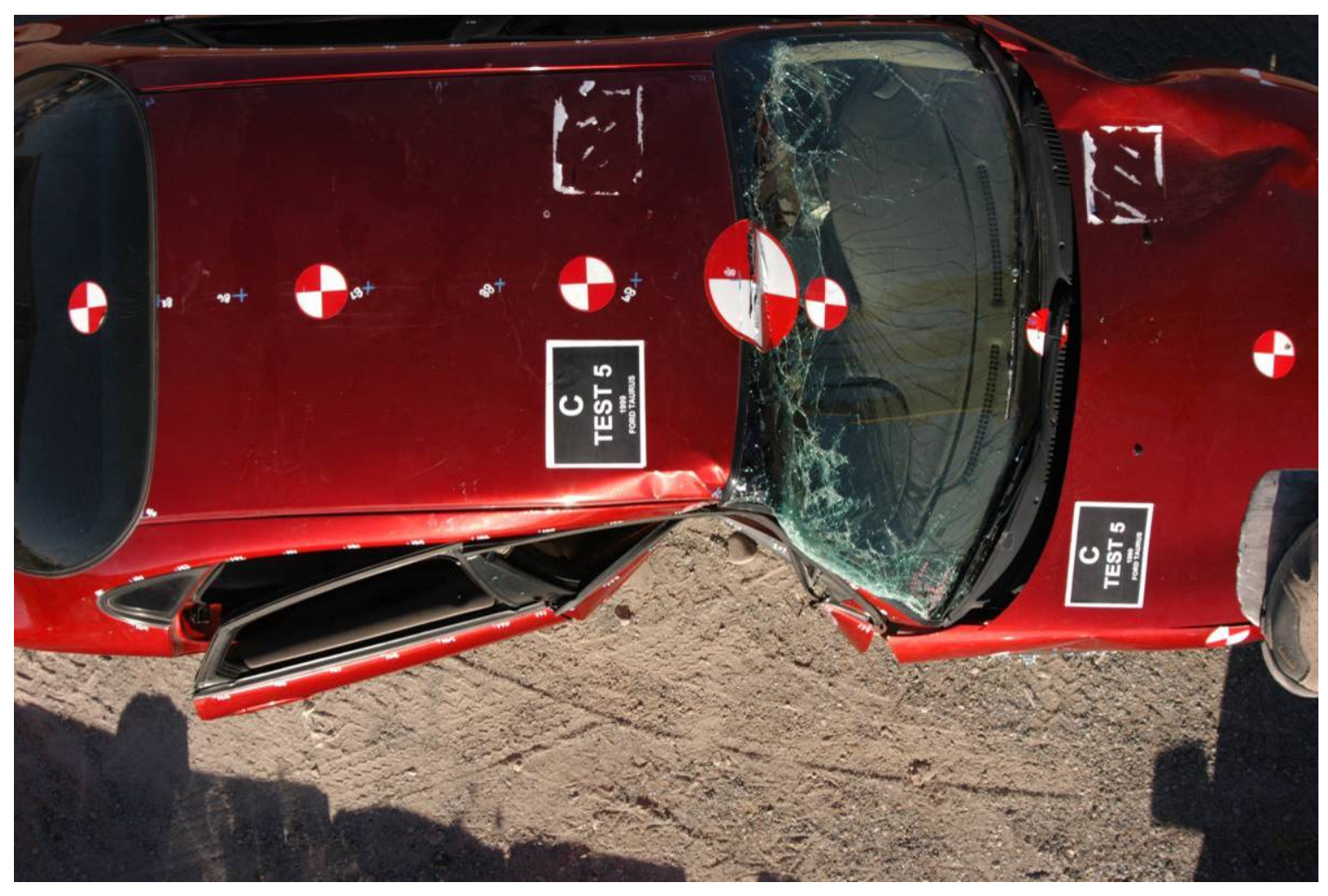


APPENDIX L - NHTSA SIDE CRUSH MEASUREMENT PROTOCOL INHTSA 88,

1. First, the length (L) of the side clamage is determined, see Figure A1. As noted in this figure, the damage length inctudes the inctuced as well as the direct contact area. It does not inctude those portions of the side of the vehicle which are displaced inward solely because the vehicle has been bowed by the impact, this bowing is handled by a separate procecture.

2. The crush length $L$ is divided into several equally spaced sublengths so that crush in the vertical plane where it is deepest can be measured at several (N). [generally 6] points. Although this uniform division is not generally a major problem. it is inferior to a nonuniform procedure where the crush would be measured at several "critical" points that would more accurately characterize the crush profile.

3. After recording these $\mathbf{N}$ crush values, the same lateral dimensions on an undamáged (exemplar) vehicle are found (these dimensions are termed the "ireespace") and thése Treespace" values are subtracted from the raw crush values. These differences represent the final crush values if there are no "major structural separations" (e.g. a B-pillar tear out from the rocker panel or sill) and there is no "bowing" of the vehicle. Note that this freespace" subtraction procecture is equivalent to measuring the crush relative to an exemplar vehicle in a vehicle mapping procedure, wherein the subject vehicle and exemplar maps are overlaid [Wamer 86].

4. If there was a so-called major stnucturai separation" - defined as a separation of door hinges, latch/striker connection or pillar attachment to sill or roof - then the crush values obtained in step 3 are modified as follows:

a.

A second longitudinal string is place on the vehicle at the sill level. The lateral, horizontal displacement between this sill string and the deformed sill is measured at the same $\mathbf{N}$ locations as ware used previously to measure the deepest crush profile.

b. The sill freespace" is determined using an exemplar vehicte in a procedure similar to that in Step 3 above, and these sill "ireespace" values are subtracted out to give the "not sill crush" at the $N$ locations. a. The previousty derived consh values are then averaged with their corresponding net sill crush values. These are the final crush values reconded if there was no vehicte bowing.

5. If it is suspected that there is sufficient vehicle bowing, then the following procecture for including the bowing effect is pertormedt

a. Using the roof of the vehicle as a reference, a longitudinal centerine is drawn in plan view and the intersection of this centeriline with the front-and rear bumpers is noted (see Figure A1)

b. The lateral displacement between the longitudinal centerline and the original front and rear bumper centerines are recorded as $\mathrm{B1}$ and $\mathrm{B2}$

c. If B1 and B2 are both less than 4 inches, then no provision for bowing is included in the crush measurements. If, on the other hand, either $\mathrm{B1}$ or $\mathrm{B2}$ is 4 inches or more, then a string is attached to the ends of the front and rear bumpers on the damaged side and the lateral hortzontal disptacement between this sting and the first string that was placed on the vehicie at the ends of the crush length $L$ is recorded as X1 and X2 (see Figure $A 1$ ). These two $X$ values are averaged and then added to the crush measurements. This added "crush" is termed the "bowing constant". 


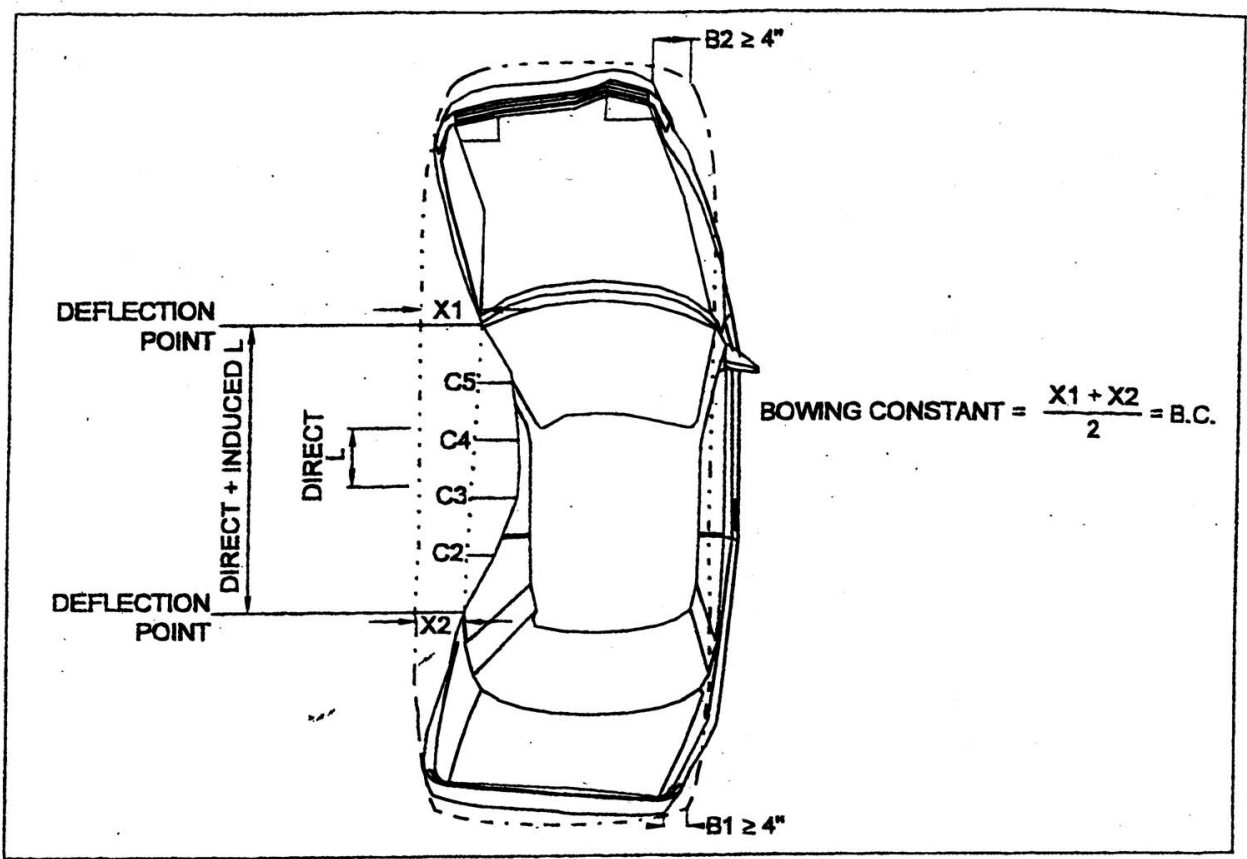

Figure L1 - NHTSA Protocol for Measuring Side-Impacted

Vehicle Crush 